UNIVERSIDAD DE BURGOS

DEPARTAMENTO DE INGENIERÍA CIVIL

TESIS DOCTORAL

\begin{abstract}
APLICACIÓN DEL PROCESO DE SWAGING PARA LA GENERACIÓN DE TENSIONES RESIDUALES EN COMPONENTES SOMETIDOS A ALTAS PRESIONES
\end{abstract}

SANTIAGO TÁRRAGO MINGO

Burgos, Mayo de 2019 

UNIVERSIDAD DE BURGOS

DEPARTAMENTO DE INGENIERÍA CIVIL

TESIS DOCTORAL

\title{
APLICACIÓN DEL PROCESO DE SWAGING PARA LA GENERACIÓN DE TENSIONES RESIDUALES EN COMPONENTES SOMETIDOS A ALTAS PRESIONES
}

\author{
Autor: \\ SANTIAGO TÁRRAGO MINGO \\ Directores: \\ ISIDORO IVÁN CUESTA SEGURA
}

ANDRÉS DIAZ PORTUGAL

Tesis Doctoral presentada en la Universidad de Burgos para la obtención del Título de Doctor en la modalidad de Doctorado Industrial 



\section{AGRADECIMIENTOS}

No puedo empezar de otra manera sino agradeciendo a las tres personas sin las que esta Tesis no habría sido posible, mis niñas Esther, Julia y Alicia. Esther, muchas gracias por haberme apoyado durante todo este camino y por haber estado ahí en todo momento aguantando y tirando del carro, has tenido mucha paciencia y sin tu ayuda, esto no habría sido posible. Julia, gracias por entender que este trabajo era importante para papá y por tus besos y alegría, eres todo un ejemplo. Alicia, aunque todavía eres muy pequeña también agradecerte tus sonrisas, tus besos y por conseguir arrancarme una sonrisa de vez en cuando, que tan necesario ha sido. Las tres sois mi apoyo y no os he podido dedicar todo el tiempo que merecéis pero, ipor fin hemos acabado!.

Quiero agradecer también a mis directores de Tesis, Iván Cuesta Segura y Andrés Díaz Portugal, por su inestimable guía durante todo este proceso y por haber ordenado todas las ideas que tenía en la cabeza lo que ha facilitado el trabajo. También gracias por aguantarme, por lo pesado que puedo llegar a ser cuando me meto en profundidad en un tema. Es el turno de Jesús Manuel Alegre Calderón, quién me convenció para que empezara la Tesis y quién me animó a continuar en los momentos bajos.

Agradecer también a HIPERBARIC, S.A. por haberme dado la oportunidad de haber desarrollado la presente Tesis y haberme apoyado y animado durante el proceso.

Gracias también a mis padres, hermanos y demás familia por su apoyo incondicional y por su ayuda cuando necesitaba tiempo para trabajar durante estos años.

Finalmente agradecer a toda esa gente que ha aportado algo, por pequeño que sea, para que esta Tesis saliese adelante. Toda conversación, ensayo, comentario, etc., ha sido importante y lo agradezco enormemente. 

Todo problema tiene solución, y si no la tiene, es que no es un problema, sino otra cosa. 



\section{ÍNDICE}

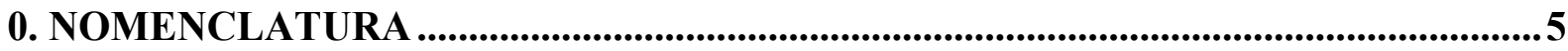

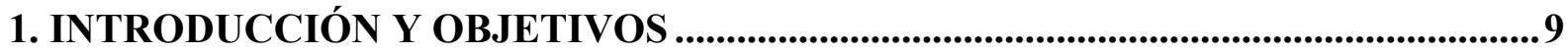

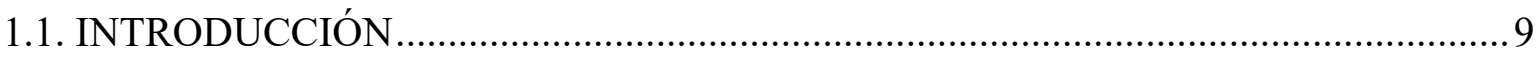

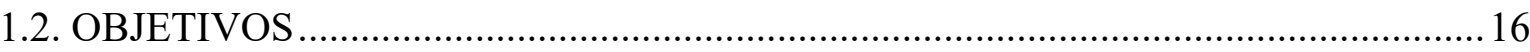

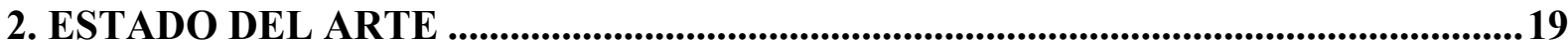

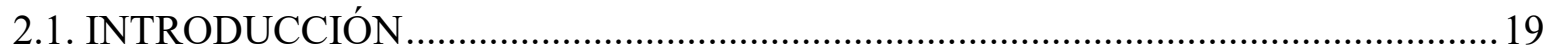

2.2. TÉCNICAS PARA LA INTRODUCCIÓN DE TENSIONES RESIDUALES EN

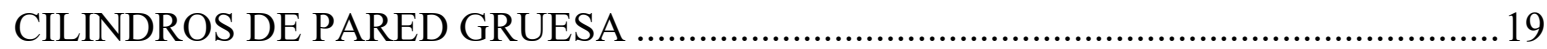

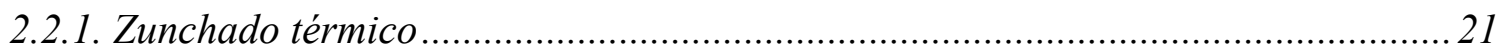

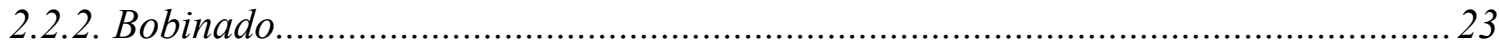

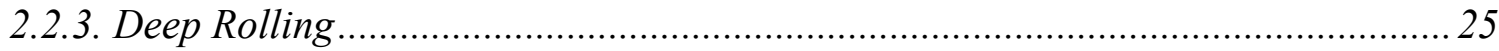

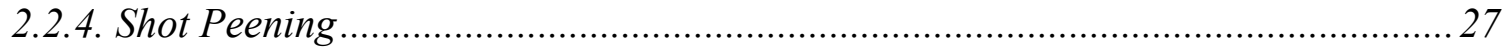

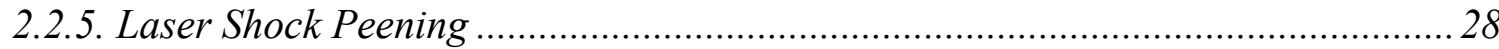

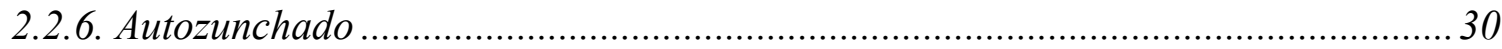

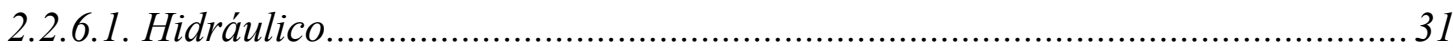

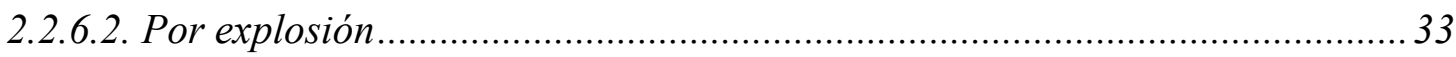

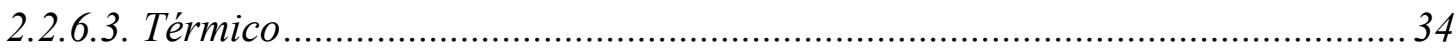

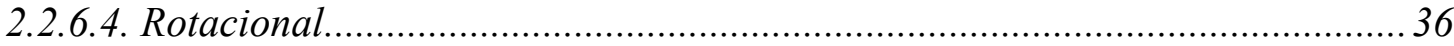

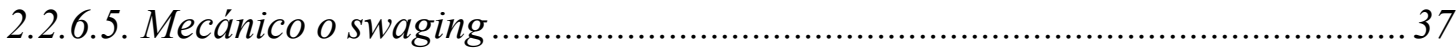

2.3. PERSPECTIVA HISTORICA DEL AUTOZUNCHADO MECÁNICO.....................39

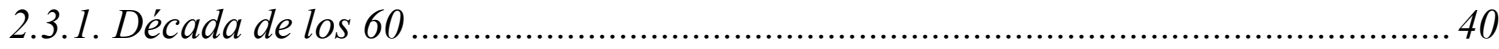

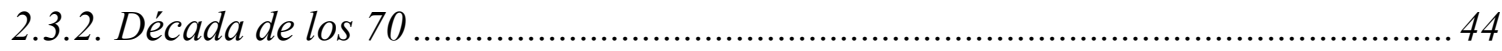

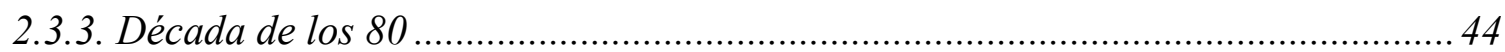




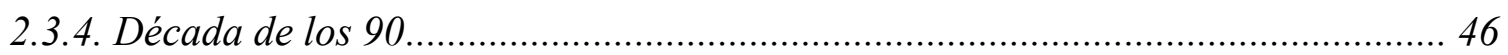

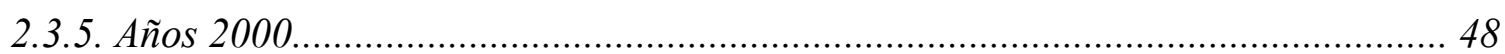

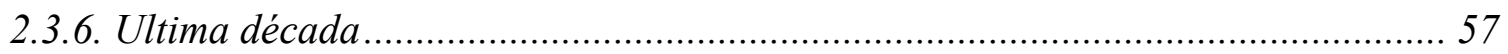

2.4. TÉCNICAS DE MEDICIÓN DE TENSIONES RESIDUALES .................................. 69

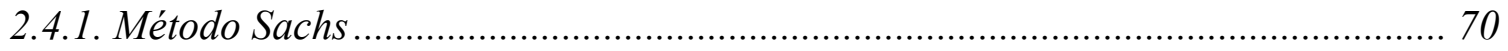

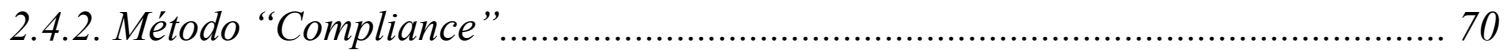

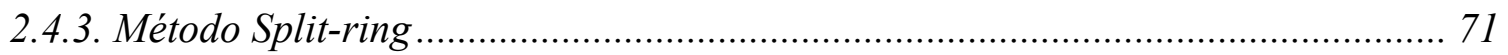

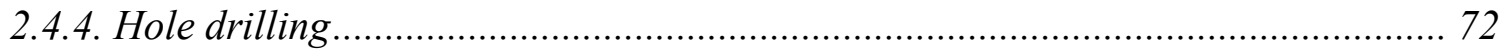

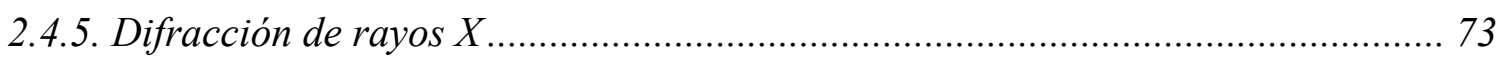

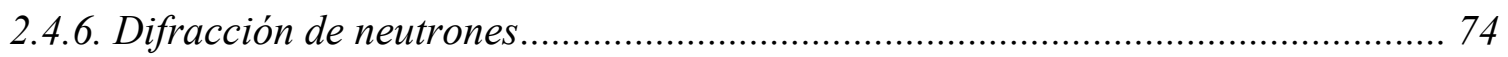

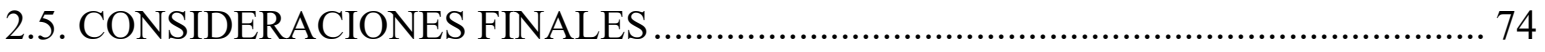

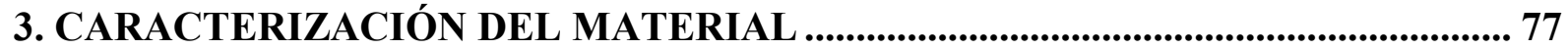

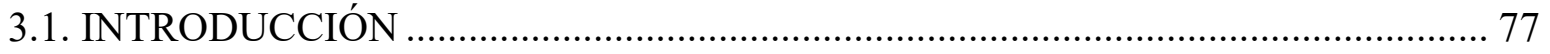

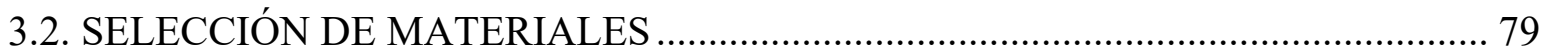

3.2.1.

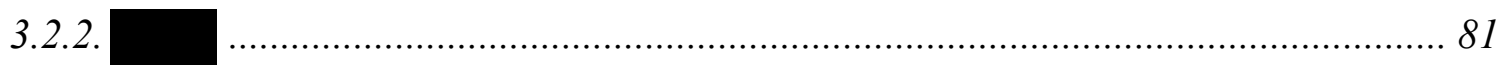

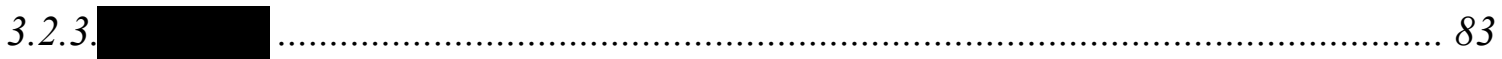

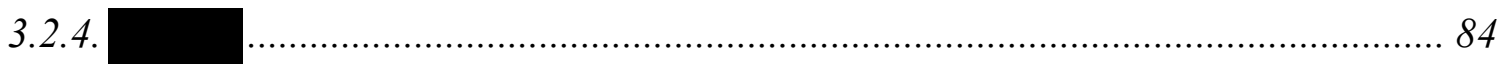

3.2.5.

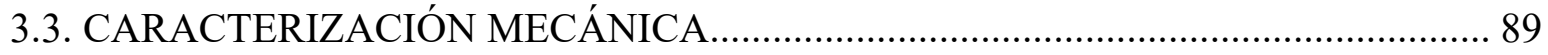

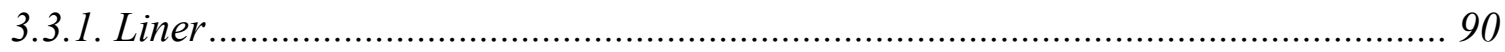

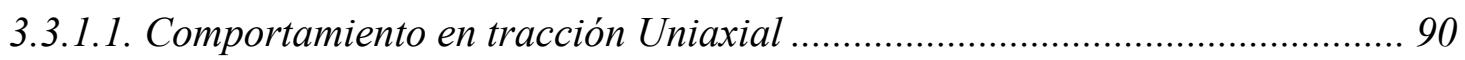

3.3.1.2. Comportamiento Bauschinger y cíclico..................................................... 94

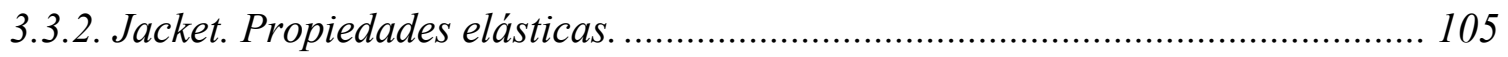

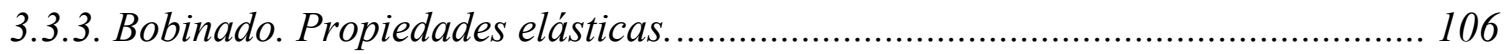

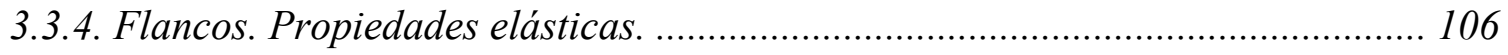

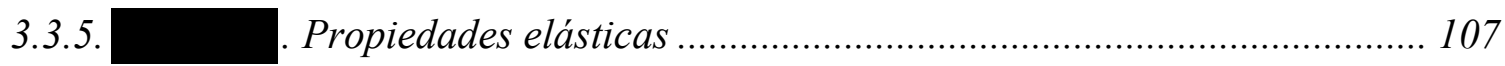

3.4. CARACTERIZACIÓN A FRACTURA Y FATIGA DEL LINER............................ 109

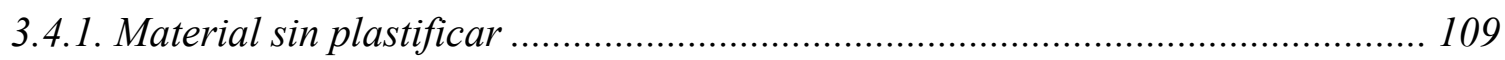

3.4.1.1. Comportamiento en propagación de grieta ............................................... 109

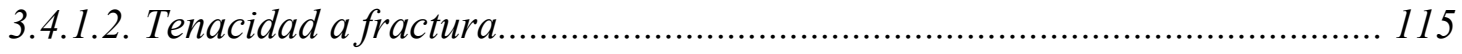




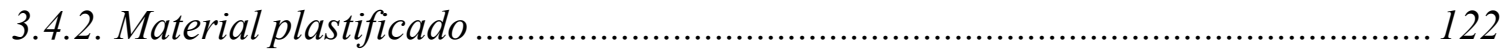

3.4.2.1. Comportamiento en propagación de grieta................................................. 123

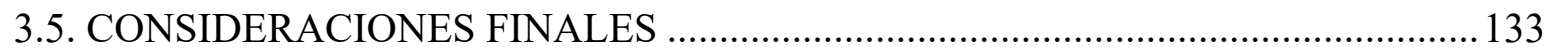

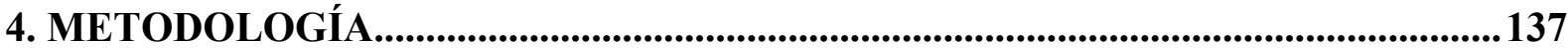

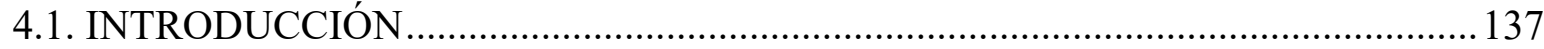

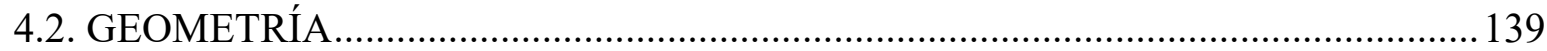

4.2 .1$.

4.2.2.

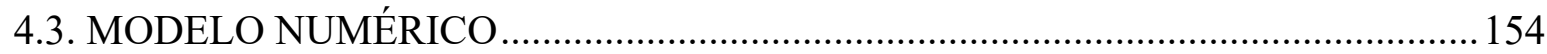

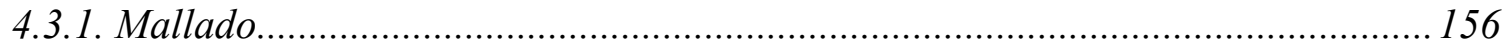

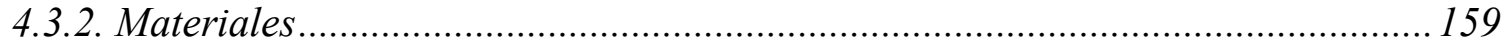

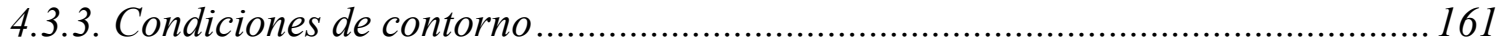

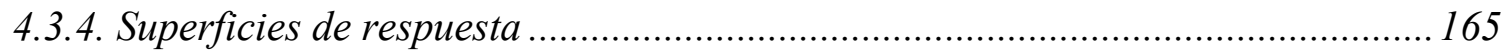

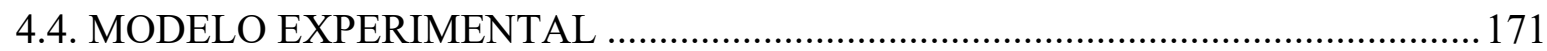

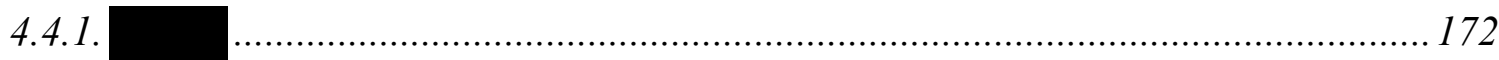

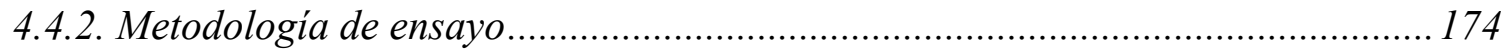

4.4.3. Medición de tensiones residuales mediante Hole drilling ................................. 176

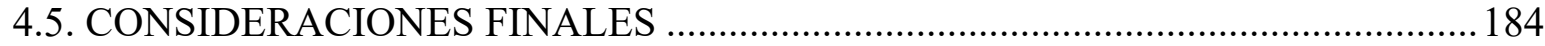

5. APLICACIÓN DE LA METODOLOGÍA Y ANÁLISIS DE RESULTADOS ........... 187

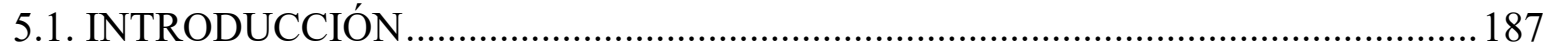

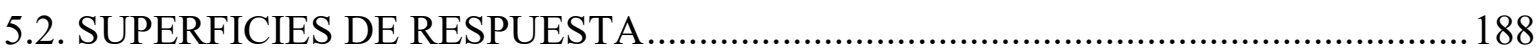

5.3. RESULTADOS CÁLCULO NUMÉRICO …........................................................ 199

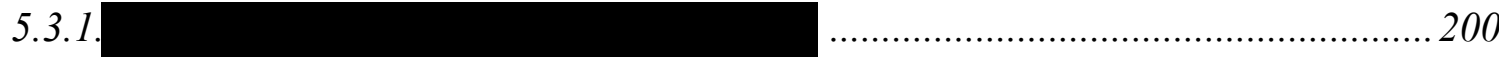

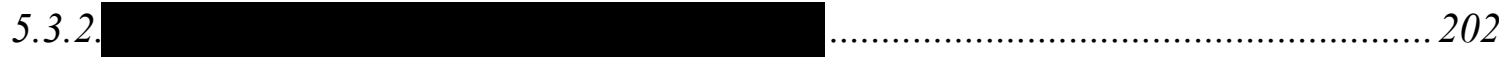

5.3.3.

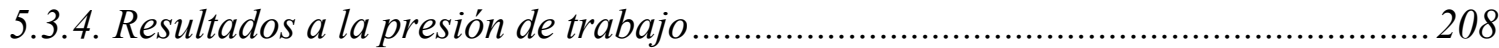

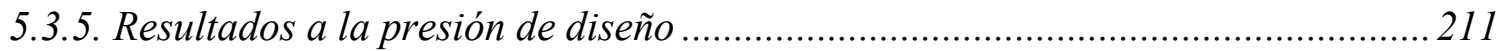

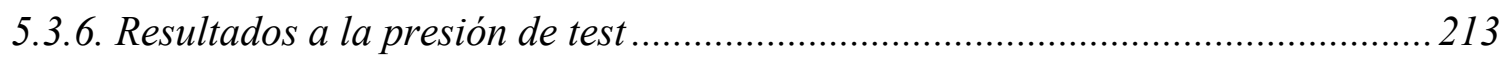

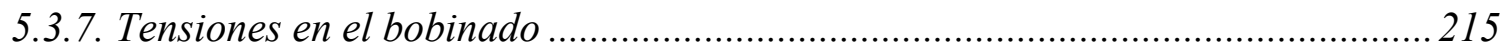

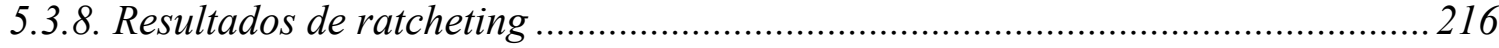


5.4. RESULTADOS MODELO EXPERIMENTAL ...................................................... 217

5.4.1. ….................. 221

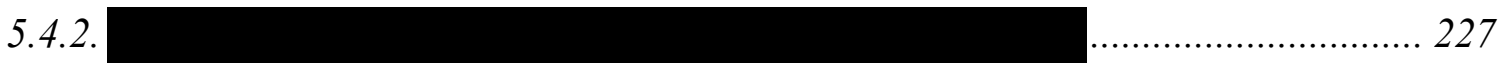

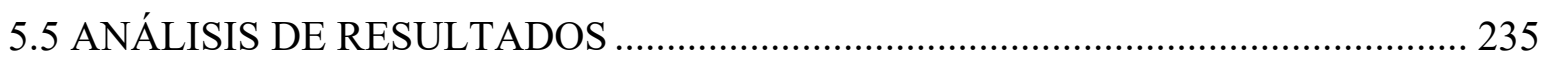

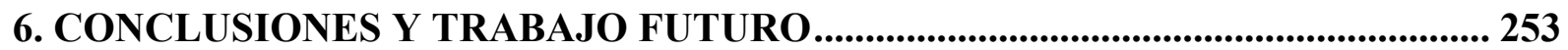

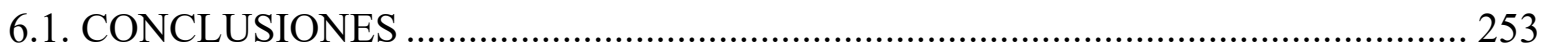

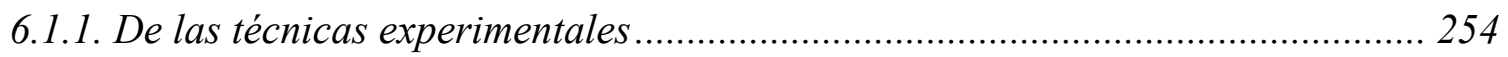

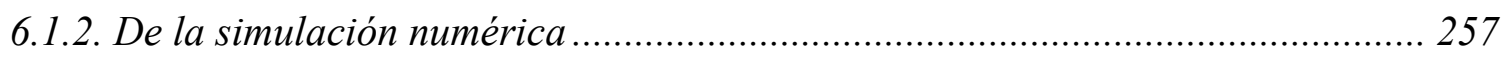

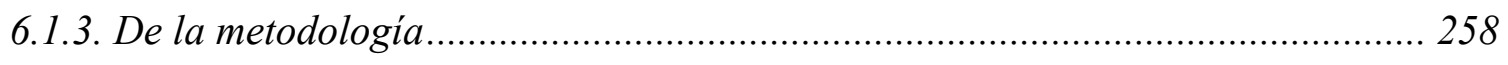

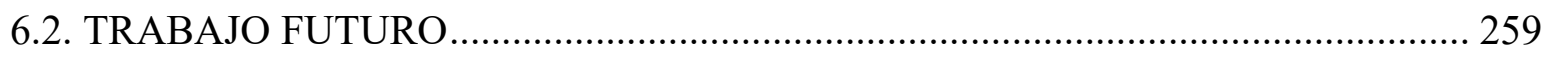

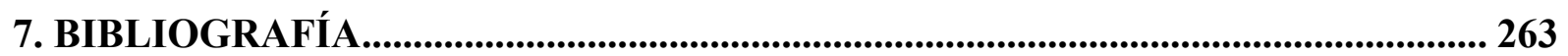




\title{
NOMENCLATURA
}

\author{
$A,[\%]$ Elongación \\ $A^{*}$, Variable codificada de A \\ $a[\mathrm{~mm}]$, Profundidad de fisura \\ $a_{f}[\mathrm{~mm}]$, Fisura final \\ $a_{n}[\mathrm{~mm}]$, en la probeta $\mathrm{C}(\mathrm{T})$, longitud de la entalla mecanizada \\ $a_{o}[\mathrm{~mm}]$, Fisura inicial \\ $\bar{a}_{j k}$, Matriz del método Hole drilling \\ $B[\mathrm{~mm}]$, Espesor de la probeta CT \\ $B^{*}$,Variable codificada B \\ $B_{N}[\mathrm{~mm}]$, Espesor neto de la probeta CT
}

BEF, Factor del efecto Bauschinger, (límite elástico tras la descarga / Límite elástico inicial) $b_{0}, b_{1}, b_{2}, b_{3}, b_{11}, b_{22}, b_{33}, b_{12}, b_{13}, b_{23}$, Coeficientes del modelo cuadrático

$b_{o}[\mathrm{~mm}]$, Ligamento remanente inicial en la probeta CT

$\bar{b}_{j k}$, Matriz del método Hole drilling

$C^{*}$, Variable codificada de $\mathrm{C}$

CTOD $[\mathrm{mm}]$, "Crack Tip Opening Displacement"

$d a[\mathrm{~mm}]$, Avance diferencial de la grieta

$d N$, Avance diferencial de ciclos

$E[M P a]$, Módulo de elasticidad

$E_{p}[\mathrm{MPa}]$, Módulo plástico

$e$, Deformación ingenieril

$f\left(\mathrm{~A}^{*}, \mathrm{~B}^{*}, \mathrm{C}^{*}\right)$, Modelo cuadrático de superficie de respuesta

$i$, Variable $A^{*}, B^{*}$ ó $C^{*}$

$J\left[\mathrm{~kJ} / \mathrm{m}^{2}\right]$, Integral $J$

$K\left[M P a \cdot m^{1 / 2}\right]$, Tenacidad a fractura

$K_{I}\left[M P a \cdot m^{1 / 2}\right]$, Factor de intensidad de tensiones 
$K_{I c}\left[M P a \cdot m^{1 / 2}\right]$, Tenacidad a fractura para condiciones de deformación plana

$K_{\max }\left[\mathrm{MPa} \cdot \mathrm{m}^{1 / 2}\right]$, Factor de intensidad de tensiones máximo

$K_{\min }\left[\mathrm{MPa} \cdot \mathrm{m}^{1 / 2}\right]$,Factor de intensidad de tensiones máximo

$K_{Q}\left[M P a \cdot m^{1 / 2}\right]$, Tenacidad a fractura medida en el ensayo

$P[k N]$, Carga

$P_{k}$, Tensión en el método Hole drilling

$P_{\max }[k N]$, Valor de carga máxima en el ensayo de tenacidad a fractura

$P_{Q}[k N]$, Valor de carga igual a $\mathrm{P}_{5}$ en tipo I o carga máxima previa a la secante a $95 \%$

$P_{5}[k N]$, Valor de carga resultante del cruce de secante al $95 \%$ de pendiente

$p_{j}$, Deformación equivalente en el método Hole drilling

$Q_{k}$, Tensión en el método Hole drilling

$q_{j}$, Deformación equivalente en el método Hole drilling

$R_{a}[\mu m]$, Rugosidad media

$r_{p}[\mathrm{~mm}]$, Radio de intercara elastoplástico

$s[M P a]$, Tensión ingenieril

$s_{u}[M P a]$, Tensión ingenieril última, igual que $\sigma_{u t s}$

$T_{k}$, Tensión en el método Hole drilling

$t_{j}$, Deformación equivalente en el método Hole drilling

$W[\mathrm{~mm}]$, Ancho de la probeta CT

$X_{i}$, Valor real de los parámetros variables

$X_{i N I n f}$, Valor real del nivel más bajo del factor $i$

$X_{i N S u p}$, Valor real del nivel más alto del factor $i$

$\tilde{X}_{i}$, Media de $X_{i N S u p}$ y $X_{i N n f}$

$x_{i}$, Valor codificado de los parámetros variables

Z [\%], Estricción de rotura o reducción de área

$\Delta_{\text {radial }}[\mathrm{mm}]$, Expansión radial del liner tras el autozunchado mecánico

$\Delta_{\text {long. }}[\mathrm{mm}]$, Elongación del liner tras el autozunchado mecánico

$\Delta \sigma[M P a]$, Variación tensional 
$\Delta \mathrm{K}\left[M P a \cdot m^{1 / 2}\right]$, Variación del factor de intensidad de tensiones

$\varepsilon$, Deformación verdadera o real

$\varepsilon_{p}$, Deformación verdadera plástica

$\varepsilon_{p l}$, Deformación plástica residual

$\varepsilon_{p l, 2}$, Nueva deformación plástica residual

$\varepsilon_{\text {tot }}$, Deformación total

$\varepsilon_{1}$, Deformación 1 registrada en cada incremento j por la roseta en el Hole drilling.

$\varepsilon_{2}$, Deformación 2 registrada en cada incremento j por la roseta en el Hole drilling

$\varepsilon_{3}$, Deformación 3 registrada en cada incremento j por la roseta en el Hole drilling

$\mu$, Coeficiente de fricción

$\mu_{1}$, Coeficiente de rozamiento entre liner y jacket

$\mu_{2}$, Coeficiente de rozamiento entre mandrino y liner

$v$, Coeficiente de Poisson

$\sigma[M P a]$, Tensión verdadera o real

$\sigma_{k}$, Vector de tensiones en el método Hole drilling

$\sigma_{u t s}[M P a]$, Tensión ingenieril última, igual que $s_{u}$

$\sigma_{y}[M P a]$, Tensión de fluencia o límite elástico

$\sigma_{0.2}[\mathrm{MPa}]$, Límite elástico convencional para una deformación plástica del $0,2 \%$

$\sigma_{1}[\mathrm{MPa}]$, Tensión en la dirección 1 del Método Hole drilling

$\sigma_{3}[\mathrm{MPa}]$, Tensión en la dirección 3 del Método Hole drilling 



\section{CAPÍTULO 1}

\section{INTRODUCCIÓN Y OBJETIVOS}

\subsection{INTRODUCCIÓN}

La competitividad de las empresas del sector de la alimentación pasa por lograr una mayor eficiencia de sus procesos productivos. En este ámbito, tal y como recoge la estrategia regional de Castilla y León RIS3 en su Prioridad 1, será clave que la innovación en productos, formatos y distribución satisfaga las necesidades cada vez más exigentes de los consumidores.

En este sentido, el procesado de alimentos por alta presión (HPP, High Pressure Processing) es una técnica relativamente nueva que está ganando cada vez más cuota de mercado por sus excelentes prestaciones. Los equipos de procesado de alimentos por alta presión comienzan a desarrollarse en la década de los 90, y desde entonces su número, capacidad y variedad de los alimentos tratados han crecido exponencialmente (Figura 1.1)

Esta técnica permite a las empresas que la utilizan comercializar alimentos saludables e innovadores tratados por alta presión, lo cual permite mejorar la seguridad alimentaria, desarrollar nuevos productos de alto valor añadido, y abrir nuevos mercados de exportación.

La tipología de alimentos que pueden ser tratados por alta presión es muy variada, desde el procesado de productos cárnicos (loncheados o incluso piezas completas de jamón), platos preparados, pescados y productos frescos (mariscos, etc) o más recientemente el procesado de zumos. 


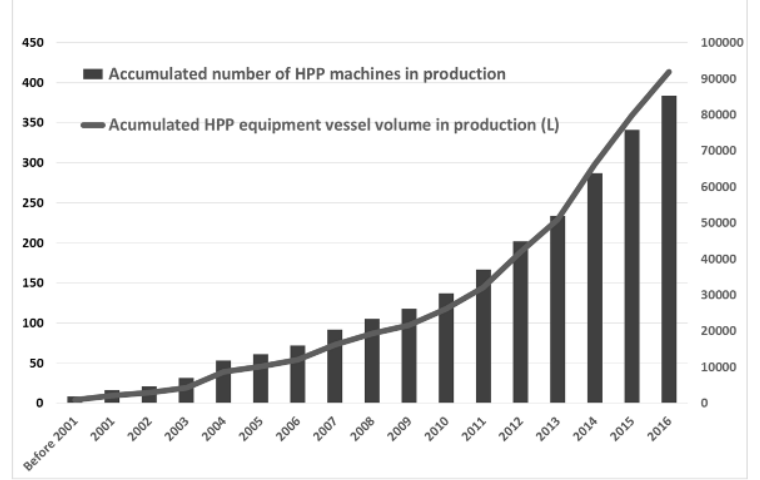

Figura 1.1. Evolución del número de equipos HPP en el mundo [1].

La tendencia natural en la tecnología HPP es conseguir alcanzar una presión de procesado cada vez más elevada (>6000 bar), así como conseguir extender la tecnología a una variedad mayor de alimentos entre los que destacan los zumos, conocidos por su carácter eminentemente ácido, y todo ello con una capacidad de producción que sea rentable a nivel industrial.

No son muchas las empresas dedicadas a la fabricación de este tipo de equipos. En nuestro país, Hiperbaric, S.A., ubicada en Burgos, se ha posicionado como la empresa líder a nivel mundial en el diseño, fabricación y distribución de este tipo de equipos. Hiperbaric, S.A. tiene instalados más de 200 equipos de HPP en cerca de 40 países de los cinco continentes, alcanzado en estos momentos más del $60 \%$ del mercado.

En las máquinas HPP (Figura 1.2), la presión se introduce en la vasija mediante un medio fluido, generalmente agua. El producto se introduce en el interior de la vasija mediante unos contenedores de plástico, guiados a través cintas transportadoras. Una vez dentro el producto, se cierra la vasija mediante dos tapones y se comienza a rellenar el interior de la vasija mediante agua, incrementando progresivamente la presión hasta alcanzar el valor nominal (generalmente unos 5000-6000 bares) mediante bombeo sucesivo con intensificadores de alta presión. Se mantiene el producto a presión durante un periodo determinado, que oscila entre los 3-10 minutos, y finalmente se reduce la presión y vacía la vasija extrayendo el producto procesado. El ciclo de procesado puede oscilar entre los 6-9 minutos, lo cual hace que el equipo pueda desarrollar unos 35.000 ciclos al año.

Obviamente, la elevada presión a alcanzar (6000 bares) hace que todos los elementos de la máquina dependientes directa o indirectamente de la presión estén sometidos a ciclos de fatiga 
extremadamente exigentes. Los actuales diseños requieren de mantenimientos preventivos, y raramente se garantiza vidas superiores a los 100.000 ciclos, lo cual hace que haya que sustituir elementos de gran importancia y de alto coste (como la vasija).

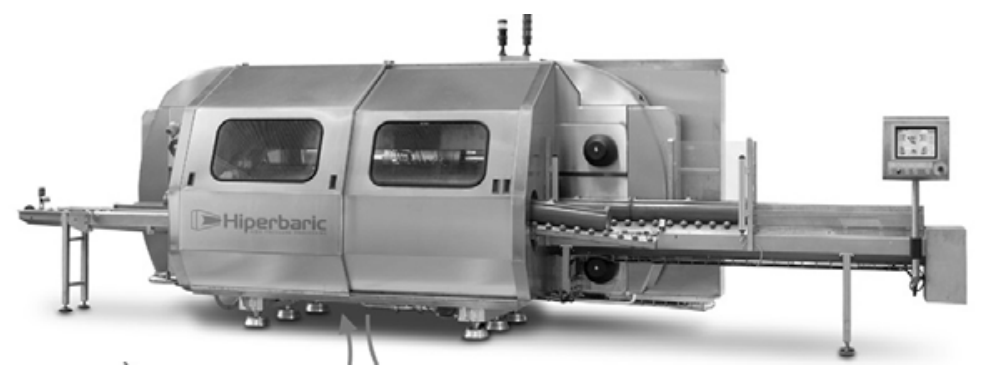

Figura 1.2. Equipo de procesado de alimentos por alta presión HPP [1].

Como ya se ha indicado anteriormente, una de las partes más importantes de los equipos HPP es la vasija de alta presión donde se introducen los alimentos. Se entiende por vasijas de alta presión todas aquellas con presiones de diseño por encima de los $100 \mathrm{MPa}$ las cuales cuentan con diversas aplicaciones como por ejemplo la fabricación de cañones, equipos para industria alimentaria, prensas para sinterizar metales etc. Debido a que las necesidades productivas de la industria alimentaria son bastante altas, es necesario utilizar vasijas con el mayor calibre posible y capaces de realizar un gran número de ciclos antes de su posible fallo. Por esta razón, existe una necesidad de contar con métodos de fabricación que permitan producir vasijas de alta presión de gran tamaño y con una gran resistencia a las cargas cíclicas, (vida a fatiga).

Una de las técnicas más efectivas para aumentar la vida en fatiga de este tipo de componentes sometidos a altas presiones es la introducción de tensiones residuales de compresión en la superficie interior con el objetivo de mejorar la vida a fatiga originada por los ciclos de carga y descarga.

Mediante algunas de las técnicas, además de tensiones residuales de compresión se produce la plastificación del material lo que se traduce en un endurecimiento por deformación plástica ("work hardening" or "cold work") modificando así las propiedades mecánicas del material. Las técnicas más empleadas actualmente para introducir tensiones de compresión en una vasija a presión son:

- El zunchado térmico consistente en la introducción de tensiones residuales de compresión en la capa más interna de las vasijas multicapa mediante el apriete que las capas más exteriores producen en la capa más interior debido a que dichas capas tienen interferencia. Para poder realizar el montaje de las capas, normalmente se calienta la capa más externa, produciendose el aumento dimensional de la misma lo 
que permite la introducción de la capa interior en la exterior. Posteriormente, tras el enfriamiento, la capa interna queda con tensiones compresivas. Debido a que el cilindro exterior no puede calentarse tanto como se quiera, pues se podría afectar a las propiedades mecánicas del material, la interferencia entre cilindros es limitada y por lo tanto el nivel máximo de tensiones residuales que se puede obtener también es bastante limitado. Las tensiones residuales tienen sentido tangencial y radial.

- El autozunchado hidráulico consistente en la aplicación a la vasija de una presión interior elevada de tal forma que se genere una zona plástica en el interior. Una vez retirada la presión de autozunchado, la recuperación elástica del campo tensional introduce tensiones circunferenciales de compresión en el interior de la vasija que reducen la tensión media a la que va a estar sometido el componente durante el proceso de trabajo (carga y descarga). Con esta técnica se produce una plastificación por tracción del material en la zona interior del depósito que posteriormente estará en contacto con el líquido o gas contenido en él.

- $\quad$ Bobinado: En este caso la vasija se bobina con un fleje de acero de alto límite elástico, de forma que se produce una compresión gradual del núcleo de la vasija. Este proceso permite un elevado control de las tensiones residuales de compresión introducidas en el interior de la vasija. No es habitual llegar en este proceso a alcanzar el nivel de plastificación del material. Las tensiones residuales generadas tienen sentido tangencial y radial.

- $\quad$ Autozunchado mecánico (Swaging): es una técnica que está cobrando cada vez más interés en el diseño de depósitos a presión por su simplicidad y gran mejora del comportamiento a fatiga de los depósitos fabricados con esta técnica. Este proceso consiste básicamente en hacer pasar longitudinalmente un cilindro (denominado “pepita", "mandrino" u "oliva") de mayor diámetro exterior que el diámetro interior de la vasija (dependiendo del diámetro del tubo unas décimas o centésimas es suficiente o puede llegar a milímetros) con lo que se produce la plastificación de una capa interior durante el paso del utillaje y que, una vez sobrepasada la zona de proceso, genera importantes tensiones residuales de compresión en una capa del interior de la vasija (Figura 1.3). En este caso se produce una plastificación por compresión en la zona interior del depósito. Es una técnica compleja de desarrollar en cilindros de gran 
diámetro por las enormes fuerzas puestas en juego durante el proceso de paso del mandrino por el interior del tubo. La fuerza que hay que ejercer depende básicamente de los coeficientes de rozamiento y de la interferencia diametral entre mandrino y vasija, aunque también tiene influencia la geometría del mandrino. La ventaja de este método es que se generan tensiones residuales de compresión en las tres direcciones del cilindro (radial, tangencial y longitudinal) de forma que se puede crear un estado tensional hidrostático donde las tensiones en alguna de las direcciones pueden ser mayores que el propio límite elástico del material.

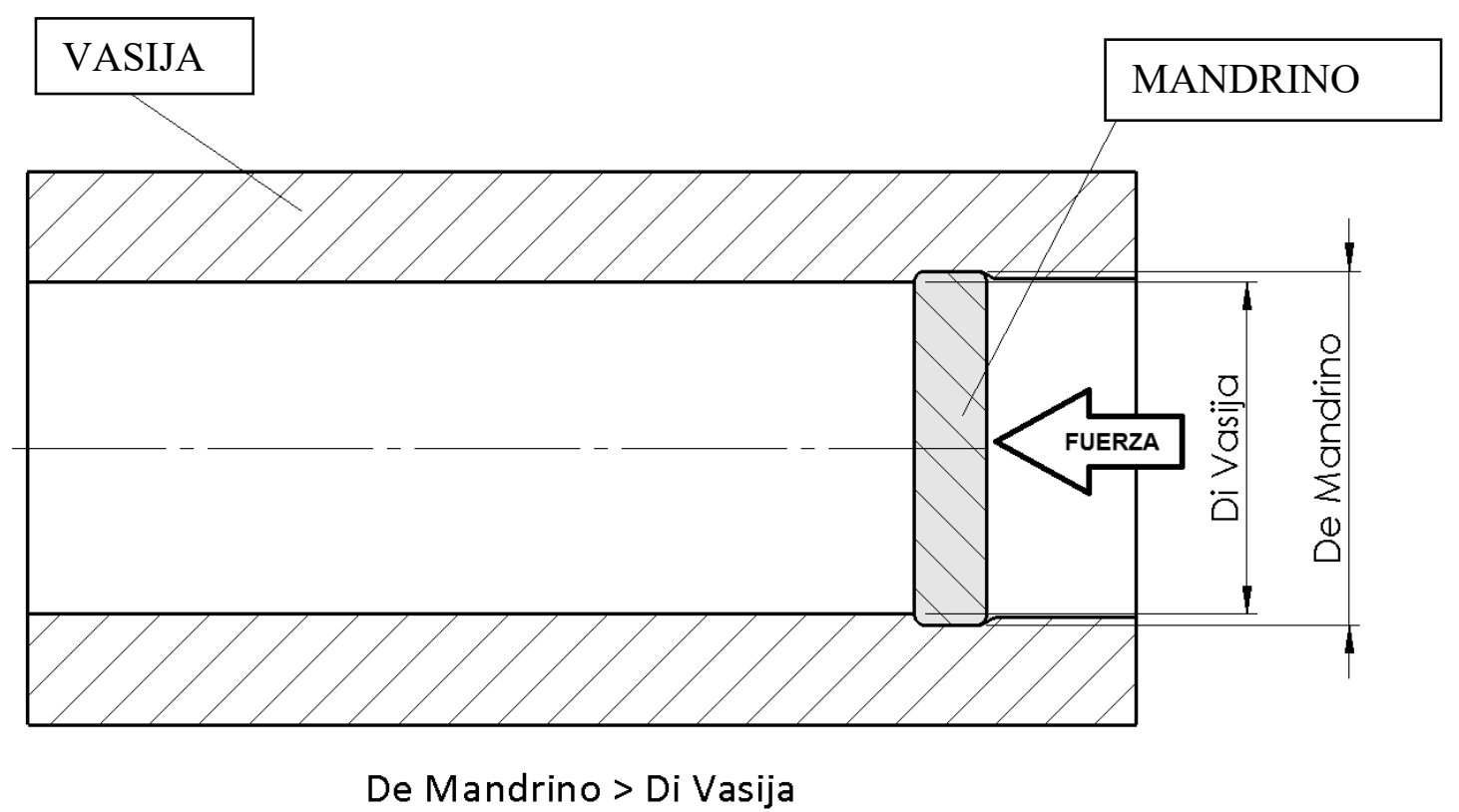

Figura 1.3. Esquema del proceso de swaging.

Por otra parte, existen otros tratamientos mecánicos para introducir tensiones residuales en cualquier superficie. Los más empleados son:

- $\quad$ Deep Rolling: una bola o rodamiento aplica una fuerza suficiente sobre la superficie del metal de tal forma que ésta se deforma plásticamente a su paso. Una vez que la bola sobrepasa la zona de acción, se produce una recuperación elástica del contorno de la zona plastificada y se crean una capa deformada plásticamente con elevadas tensiones residuales de compresión. En esta técnica tiene especial relevancia el diámetro y dureza de la bola, la presión de contacto, el coeficiente de rozamiento o la separación entre pasadas. 
- $\quad$ Shot peening: se disparan partículas metálicas o cerámicas mediante un chorro de aire a gran velocidad contra la superficie, de forma que se produce la deformación plástica $y$, en consecuencia, la generación de tensiones residuales. Tiene como inconveniente el acabado superficial conseguido.

- $\quad$ Laser shock peening: es un proceso análogo al shot peening donde el agente que produce la deformación es el impacto de un haz láser. El proceso es mecánico, a diferencia de otros tratamientos térmicos de metales donde se emplea el láser.

La frontera del conocimiento en el diseño de componentes de alta presión para el tratamiento de alimentos (HPP) se centra ahora en la posibilidad de aplicar técnicas de generación de tensiones residuales tales como el autozunchado mecánico. Este proceso se utiliza con éxito en otros componentes industriales para mejorar la vida en fatiga como en el mundo armamentístico en la fabricación de cañones, llegando a procesar hasta calibres de $150 \mathrm{~mm}$. Sin embargo, actualmente, uno de los grandes retos es la posibilidad de aplicar la técnica del autozunchado mecánico en vasijas de elevado diámetro interior pues las fuerzas necesarias para desplazar el mandrino por el interior de la vasija son enormes, lo que dificulta industrialmente el proceso elevando el riesgo de gripado del mandrino dentro de la vasija, algo que si sucede, obliga a tirar piezas que por lo general tienen un precio muy elevado.

Además, el campo de la generación de tensiones residuales en el interior de componentes sometidos a alta presión, fabricados con aceros de alta resistencia, presenta numerosos frentes abiertos que hacen referencia entre otros a los siguientes:

- Conocimiento del estado de tensiones residuales generadas por los diferentes procesos (Autozunchado mecánico, etc). En particular, se necesita avanzar en las técnicas numéricas para calcular estas tensiones, y en las técnicas experimentales para determinar experimentalmente su valor. 
- Estudio de la influencia de las variables que afectan a los estados de tensiones residuales generados, tales como la geometría, el tipo de material (aceros de alta resistencia), el conocimiento de los cambios en el material derivados de la elevada plastificación local a la que se ve sometido el material durante la generación de las tensiones residuales y, finalmente, su efecto en el comportamiento en fatiga (en particular los efectos del proceso en las propiedades asociadas a la velocidad de propagación).

- Conocer el comportamiento de los aceros de alta resistencia a los procesos combinados de generación de tensiones residuales. Analizar efectos de las propiedades cíclicas (efecto Bauschinger, etc) en los niveles de tensiones residuales previstos y realmente alcanzados. Estudiar los acabados superficiales obtenidos y su efecto en la iniciación de fisuras en ambientes ácidos, etc.

- Estudiar el grado de aproximación entre las técnicas numéricas basadas en simulaciones por elementos finitos, para determinar las tensiones residuales (incluyendo no linealidades, modelos de endurecimiento por deformación,...) y las técnicas experimentales disponibles para conocer las tensiones realmente generadas en el proceso.

La presente Tesis pretende establecer un procedimiento industrialmente viable para el diseño de vasijas de elevado diámetro interior (superior a $150 \mathrm{~mm}$ )

permitiendo vasijas capaces de resistir un elevadísimo número de ciclos.

El reto surge en la definición de la metodología para intentar interconectar las diferentes etapas de fabricación, y por tanto de cálculo, ya que al tratarse de una vasija multicapa, con tres procesos de fabricación, son muchos los parámetros que entran en juego. 


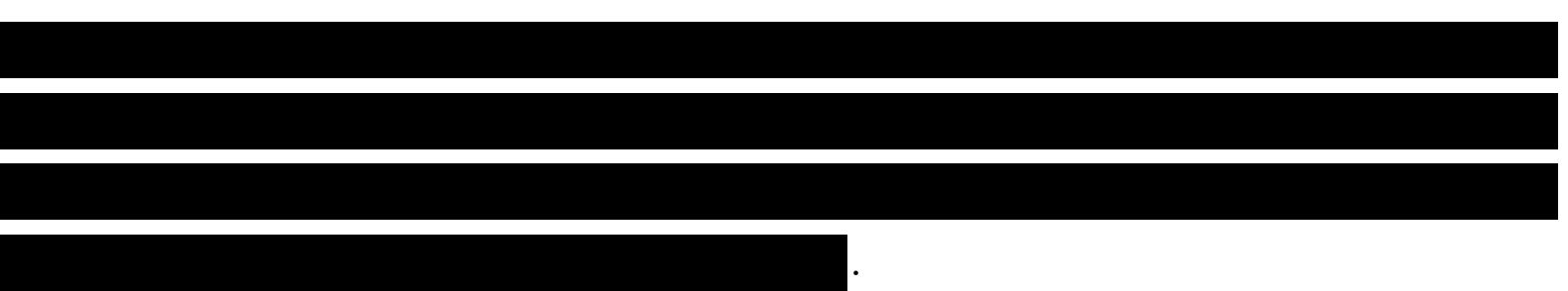

Para validar la metodología presentada, esta se ha aplicado a una vasija de alta presión multicapa, con la capa interior realizada en un acero inoxidable martensítico endurecido por precipitación utilizado en componentes de altas presiones. Posteriormente se ha evaluado la correlación de los resultados obtenidos mediante la simulación con los determinados a partir de la medición de las tensiones residuales en una vasija de muestra.

\subsection{OBJETIVOS}

Tras lo expuesto anteriormente, los principales objetivos de la presente Tesis son los siguientes:

- Desarrollar una metodología para el diseño y cálculo de vasijas de alta presión de gran calibre

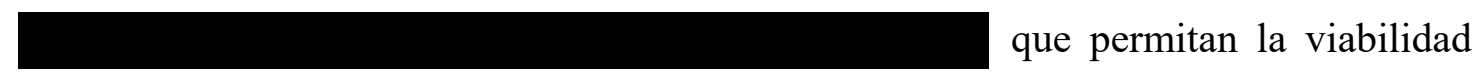
industrial de su fabricación. Vasija de alta presión capaz de soportar una vida elevada de ciclos.

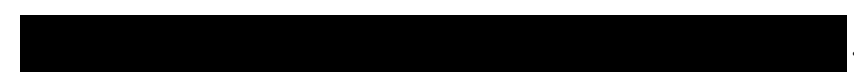

- Aplicar dicha metodología en el diseño de una vasija fabricada con un acero perfectamente caracterizado, de tal forma que se pueda analizar posteriormente el grado de precisión obtenido mediante la aplicacion de técnicas de medición de tensiones residuales.

Para lograr estos objetivos principales, se planteará una serie de etapas intermedias que se pueden considerar como objetivos secundarios, los cuales se recogen a continuación:

- Realizar la caracterización mecánica del material tanto de la vasija que se utilizará. También se caracterizará a fractura y fatiga el material y se estudiará la influencia en dichas propiedades de la elevada plastificación que se introduce mediante el autozunchado mecánico. 
- Desarrollar un modelo de simulación que permita el cálculo de las tensiones residuales obtenidas durante todas las fases de fabricación de la vasija.

- Definir los parámetros que influyen en el proceso de autozunchado mecánico y determinar la influencia de ellos en la viabilidad industrial del proceso.

- Analizar, mediante la utilización de superficies de respuesta, la influencia y relación entre los parámetros y variables del proceso.

- Aplicar el proceso de fabricación a vasijas reales, realizando mediciones de los parámetros que caracterizan el proceso, para posteriormente, mediante la utilización de las superficies de respuesta previas, determinar los valores que se introducirán en las simulaciones.

- Finalmente comprobar el grado de precisión de las tensiones residuales obtenidas mediante el proceso de autozunchado mecánico, utilizando técnicas de medición de tensiones residuales, con aquellas obtenidas en la simulación numérica.

Para cumplir los objetivos mencionados, la presente Tesis ha sido dividida en seis capítulos, sin tener en cuenta los correspondientes a la nomenclatura y a la bibliografía. En el presente capítulo se han descrito la motivación y los objetivos a alcanzar en este trabajo. El Capítulo 2 analizará los trabajos realizados relacionados con el autozunchado mecánico. El Capítulo 3 incluirá la caracterización de los materiales utilizados para la vasija de alta presión. A lo largo del Capítulo 4 se mostrará la metodología propuesta para la definición del modelo numérico y del modelo experimental para la consecución de los objetivos. En el Capítulo 5 se recogen los resultados obtenidos de la simulación y de los modelos reales para su análisis. El último capítulo describirá las principales conclusiones alcanzadas en el desarrollo de la presente Tesis así como el posible trabajo futuro. El esquema de la (Figura 1.4) muestra las relaciones existentes entre los diferentes capítulos que conforman la Tesis. 


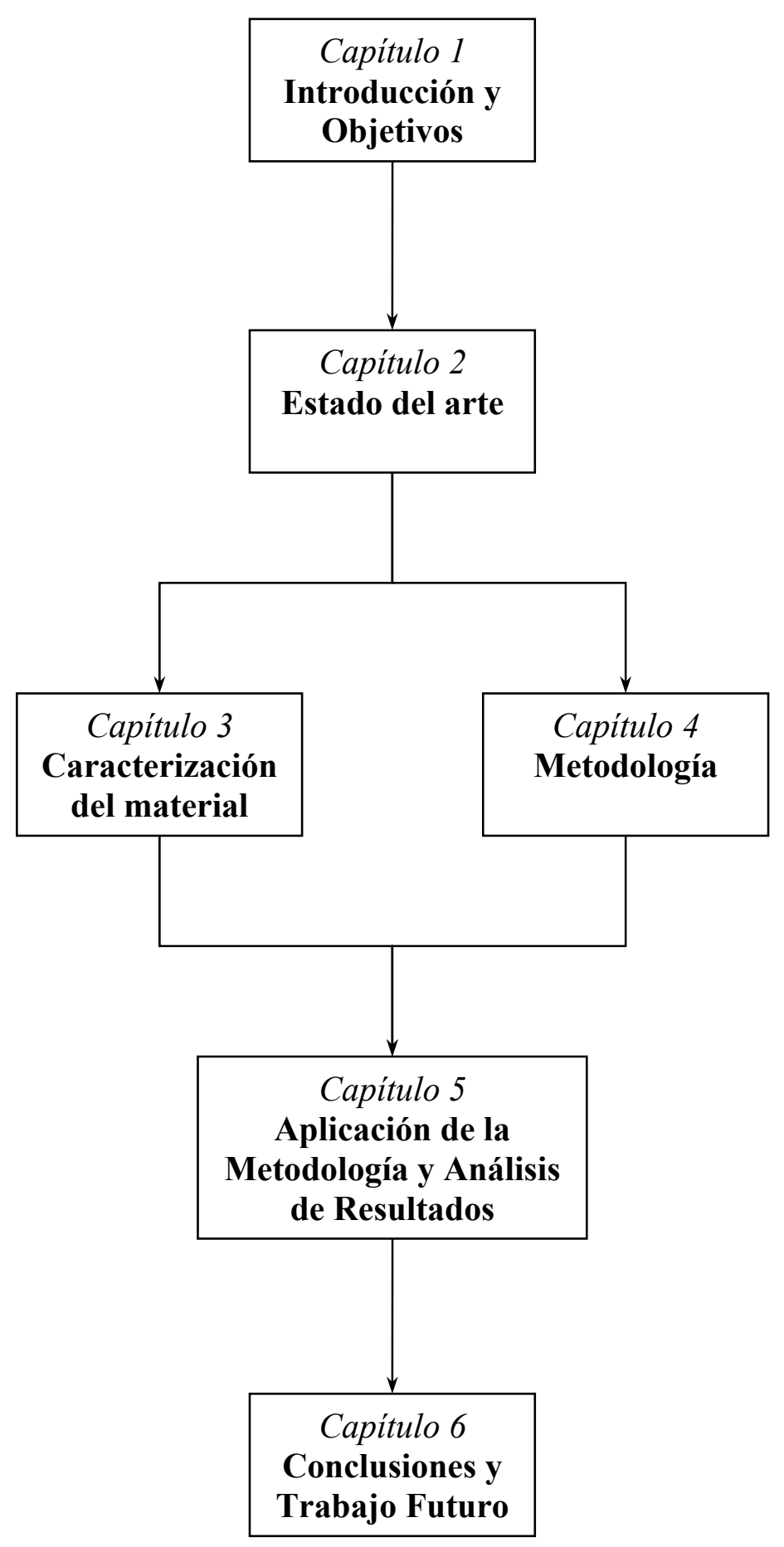

Figura 1.4. Relación entre los Capítulos de la presente Tesis. 


\section{CAPÍTULO 2}

\section{ESTADO DEL ARTE}

\subsection{INTRODUCCIÓN}

En el presente capítulo se ha realizado en primer lugar una descripción introductoria de las diferentes técnicas para la generación de tensiones residuales en cilindros de pared gruesa, entre las cuales se encuentra la que es objeto principal de esta Tesis. Posteriormente, se ha realizado una recopilación exhaustiva de los principales trabajos de investigación que se han realizado relacionados con la técnica del autozunchado mecánico, desde su origen en la década de los 60 hasta la actualidad. Para finalizar, se han recogido los principales métodos para la medición de tensiones residuales utilizadas en cilindros de pared gruesa, haciendo hincapié en el método del "Hole drilling" cuya metodología se explica en el Capítulo 4.

\subsection{TÉCNICAS PARA LA INTRODUCCIÓN DE TENSIONES RESIDUALES EN CILINDROS DE PARED GRUESA}

Tanto los diseñadores como los fabricantes de vasijas de alta presión han utilizado técnicas de introducción de tensiones residuales durante aproximadamente 170 años con el objetivo de incrementar la vida útil de los cilindros de pared gruesa. 
Las vasijas cilíndricas de pared gruesa tales como calderas, reactores nucleares y contenedores de alta presión son utilizados en una gran variedad de aplicaciones en las industrias nuclear, química, armamentística, energética, petrolífera y alimentaria donde se deben contener elevadas presiones internas.

En el caso de que no haya tensiones residuales, las grietas generalmente se forman en el interior, donde las tensiones tangenciales debidas a la presión son más elevadas, por lo que para prevenir dicho fallo y poder incrementar la presión interna se han desarrollado diferentes técnicas de introducción de dichas tensiones residuales.

La principal industria propulsora de estas técnicas ha sido la industria armamentística, principalmente en lo relacionado con el diseño y fabricación de cañones. Ya en 1856 el Capitán Thomas Jefferson Rodman, del ejército de Estados Unidos, realizó un test mediante un nuevo método de fundido de los cañones para producir tensiones residuales que consiguió multiplicar la vida de los cañones por un factor de 9. Está claro que en aquel tiempo no se entendía en profundidad la razón exacta de dicho aumento de vida pero posteriormente, ya en 1880, este problema se corrigió mediante la medición de tensiones residuales con un sistema de corte en anillos de prueba. Para 1890 ya se discutía sobre la producción de cañones con varias capas zunchadas y cañones bobinados, en los cuales se generaban unas elevadas tensiones tangenciales de compresión en el interior. Posteriormente, en 1907 , un oficial Francés de Artillería [2] sugirió un proceso para pretensar cañones monobloques denominado autozunchado, siendo en 1913 cuando se produjo en Francia el primer cañón autozunchado. Durante la Segunda Guerra Mundial, la disponibilidad de aceros de alta resistencia era muy limitada debido a la capacidad industrial y al pobre acceso a los elementos aleantes por lo que se desarrolló el "trabajo en frio" para poder utilizar aceros de baja resistencia. Durante los años 50, se empezó a desarrollar un mejor conocimiento del papel de las tensiones residuales en la vida a fatiga y la ciencia de la mecánica de la fractura. La técnica del autozunchado hidráulico fue utilizada durante muchos años pero debido a que los aceros utilizados fueron teniendo resistencias más elevadas, la presión hidráulica necesaria para el proceso también comenzó a ser más elevada lo que hizo que el autozunchado hidráulico comenzara a ser un proceso complicado.

Durante este periodo, los fabricantes de rifles de pequeño calibre estaban experimentando con un nuevo método de fabricación forzando un tapón, con el contorno del rifle en el diámetro 
exterior, por el diámetro interior del cañón. Esto llevó al desarrollo del denominado autozunchado mecánico o "swaging” [3], el cual producía una distribución tensional similar al autozunchado hidráulico. Lo que sí que es cierto, es que no se podrían entender los avances en la tecnología de introducción de tensiones residuales en cilindros de pared gruesa sin la aportación de Lamé [4], el cual resolvió el problema de la determinación de la tensión tangencial y radial en un cilindro de pared gruesa en función de las presiones exterior e interior aplicadas y de las condiciones geométricas.

A continuación se describen los principales métodos de introducción de tensiones residuales en cilindros de pared gruesa, los cuales pueden clasificarse de forma general:

- Sin deformación plástica:

o Zunchado térmico

o Bobinado.

- Con deformación plástica:

o Tratamientos superficiales: Deep Rolling, shot peening, laser shock peening.

o Tratamientos no superficiales: autozunchado en sus diferentes variantes.

\subsubsection{Zunchado térmico}

El zunchado térmico fue una de las primeras técnicas de introducción de tensiones residuales en cilindros de pared gruesa que se utilizó. Se aplica en vasijas multicapa en las que la capa más externa tiene interferencia, ya que su diámetro interior es más pequeño que el diámetro exterior de la capa interna, con la capa más interna. Para poder realizar el montaje de un cilindro dentro del otro, se calienta la capa más externa o se enfría la más interna, para cambiar sus dimensiones y así generar un juego entre ambos. Una vez que las temperaturas se igualan, los cilindros quedan con una interferencia entre ellos, es decir, el cilindro interior es "apretado" por el cilindro más exterior por lo que el cilindro interior queda con tensiones residuales de compresión tanto radiales como circunferenciales y el cilindro exterior queda con tensiones de tracción circunferenciales y radiales de compresión (Figura 2.1). 


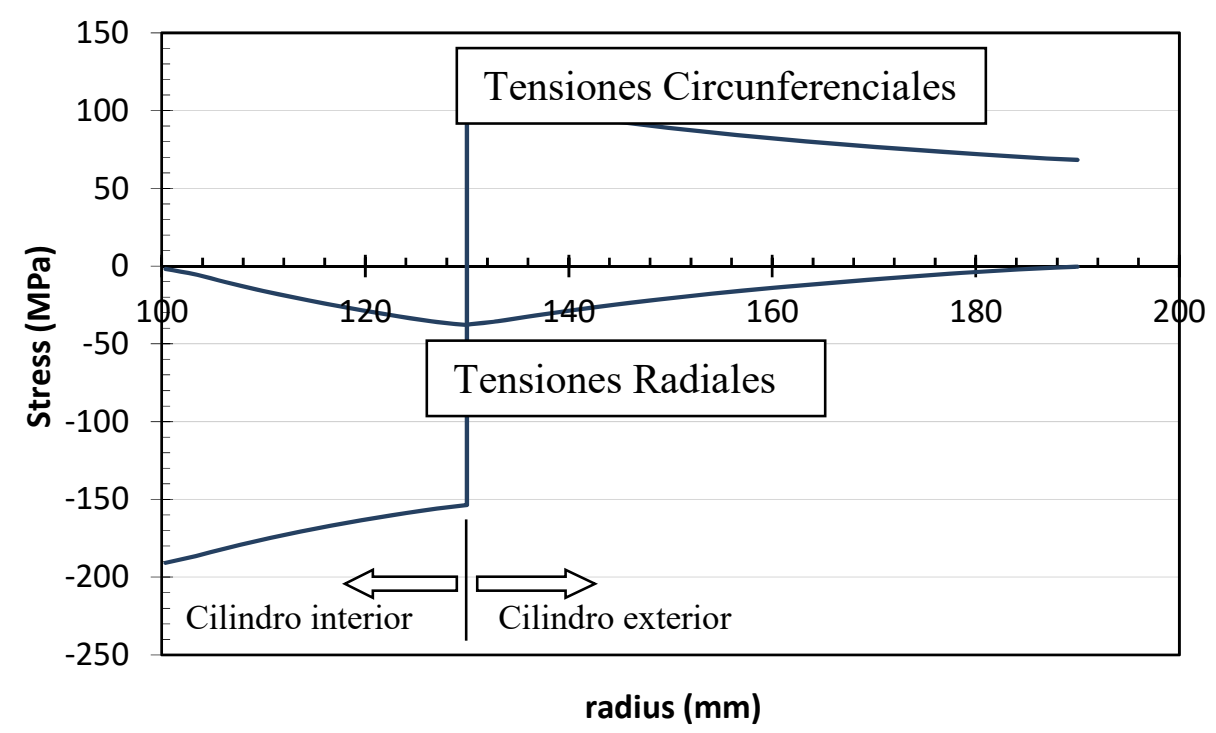

Figura 2.1. Tensiones en una vasija multicapa zunchada térmicamente.

La principal ventaja de esta técnica es su simplicidad, lo que hizo que fuera una de las primeras técnicas utilizadas. Otra ventaja importante es que facilita el cumplimiento de "fuga antes de rotura" pues en el caso de que se inicie una grieta en el cilindro interior, esta propaga hasta alcanzar la intercara de los cilindros donde, de forma segura, se puede detectar la fuga sin producirse una rotura catastrófica del recipiente. Sin embargo, como desventaja cabe destacar que el nivel de tensiones que se puede introducir no es muy elevado ya que la interferencia entre cilindros es limitada debido a que el cilindro exterior no puede calentarse tanto como se quiera, pues se podría afectar a las propiedades mecánicas del material. Por lo tanto, esto hace que el nivel máximo de tensiones residuales que se puede obtener sea limitado a no ser que se utilicen varias capas zunchadas lo que puede hacer que en la capa interna se pueda conseguir un nivel elevado de tensiones residuales pero a costa de aumentar la complejidad y el coste. Otra desventaja radica en que la capa externa está sometida a tensiones de tracción por lo que puede sufrir problemas de vida a fatiga.

Normalmente esta técnica se utiliza sin llegar a la plastificación de los materiales, manteniéndose en la zona elástica, y se utiliza en combinación con otros métodos que complementan las desventajas que tiene. 
Como ya se ha indicado anteriormente, la tecnología del zunchado térmico fue de las primeras que fueron utilizadas. Ya a finales del siglo XIX, se hablaba sobre lo beneficioso de los cañones fabricados zunchando varias capas e incluso se fabricaron cañones mediante esta técnica. Posteriormente, Timoshenko [5] ya determinó la presión de intercara en dos cilindros del mismo material zunchados térmicamente. Las tensiones residuales resultantes podían ser determinadas desde la presión de intercara y las ecuaciones de Lamé [4]. Basado en el trabajo de Manning [6], el diseño óptimo de una vasija con dos capas era donde el ratio del diámetro del liner y jacket (siendo el liner la capa interna y el jacket la externa) era el mismo y la presión de intercara era tal que resultaba en la plastificación simultanea en el diámetro interior del liner y el jacket a la máxima presión de operación. Posteriormente Pugh [7] estudió el zunchado térmico de dos cilindros de diferente material. Crossland and Burns [8] experimentalmente examinaron los parámetros de diseño, tales como las tensiones y las características de plastificación, de cilindros de dos capas observando buena correspondencia con las soluciones teóricas. Sin embargo, observaron la existencia de tensiones longitudinales significantes. También presentaron un análisis del comportamiento del cilindro tras la plastificación y compararon las curvas experimentales presión-expansión con este análisis dentro de la región plástica. Becker et al. [9]-[11] y Pugh [7] investigaron cilindros multicapa con más de dos elementos utilizando el criterio de Tresca.

\subsubsection{Bobinado}

El bobinado [12] es una técnica de introducción de tensiones residuales en una vasija de pared gruesa consistente en el enrollamiento helicoidal de un alambre (normalmente de sección plana) pretensado en el diamétro exterior y de un extremo a otro de la vasija, en un número de vueltas y capas. Cada capa de bobinado introduce en la vasija tensiones residuales de compresión, mientras que las capas internas del alambre se van descargando ligeramente debido a las tensiones radiales compresivas generadas por la última capa bobinada. Mediante este sistema el cilindro de pared gruesa queda con tensiones residuales de compresión, tanto radiales como tangenciales, quedando las capas de alambre con tensiones tangenciales de tracción y radiales de compresión (Figura 2.2). 


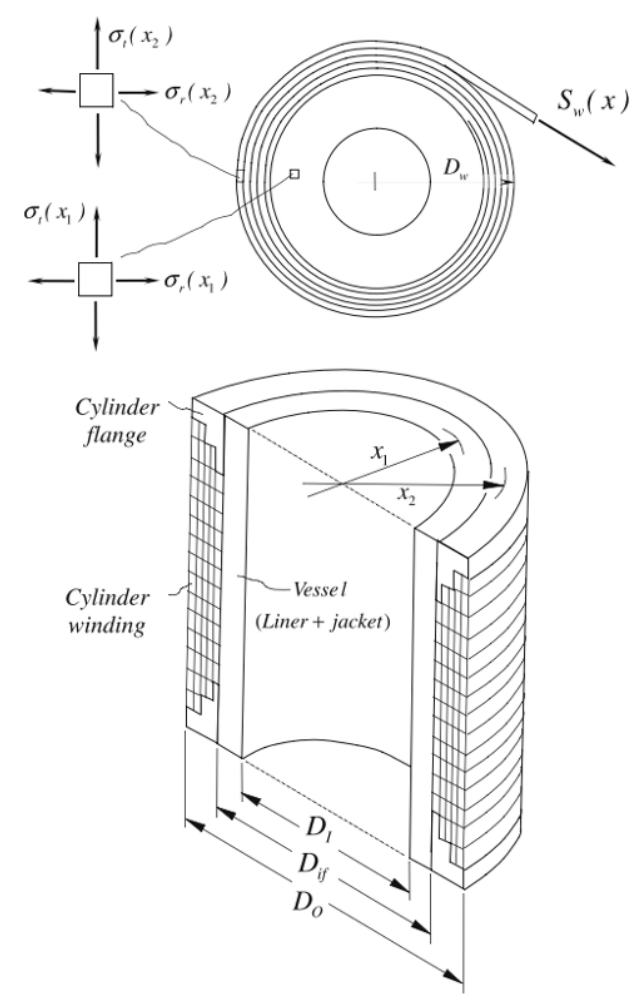

Figura 2.2. Tensiones y nomenclatura en un cilindro de pared gruesa bobinado [12].

Mediante este método las tensiones residuales introducidas en el cilindro de pared gruesa no son debidas a la plastificación del material, sino que normalmente y recomendablemente se debe permanecer en la zona elástica del material del que está fabricado. De hecho las tensiones introducidas están limitadas por el límite elástico del material a compresión.

Bajo la presión de trabajo, las tensiones iniciales compresivas del cilindro se reducen, mientras que las tensiones de tracción del bobinado se incrementan. Sin embargo las tensiones en el diámetro interior del cilindro pueden permanecer compresivas si estas eran suficientemente elevadas de inicio. Obviamente el alambre se encuentra sometido a tensiones tangenciales de tracción y por tanto a fatiga, pero el alambre utilizado para dicha técnica es uno de elevada resistencia con un comportamiento a fatiga excelente.

El bobinado es una técnica en el que se puede tener un control muy preciso de las tensiones introducidas, pues capa a capa, se puede ajustar la tensión del alambre para conseguir el objetivo tensional deseado. Además, dado que se trabaja en la zona elástica del material del cilindro, mediante un control de la reducción del diámetro interior durante el proceso de bobinado se puede controlar todo el proceso. Como desventajas cabe indicar que lleva más 
tiempo que otras técnicas y que el alambre puede rompense durante el proceso. También hay otras dificultades en el comienzo y el final del proceso de bobinado así como en la continuidad del alambre cuando se utilizan varias bobinas.

Ha habido diferentes métodos e hipótesis para bobinar y analizar cilindros. El método más simple para afrontar el problema es la consideración de una tensión de tracción constante para todas las capas de alambre durante el proceso de bobinado aunque Young y Brownell [13], en 1959 calcularon la tensión del alambre para cada capa durante el bobinado. Utilizando esta teoría, se obtuvo una tensión de tracción constante a la presión de trabajo en todas las capas. Maksimov [14] propuso la teoría de la máxima tensión cortante constante, lo cual conseguía un uso más eficiente de la capacidad del bobinado. Harkegard [15] presentó un procedimiento para el análisis y diseño óptimo de vasijas y yugos bobinados. Talako [16] utilizó una nueva hipótesis asumiendo el cilindro interior como un cilindro de pared gruesa y las capas de bobinado como vasijas de pequeño espesor. Fryer and Havery [17] utilizaron las relaciones de Lamé y asumieron la vasija como una vasija multicapa de pared gruesa. Alegre et al. [12] presentaron un nuevo procedimiento para la simulación de una vasija de pared gruesa bobinada. El Código ASME, Sección VIII, Division 3 proporciona los requerimientos de diseño y fabricación para vasijas de alta presión bobinadas [18]. Mientras que todos los métodos analíticos existentes para el bobinado eran aplicables para una vasija con módulo de elasticidad constante $E$ y comportamiento elástico, Sedighi et al. [19] propusieron un nuevo método de bobinado basado en el Método Directo, que podía ser utilizado para calcular las tensiones residuales en un cilindro bobinado con Módulo de elasticidad $E$ variable. Para el cálculo de fatiga de vasijas bobinadas, Alegre et al. [20], estudiaron el diseño a fatiga de una vasija bobinada utilizando el procedimiento ASME API 579 [21]. Sedigui et al. [22], en 2017 investigaron la vida a fatiga de una vasija autozunchada y bobinada aplicando un método que considera los cambios que se pueden dar en el módulo de elasticidad $E$ durante el paso de descarga en el autozunchado o durante la plastificacion inversa.

\subsubsection{Deep Rolling}

El Deep Rolling es una técnica de introducción superficial de tensiones residuales mediante la aplicación de una presión específica con una bola o cilindro controlada mecánica o hidráulicamente. Dicha presión provoca una deformación plástica en la superficie y bajo ella, introduciendo una capa (de 1 a $2 \mathrm{~mm}$ ) de tensiones residuales de compresión (Figura 2.3). 
Lógicamente, estas tensiones residuales producen un aumento de la vida a fatiga no sólo por las tensiones residuales introducidas, sino también debido al endurecimiento y a la menor rugosidad superficial.

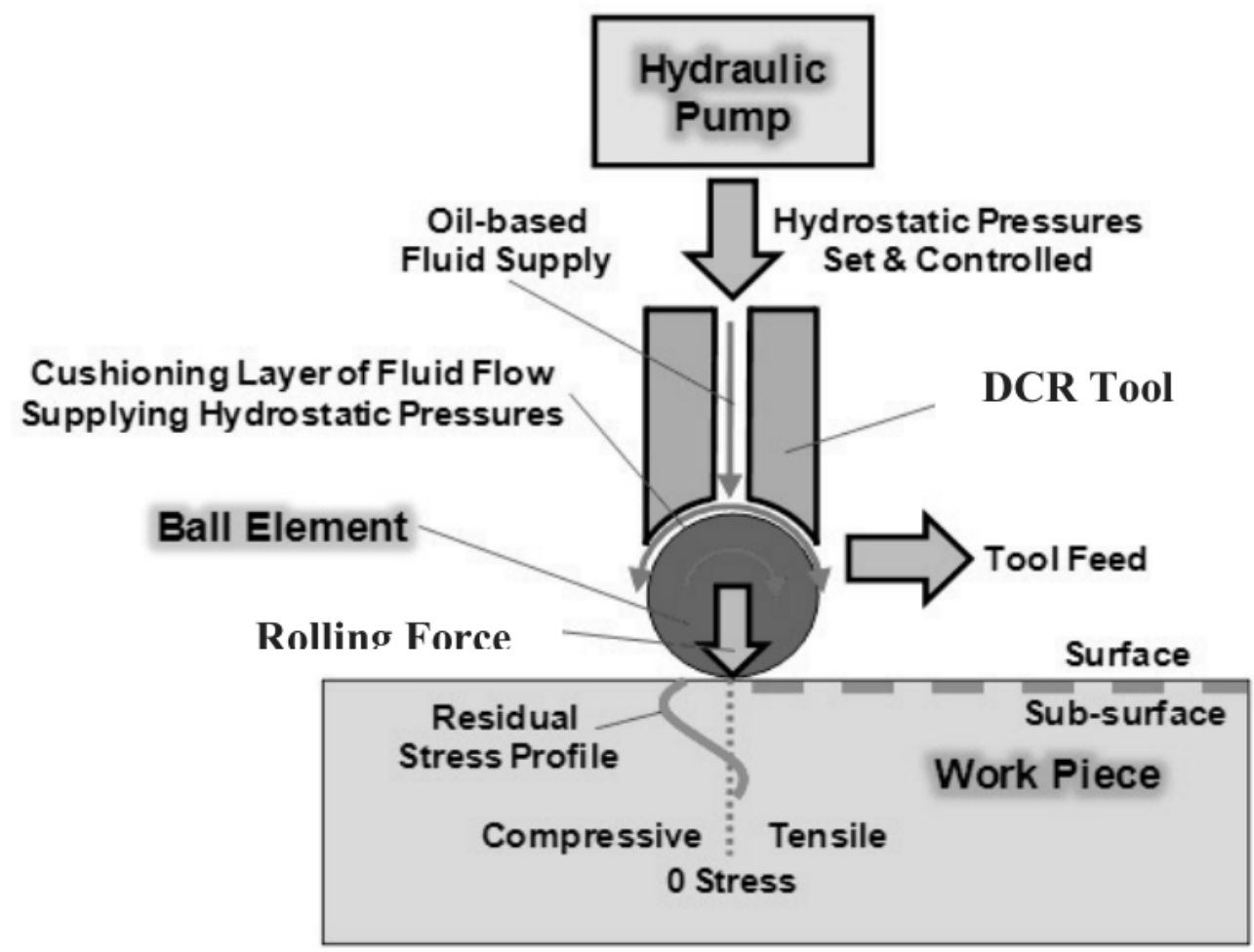

Figura 2.3. Deep Rolling en componentes planos [23].

El proceso de Deep Rolling puede llevarse a cabo de diferentes formas, dependiendo de la forma del elemento en el que se va a realizar. En agujeros interiores de componentes cilíndricos, como puede ser un cilindro de pared gruesa, se suele realizar en un torno en el que se coloca una herramienta, donde suele ir la herramienta de corte, consistente en tres bolas espaciadas $120^{\circ}$ respecto al eje de la pieza. La pieza se hace girar con el torno respecto a su eje longitudinal y la herramienta se desplaza en la dirección de dicho eje.

La principal ventaja de este proceso es la sencillez de aplicación y el bajo coste comparado con otros procesos de generación de tensiones residuales. Como desventajas señalar que su aplicación está normalmente limitada a geometrías sencillas y que el espesor afectado en el que se introducen tensiones residuales no es muy elevado. 
Ya en los años 30, Thumb y Föppl y Horger [24], [25] reportaron por primera vez el incremento en la resistencia a fatiga como resultado del Deep Rolling. Posteriormente han sido muchos los trabajos que se han realizado en este campo destacando, como primer paso, el realizado por Kloos et al. [26] en el que propusieron un método para determinar la carga aplicada en el Deep Rolling que producía el incremento óptimo de la resistencia a fatiga pues, hasta el momento, se determinaba empíricamente. Posteriormente, ya en la década de los 90, años 2000 y hasta nuestros días han sido numerosos los estudios e investigaciones realizados sobre el Deep Rolling.

P. Delgado et al. [27] realizaron una revisión completa de este proceso presentando diferentes procedimientos de ejecución del Deep Rolling así como los parámetros que controlan el proceso y su influencia en los parámetros de material como la microestructura, dureza superficial o límite elástico. También presentaron los estudios de simulación numérica y se revisaron los materiales más comunes a los que se aplica este método y los nuevos procedimientos de implementación del Deep Rolling a alta y baja temperatura.

\subsubsection{Shot Peening}

El Shot Peening es un proceso de introducción de tensiones residuales superficiales mediante la plastificación del material generada por el múltiple impacto de partículas sólidas contra la superficie (Figura 2.4). En este proceso el resultado de generación de tensiones se consigue bombardeando la superficie con partículas relativamente duras, normalmente partículas esféricas frías $(0,25$ a $1 \mathrm{~mm}$ de diámetro) hechas de acero, cristal o cerámica teniendo velocidades de impacto en el rango de 20 a $150 \mathrm{~m} / \mathrm{s}$. Las partículas se proyectan con la suficiente velocidad para indentar la superficie y producir la plastificación local. Como las regiones deformadas tienden a expandir, estas son contenidas por el metal adyacente más profundo que no había sido deformado por los impactos. Dado que la capa superficial deformada plásticamente busca ocupar más espacio, es forzada en compresión, produciéndose tensiones residuales compresivas. Lógicamente estas tensiones de compresión tienen un efecto positivo en la vida a fatiga. 


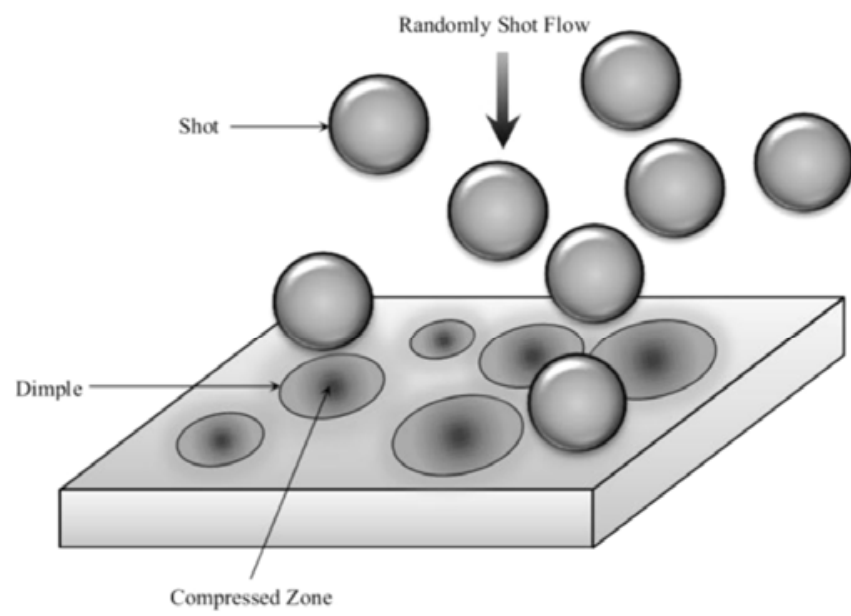

(a)

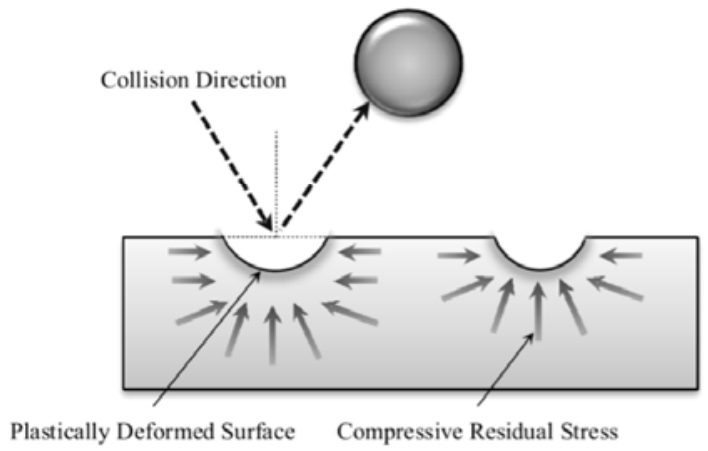

(b)

Figura 2.4. Ilustración esquemática del (a) proceso de Shot Peening y (b) de la deformación plástica producida [28].

El Shot Peening es uno de los tratamientos más comúnmente utilizados en la industria aeronáutica para mejorar las propiedades superficiales e introducir tensiones residuales de compresión aunque la rugosidad superficial después del tratamiento requiere ser reducida mediante la utilización de un pulido adicional o de otro tratamiento superficial. Las principales ventajas del proceso son que se puede realizar en geometrías complejas, que es un proceso relativamente barato y que utiliza equipos robustos aunque sus desventajas radican en que el espesor de material en el que se introducen tensiones residuales de compresión es bajo (normalmente no supera los $0,25 \mathrm{~mm}$ ) y la necesidad, antes expuesta, de pulir posteriormente la superficie, pues las marcas generadas por los impactos son concentradores de tensiones para la generación de grietas.

El Shot Peening es una tecnología que fue utilizada por primera vez a finales de los años $20 \mathrm{y}$ principios de los 30 del siglo XX. Desde entonces son numerosos los estudios e investigaciones realizadas en ese campo [29]-[31].

\subsubsection{Laser Shock Peening}

El Laser Shock Peening (LSP) es una técnica de introducción de tensiones superficiales residuales de compresión basada en la acción de uno o varios pulsos cortos láser de alta energía en la superficie del material. La deformación plástica causada por la onda de choque 
mientras se propaga en el metal resulta en la generación de tensiones residuales. Normalmente se utilizan recubrimientos transparentes a la energía del láser para incrementar la intensidad de la onda de choque ya que evita la expansión rápida fuera de la superficie del plasma generado por el láser. También se suelen utilizar recubrimientos absorbentes de sacrificio pues incrementan también la intensidad de la onda de choque aparte de proteger la superficie del metal de la fusión por el láser (Figura 2.5).

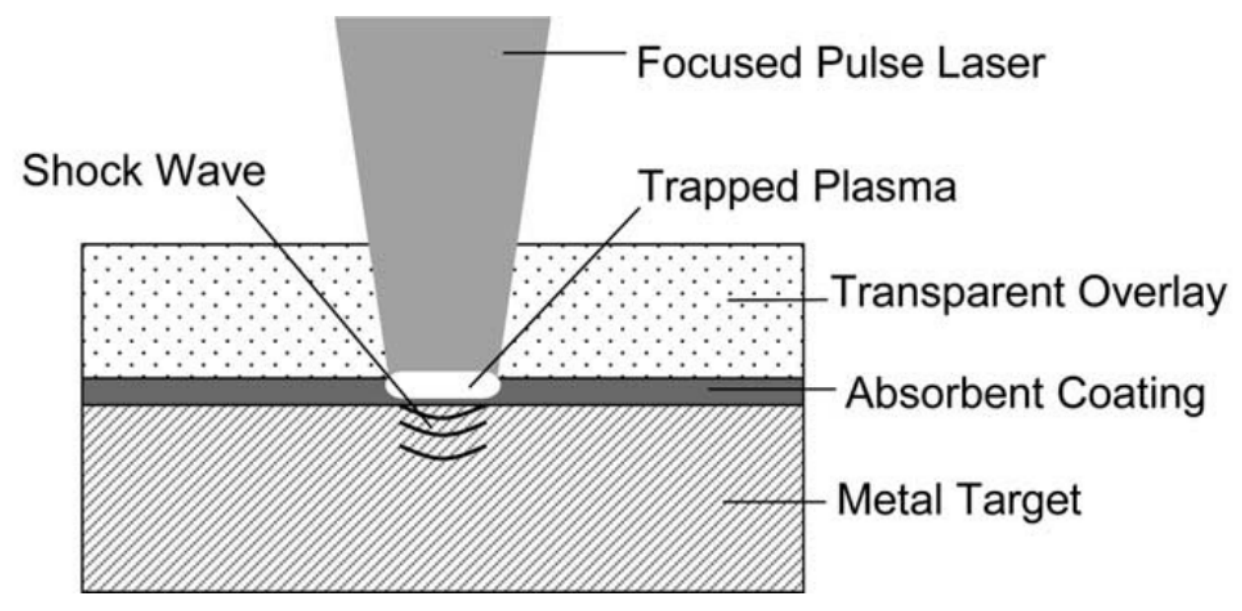

Figura 2.5. Ilustración esquemática del LSP [32].

El LSP resuelve dos de las desventajas del Shot Peening en cuanto que la profundidad afectada es superior a esta (pudiendo llegar a 0,5 - $1 \mathrm{~mm}$ en función del material y de los parámetros del proceso) y que no aumenta la rugosidad de la pieza o incluso produce una mejora muy pequeña. Otra de las ventajas del LSP es que el láser puede ser controlado y ajustado en tiempo real ya que mediante sistemas informáticos de control la energía por pulso puede ser medida y grabada para cada localización del componente que se está tratando. Además de todo lo anterior, el proceso es limpio y es susceptible de un elevado grado de automatización en líneas de fabricación. Además el LSP ha demostrado que endurece la superficie y mejora las propiedades mecánicas de los materiales. Como desventajas respecto a otros métodos destacar que, al ser un tratamiento superficial, la profundidad afectada no es muy elevada.

La posibilidad de generar ondas de choque mediante rayos láser pulsados fue por primera vez reconocido y explorado a principios de los años 1960 [33], [34]. Posteriormente, durante finales de los años 1960 y principios de los años 1970 se realizaron estudios para mejorar la 
amplitud de las ondas de tensión [35], haciendo posible la inducción de deformación plástica en objetivos metálicos. A partir de entonces se desarrollaron instalaciones y estudios de viabilidad iniciales en Estados Unidos para utilizar ondas de choque inducidas por láser para modificar las propiedades del material. Posteriormente, ya en los años 1990, muchos grupos de investigación, sobre todo en Francia, realizaron muchos esfuerzos en la investigación y explotación industrial del proceso, lo que derivó en multitud de patentes. Desde entonces se han realizado multitud de trabajos de investigación en este campo [36]-[38].

\subsubsection{Autozunchado}

El autozunchado es una técnica de introducción de tensiones residuales de compresión en cilindros de pared gruesa basada en el principio de someter inicialmente al cilindro a una deformación plástica parcial en su diámetro interior mediante la aplicación de una carga para luego descargarlo, resultando en la generación de tensiones residuales compresivas. La carga aplicada, que provoca únicamente una plastificación parcial, crea dos zonas deformadas en el cilindro, una zona interior plástica y otra zona exterior elástica. La zona plástica interior se extiende desde el diámetro interior hasta el radio de intercara elastoplástico $\mathrm{r}_{\mathrm{p}}$ mientras que la zona elástica se extiende desde dicho radio hasta la superficie exterior. Cuando la carga aplicada es retirada, la zona exterior elástica intenta volver a su radio inicial mientras que la zona interior plástica permanece permanentemente deformada (Figura 2.6). Esta interacción entre las dos zonas induce unas tensiones residuales de compresión en la zona plástica interior del cilindro lo que aumenta la capacidad de contención de presión, la vida a fatiga y la resistencia a corrosión bajo tensión.

El principio de autozunchado, como se ha explicado en apartados anteriores, fue introducido en el siglo XIX por Jacob [2], un oficial de artillería Francés para pretensar cañones monobloque. Desde su introducción la técnica ha evolucionado, desde ser originalmente una aplicación militar, a su aplicación en otros campos industriales. Dependiendo del sistema utilizado para provocar la deformación plástica inicial, el autozunchado se puede clasificar en hidráulico, por explosión, térmico, rotacional y mecánico o swaging. 


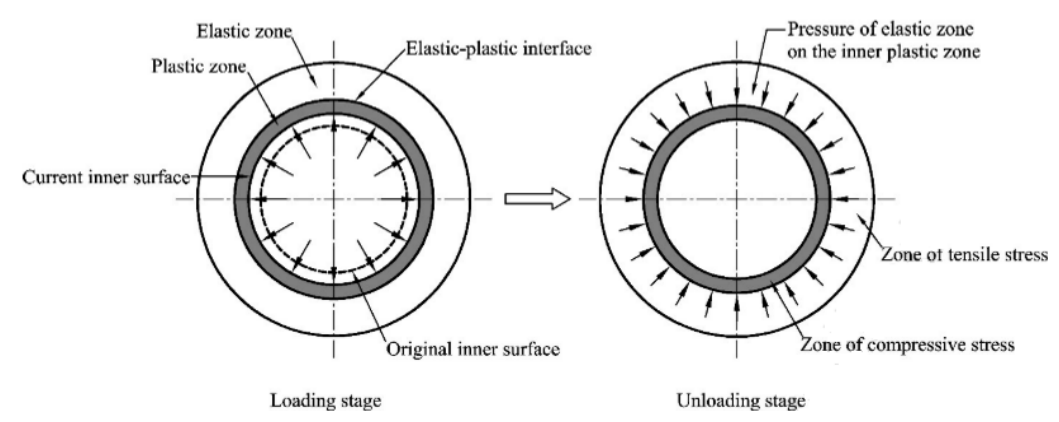

Figura 2.6. Principio de trabajo de un proceso de autozunchado [39].

\subsubsection{Hidráulico}

En este caso las tensiones residuales se consiguen mediante la aplicación de presión. El cilindro de pared gruesa se rellena de un fluido, aceite hidráulico o incluso agua (rellenando el interior de la vasija con un espaciador para que la cantidad de fluido que haya que meter sea inferior y por tanto también el tiempo presurizando) y se presuriza a una elevadísima presión (Figura 2.7). La presión aplicada causa la plastificación inicial del cilindro en su diámetro interior a una presión denominada presión de plastificación, que representa la capacidad de contención de presión del cilindro con el material específico y las dimensiones consideradas. Como la presión introducida sobrepasa ese límite, se produce una plastificación posterior creando dos zonas en el cilindro separadas por el denominado radio de intercara elastoplástico $\mathrm{r}_{\mathrm{p}}$, una interna plastificada y otra externa elástica. Al cesar la presión interna, la zona elástica interna retorna a su posición original "comprimiendo" la zona plastificada que no vuelve a su posición, generando de esta forma tensiones residuales compresivas.

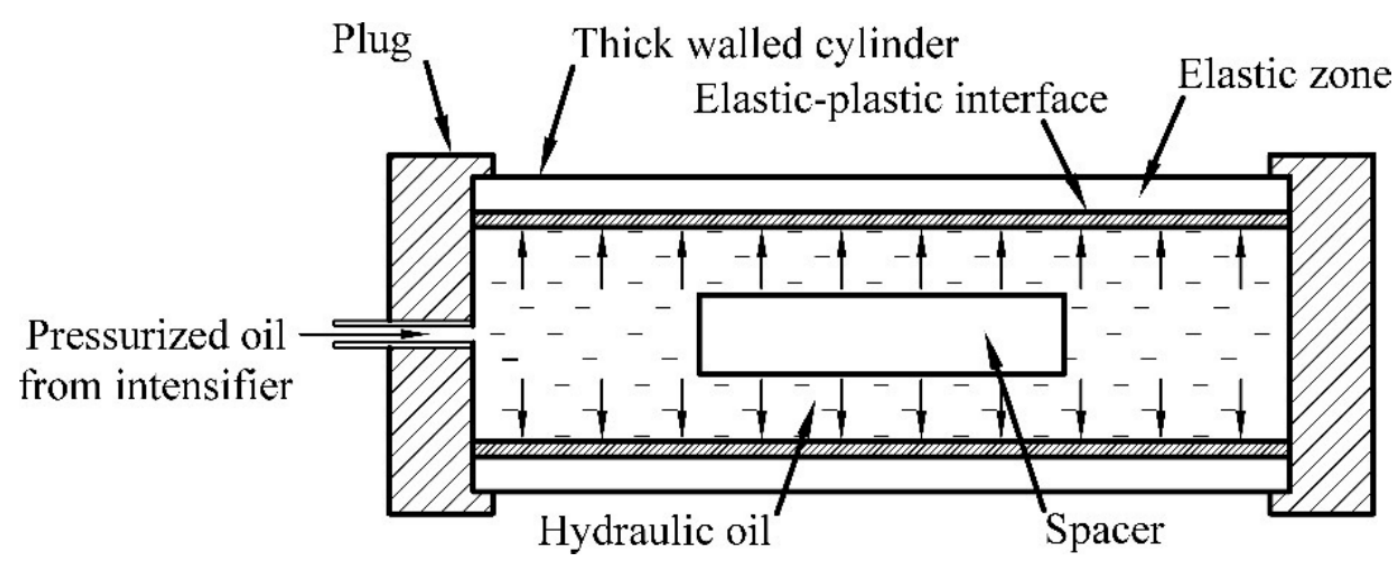

Figura 2.7. Esquema típico de un autozunchado hidráulico [39]. 
Es un método relativamente fácil de aplicar para cilindros de aleaciones de baja y media resistencia por lo que ha sido utilizado desde hace muchos años. Sin embargo, su desventaja principal es que, desde el punto de vista práctico, llevar a cabo el autozunchado en cilindros de pared gruesa de aceros de alta resistencia es complicado pues las presiones que son necesarias alcanzar son altísimas y la posibilidad de fallo durante el proceso es elevada, sobre todo en las juntas que cierran los extremos y en los racores del circuito que conducen la alta presión. También las bombas intensificadoras necesarias para elevar la presión pueden fallar con asiduidad.

El autozunchado hidráulico es el concepto original de autozunchado que fue por primera vez concebido por Jacob [2] en 1907. Son muy númerosos los estudios que se han realizado de esta técnica de introducción de tensiones residuales a lo largo de los años. Numerosos investigadores han investigado el proceso tanto analítica como numéricamente. Ya en 1947, Hill et al. [40] formularon un modelo de un cilindro autozunchado hidráulicamente, sin endurecimiento, para el caso de deformación plana. Posteriormente, en 1953, Thomas [41] realizó una investigación numérica inicial del autozunchado hidráulico de un tubo de pared gruesa con los extremos libres basado en los criterios de plastificación de Tresca y las relaciones tensión-deformación incrementales de Prandtl-Reuss. También, varios investigadores analizaron el efecto Bauschinger a lo largo de la historia. Por ejemplo, en 1987 Kendall [42] presentó un método analítico para predecir la presión de replastificación de cilindros autozunchados incluyendo una mejora de una corrección simple del efecto Bauschinger a las tensiones residuales que previamente había estimado en otros estudios y en 1999 Kendall et al. [43], determinaron una serie de procedimientos para determinar la influencia del efecto Bauschinger en tubos autozunchados. En 1993, Avitzur [44] desarrolló un modelo analítico para investigar la distribución de tensiones elastoplásticas y el campo de tensiones residuales para un tubo de pared gruesa sometido a autozunchado hidráulico para condiciones tanto de deformación plana, como de tensión plana. La distribución de tensiones se analizó utilizando respectivamente el criterio de Tresca y el de Von Mises. Se observó una desviación inferior al 15,5\% entre ambas distribuciones tensionales. Parker [45], en 2001, propuso un procedimiento de diseño numérico para el autozunchado de cilindros de pared gruesa con extremos abiertos e incluso se comparó con el código ASME [18], siendo los resultados de Parker incorporados en él. También se han realizado númerosos estudios analizando la redistribución de tensiones tras la eliminación de material tras el autozunchado 
[43], [46]-[48]. Además se han realizado estudios en los que el autozunchado se junta con el zunchado térmico [43], [47], [49], [50] e incluso con otros métodos como el bobinado [22]. En las últimas décadas se han realizado números estudios utilizando simulación FEM para modelizar el autozunchado de los cilindros [46], [51]-[55].

\subsubsection{Por explosión}

En el autozunchado por explosión [56], la deformación plástica interna del cilindro es causada por la presión debida a la detonación de una carga explosiva dentro del cilindro en un medio fluido propagador como el aire o el agua (Figura 2.8). Este proceso no ha sido tan estudiado por los investigadores dado que, al ser una técnica que necesita explosivos, se necesitan permisos legales para la implementación experimental lo cual es una de sus principales desventajas junto con la peligrosidad del método.

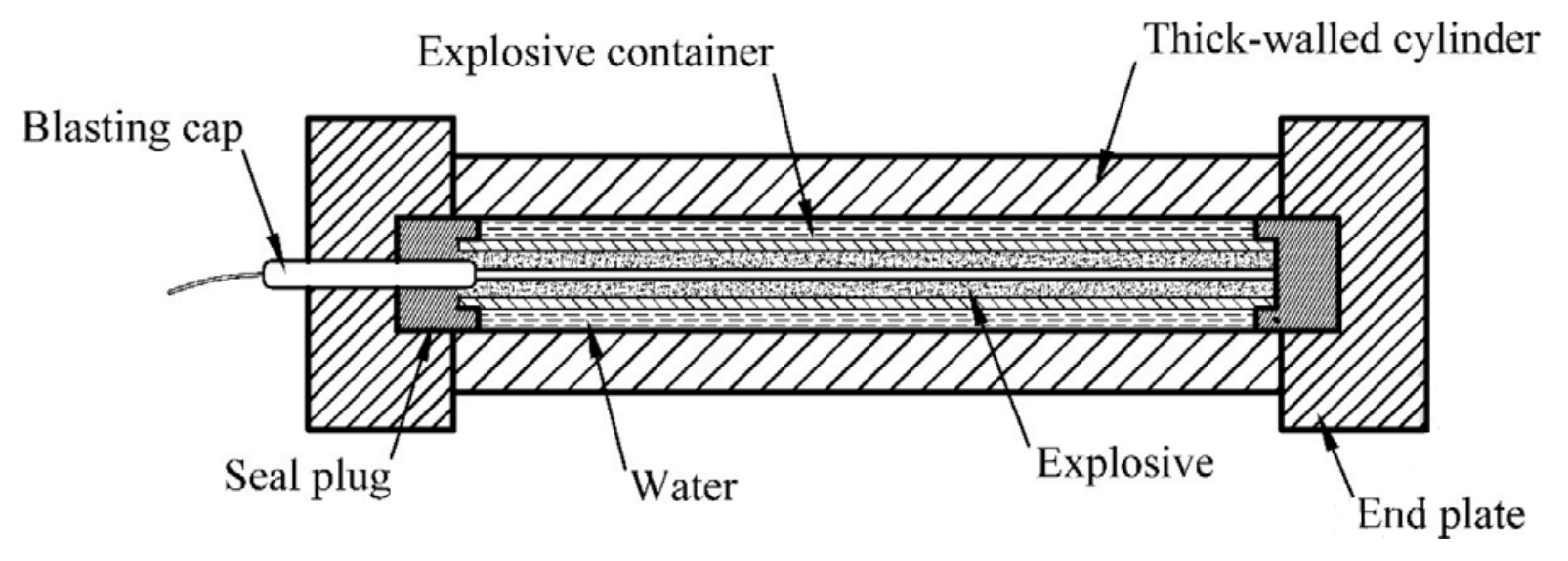

Figura 2.8. Esquema típico de un proceso de autozunchado por explosión [39].

Fue en 1971 cuando Mote et al. [56] publicaron el primer modelo analítico para el análisis de factibilidad del autozunchado por explosión basado en una formulación de plasticidad utilizando el criterio de Von Mises y asumiendo un comportamiento del material sin ningún endurecimiento por deformación o endurecimiento por velocidad de deformación. Incluso realizaron un análisis experimental riguroso junto con las formulaciones teóricas en cañones de diámetro interior de $152 \mathrm{~mm}$. Las tensiones residuales obtenidas en los experimentos fueron medidas utilizando el método Sachs que, como se explica más adelante en este capítulo, es un método destructivo de medición de tensiones residuales basado en la medición de la relajación exterior del cilindro al ir mecanizando capas de material en su diámetro interior. En 1999, Zhan et al. [57] realizaron autozunchado por explosión en un cilindro de pared gruesa de 
acero 43CrNiMoVA y utilizaron la técnica Sachs para medir las tensiones residuales. Posteriormente, en 2005, Zhan et al. [58] estudiaron el efecto del autozunchado por explosión en la vida a fatiga de diferentes componentes autozunchados utilizando dos medios explosivos (aceite y un líquido dinámico). La explosión con aceite fue similar a la técnica de endurecimiento por explosión donde la onda de choque inicial de la explosión fue utilizada para deformar el cilindro mientras que el líquido dinámico utilizó la expansión gradual del medio después de la detonación. Las tensiones residuales se midieron utilizando la técnica de difracción de Rayos X y fue demostrado que los componentes autozunchados por la explosión del aceite tuvieron una mejora de la vida a fatiga superior.

\subsubsection{Térmico}

En el autozunchado térmico [59], las tensiones residuales se introducen en el cilindro debido a la deformación elastoplástica causada por las tensiones térmicas generadas debido al mantenimiento de un gradiente térmico a lo largo del espesor del cilindro y a un posterior enfriamiento gradual a temperatura ambiente. Se necesita crear una diferencia de temperatura en la pared del cilindro lo suficientemente elevada para causar la deformación elástoplástica requerida en el cilindro. Esto se puede conseguir calentando el diámetro exterior mediante resistencias eléctricas y enfriando el diámetro interior mediante la circulación de un fluido de refrigeración (Figura 2.9).

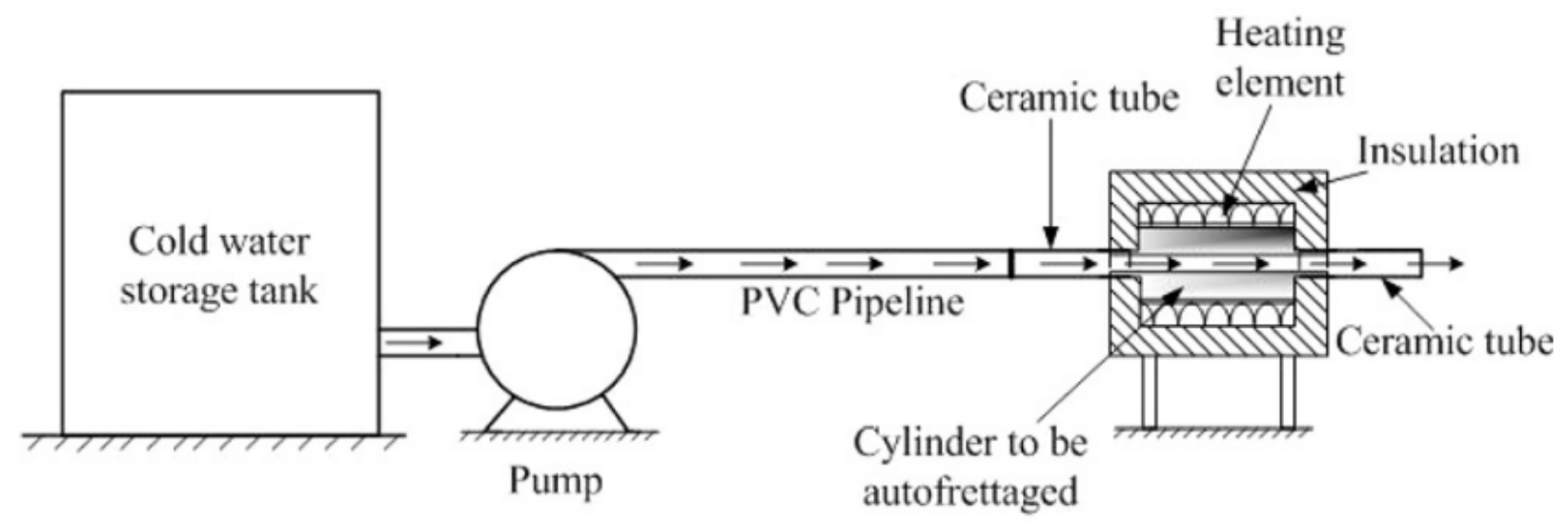

Figura 2.9. Esquema del ensayo de autozunchado térmico [59].

Como principal ventaja de este método se podría destacar la simplicidad de aplicación, pues únicamente aplicando calor en el exterior y frío en el interior se pueden introducir tensiones 
residuales. Como desventajas tenemos que la cantidad de tensiones residuales que se pueden introducir está limitada por la máxima temperatura a la que se puede someter al material sin producir cambios microestructurales en el mismo que puedan afectar a su comportamiento posterior. Una de sus posibilidades es su aplicación junto con otros métodos de introducción de tensiones residuales que permitan complementar las tensiones residuales introducidas.

Este método de autozunchado fue introducido en 2015 por Kamal y Dixit [59], los cuales fueron los primeros en llevar a cabo un análisis elastoplástico riguroso del autozunchado térmico para un cilindro largo de pared gruesa con los extremos abiertos basado en el criterio de plastificación de Tresca y en un material sin endurecimiento. Independientemente hay que señalar que el origen del concepto no es suyo, ya que a mediados del siglo XIX ya se aplicaban tensiones generadas térmicamente para introducir tensiones residuales compresivas en tubos de pared gruesa en el enderezamiento de cañones. Como ya se introdujo al principio de este capítulo, el General Thomas Rodman del ejército de Estados Unidos utilizó este método en los años 1850 para fabricar cañones desde colada directa utilizando una técnica de enfriamiento diferencial calentando la superficie exterior mientras enfriaba el interior con agua fría [60]. El concepto de autozunchado térmico está basado en un principio similar ya que el cilindro de pared gruesa se somete a un gradiente térmico en su fase de carga y, en la fase de descarga, se enfría a temperatura ambiente donde ocurre la descarga elástica de las tensiones térmicas y por tanto se inducen las tensiones residuales. El término "autozunchado térmico" fue introducido por primera vez en 2002 por Wen et al. [61] como un método alternativo al autozunchado del liner interno de metal de una línea de alimentación criogénica de composite aunque, como se ha indicado anteriormente, fue Kamal y Dixit [59] quienes realizaron por primera vez un análisis elastoplástico riguroso para un cilindro de pared gruesa. Ya en 2016, Kamal et al. [62] realizaron un estudio comparativo entre el autozunchado térmico e hidráulico asumiendo propiedades independientes de la temperatura y mostraron que el incremento alcanzable de la capacidad de contención de la presión mediante autozunchado térmico era inferior que la alcanzable mediante autozunchado hidráulico debido al límite de temperatura alcanzable para evitar la recristalización del material. También en 2016, Kamal et al. [63] realizaron un estudio experimental para la investigación de las tensiones residuales inducidas en un cilindro por autozunchado térmico. La evidencia de las tensiones residuales inducidas fue identificada mediante microdurezas y el método de "Splitring”, método destructivo de medición de tensiones residuales consistente en la medición del 
ángulo de apertura debido a un corte longitudinal realizado en un anillo de muestra del cilindro autozunchado, y las tensiones fueron medidas mediante el método Sachs. Posteriormente, en 2017, presentaron modelos analíticos para el autozunchado térmico de un cilindro de pared gruesa asumiendo tensión plana y condición de deformación plana con los extremos abiertos. El comportamiento plástico del material fue modelizado utilizando la ley de endurecimiento isotrópo de Ludwik. Comparando con resultados de análisis FEM 3D, se demostró que el modelo analítico de deformación plana generalizada era válido para ratios de longitud - espesor de pared mayores que 6 y que el modelo analítico de tensión plana era válido para ratios menores de 0,5 .

\subsubsection{Rotacional}

En el autozunchado rotacional [64], la superficie interior del cilindro de pared gruesa se deforma plásticamente por las fuerzas centrífugas debido a la rotación a alta velocidad angular (Figura 2.10). Las tensiones residuales se inducen cuando el cilindro se lleva a reposo gradualmente.

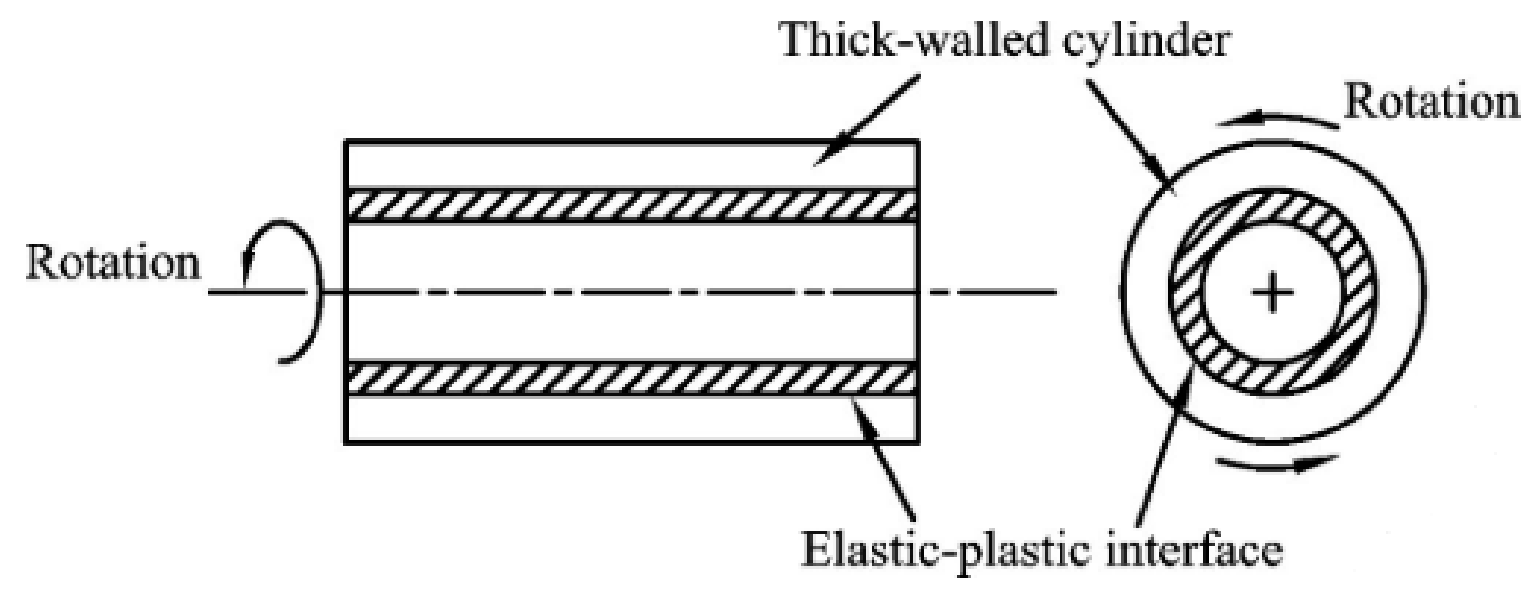

Figura 2.10. Esquema típico de un proceso de autozunchado rotacional [39].

Las principales desventajas de este método es que para piezas de gran tamaño se necesitan potencias enormes para producir la alta velocidad angular necesaria, es decir, en la práctica hay que encontrar motores eléctricos o de otro tipo capaces de suministrar la velocidad angular y la potencia mecánica necesaria para producir el autozunchado. También es importante aplicar el método en piezas axisimétricas para no producir elevadísimas descompensaciones de las fuerzas. 
El autozunchado rotacional es una técnica reciente propuesta en 2016 por Zare y Darijani [64] en donde realizaron un riguroso análisis y desarrollaron un modelo analítico basado en el criterio de plastificación de Tresca y su regla de fluencia asociada. El endurecimiento no se tuvo en cuenta para la fase de carga aunque el efecto Bauschinger fue considerado en la fase de descarga utilizando el parámetro BEF (Factor del efecto Bauschinger) definido como el límite elástico tras la descarga dividido entre el límite elástico inicial. Posteriormente en 2017, Zare y Darijani [65] extendieron el estudio para un material lineal con endurecimiento cinemático.

\subsubsection{Mecánico o swaging}

En el autozunchado mecánico o swaging [3] la deformación interior es conseguida mediante el empuje de un mandrino o "pepita" sobredimensionado respecto al diámetro interior del clilindro de pared gruesa a lo largo de toda su longitud causando por lo tanto fluencia plástica debido a la interferencia mecánica (Figura 2.11).

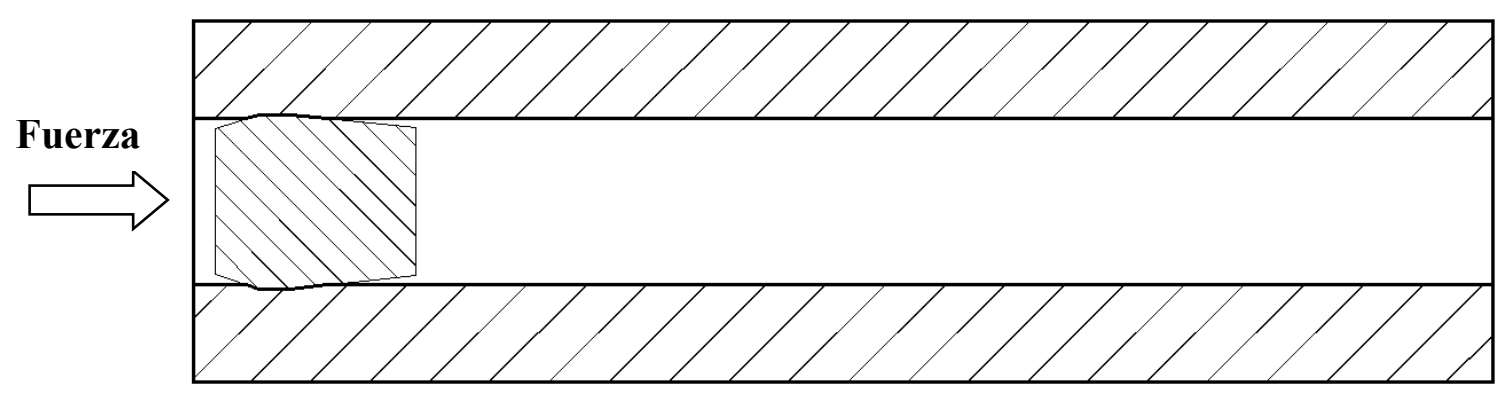

Figura 2.11. Esquema típico de un proceso de autozunchado mecánico.

Se pueden considerar tres tipos de autozunchado mecánico en función de la forma en la que se fuerce el movimiento de la pepita, empuje mecánico, tiro mecánico y empuje hidráulico (Figura 2.12). 


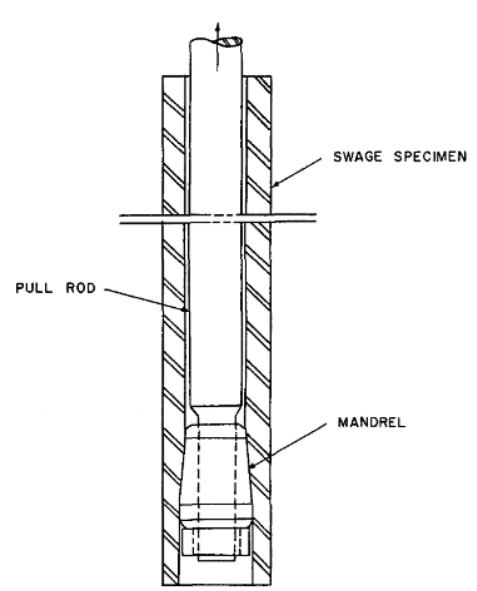

a)

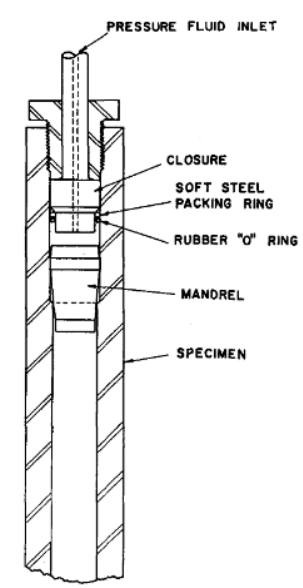

b)

Figura 2.12. Esquema típico de un proceso de autozunchado mecánico a) tiro mecánico y b) empuje hidráulico [3].

En el autozunchado mecánico con empuje mecánico normalmente se fuerza el movimiento de la pepita mediante un actuador hidráulico; en el de tiro mecánico normalmente también se utiliza un actuador para provocar el arrastre de la pepita y en el autozunchado mecánico con empuje hidráulico, se utiliza la presión de un fluido para producir el movimiento de la pepita a través del cilindro. Para facilitar el movimiento del mandrino a través del cilindro es muy importante un buen acabado superficial del mismo así como una lubricación adecuada.

Una de las ventajas de esta tecnología es que se generan tensiones residuales de compresión en las tres direcciones del cilindro (radial, tangencial y longitudinal) de forma que se puede crear un estado tensional hidrostático pudiendo ser la tensión equivalente muy baja. Otra ventaja del autozunchado mecánico es que para el mismo nivel de sobredeformación, la presión equivalente requerida en cualquiera de los tres métodos de autozunchado mecánico es significativamente inferior a la requerida en un proceso de autozunchado hidráulico por lo que ofrece ventajas económicas y de proceso respecto a otros métodos. La principal desventaja del método es que para materiales de alta resistencia es necesario una interferencia muy elevada para conseguir vidas a fatiga adecuadas, lo que hace que el proceso para cilindros de pared gruesa de dichos materiales y de gran diámetro, sean muy complicados de procesar. Es decir, en cilindros de pared gruesa de gran calibre, la fuerza necesaria para forzar la pepita a través del mismo es elevadísima lo que hace que el proceso no sea industrialmente viable. La fuerza que hay que ejercer depende básicamente de los coeficientes de rozamiento y de la 
interferencia diametral entre mandrino y vasija aunque también tiene influencia la geometría de la pepita.

A modo de resumen son tres los problemas principales que hay que resolver para la realización del autozunchado mecánico en cilindros de pared gruesa. En primer lugar encontrar un material para el mandrino con la combinación requerida de resistencia mecánica, resistencia al desgaste y resistencia a la fractura así como con la geometría adecuada para que la fuerza de empuje sea la mínima posible. Para ello también es importe resolver el segundo problema que es encontrar un lubricante adecuado que baje ese coeficiente de rozamiento. Finalmente, para vasijas de gran calibre, las fuerzas para empujar el mandrino pueden ser muy elevadas por lo que el sistema de empuje debe ser capaz de resistir.

\subsection{PERSPECTIVA HISTORICA DEL AUTOZUNCHADO MECÁNICO}

A lo largo de los últimos 55 años, desde la primera definición del proceso, los trabajos en el que el autozunchado mecánico ha sido la base de investigación no han sido muy numerosos. El presente apartado se centra en recopilar aquellas investigaciones más importantes en el desarrollo de dicha técnica y que sirven para posicionar el marco y los motivos por los que se desarrolla la presente Tesis, es decir, la definición de un método para el diseño y cálculo de una vasija de pared gruesa de gran calibre y fabricada en aceros de alta resistencia, industrialmente viable, mediante la técnica del autozunchado mecánico capaz de resistir un elevado número de ciclos superando todas las dificultades que tienen lugar durante el proceso. Como se verá a lo largo de esta revisión, las investigaciones realizadas no han considerado la posibilidad de aplicación del autozunchado mecánico en vasijas de gran calibre. 


\subsubsection{Década de los 60}

En 1962, Davidson et al. [3] fueron los primeros investigadores que propusieron el autozunchado mecánico. Hasta ese momento la técnica habitual de autozunchado para los cañones utilizaba presión hidráulica directamente en el diámetro interior para producir la deformación plástica y de esa forma introducir las tensiones residuales. La razón principal por la que desarrollaron la técnica del autozunchado mecánico fue que, aunque la utilización de aceros de alta resistencia era beneficiosa pues permitía elevar las presiones de operación, el proceso de autozunchado hidráulico se complicaba bastante dado que la presión de plastificación es directamente proporcional al límite elástico del material. Mediante la técnica del autozunchado mecánico se podían autozunchar cilindros de alta resistencia necesitando presiones bastante inferiores.

Para ello, estos autores forzaron un mandrino sobredimensionado a través de un cilindro de diámetro interior $4 \frac{1}{4}$ pulgadas $(107,95 \mathrm{~mm})$. Utilizaron tres técnicas, (1) empuje mecánico para probetas de 5 pulgadas $(127 \mathrm{~mm}$ ) de longitud y (2) tiro mecánico y (3) empuje hidráulico para probetas de 40 pulgadas $(1016 \mathrm{~mm})$ de longitud aunque casi todo el estudio lo realizaron en las probetas tipo 1. Todas las probetas cilíndricas eran de acero 4340 tratadas a diferentes resistencias (límites elásticos desde 620MPa a $1240 \mathrm{MPa}$ ) y con ratios de pared desde 1,5 a 2,8. Los porcentajes de expansión del diámetro interior fueron desde 1 a 5. Con estas probetas realizaron un análisis ingenieril investigando factores como el porcentaje de expansión y recuperación elástica del diámetro interior, el ratio de presión requerida para empujar el mandrino respecto al límite elástico del material, los efectos de varios lubricantes (recubrimiento de cobre y bisulfuro de molibdeno) en las fuerzas de rozamiento involucradas y las tensiones residuales inducidas en las paredes del cilindro. Para la medición de las tensiones residuales utilizaron la técnica Sachs y las deformaciones las midieron mediante galgas extensiométricas. Es decir, realizaron una serie de ensayos y midieron los resultados obtenidos para poder entender la influencia de los factores que afectan al proceso.

Respecto al mandrino (Figura 2.13) el ángulo frontal y trasero se mantuvieron en $1,5^{\circ}$ y $3^{\circ}$ respectivamente con una longitud de sección paralela de $19,05 \mathrm{~mm}$ y fue pulido a aproximadamente $0,05-0,4 \mu \mathrm{m} \mathrm{Ra}$. 


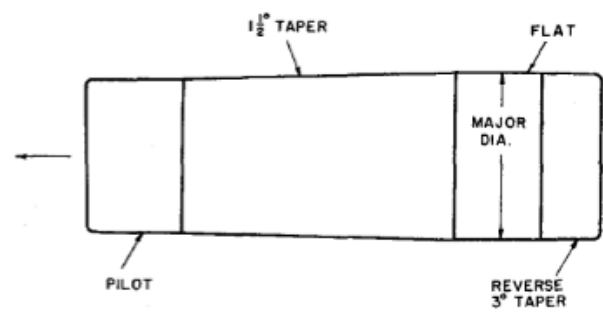

Figura 2.13. Mandrino utilizado por Davidson et al. [3].

Estos autores vieron que no había evidencia de cambio estructural o daño a pesar de la gran cantidad de deformación plástica en el diámetro interior y que además el acabado superficial dejado después del proceso en el diámetro interior era muy bueno. El mejor lubricante que hacía que la fuerza de empuje fuera más baja fue la combinación de los dos lubricantes utilizados, es decir bisulfuro de molibdeno en una suspensión de aceite y un recubrimiento de cobre.

Otra de las conclusiones fue que la relación de la presión hidráulica necesaria respecto al límite elástico no era lineal (Figura 2.14), como en el autozunchado hidráulico, lo que hacía que fuera una alternativa viable para el autozunchado de cilindros de elevada resistencia. Además para bajos límites elásticos la fuerza durante el proceso era casi constante y para altos aumentaba pero manteniéndose mucho más bajo que en el autozunchado hidráulico.

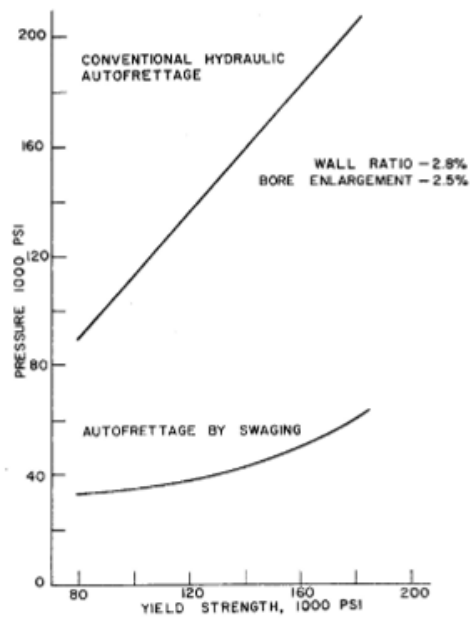

Figura 2.14. Presión hidráulica vs límite elástico. Davidson et al. [3].

También analizaron los resultados de la recuperación elástica tras el proceso. Observaron que la recuperación elástica variaba a lo largo de la longitud del cilindro, siendo mayor a mitad de 
longitud que en los finales, en los que era inferior pues se producía una "expulsión" longitudinal de material del diámetro interior cuando pasaba el mandrino. Definieron las ecuaciones de recuperación elástica la cual estaba formada por dos factores: (a) la compresión elástica del mandrino debido a la presión radial ejercida por las probetas y (b) la recuperación elástica de la probeta tras el paso del mandrino. Para ello utilizaron las ecuaciones de Lamé y, además de otras suposiciones, materiales elástico lineales para tanto el mandrino como para los cilindros, determinaron una buena correlación con los resultados experimentales.

En relación con las tensiones residuales introducidas (Figura 2.15) y medidas mediante el método Sachs en la mitad de longitud de la probeta, observaron una buena correlación con las curvas teóricas basadas en el autozunchado hidráulico de un cilindro monobloque con los extremos abiertos. Lógicamente el autozunchado hidráulico no introduce tensiones longitudinales residuales como si lo hace el autozunchado mecánico.

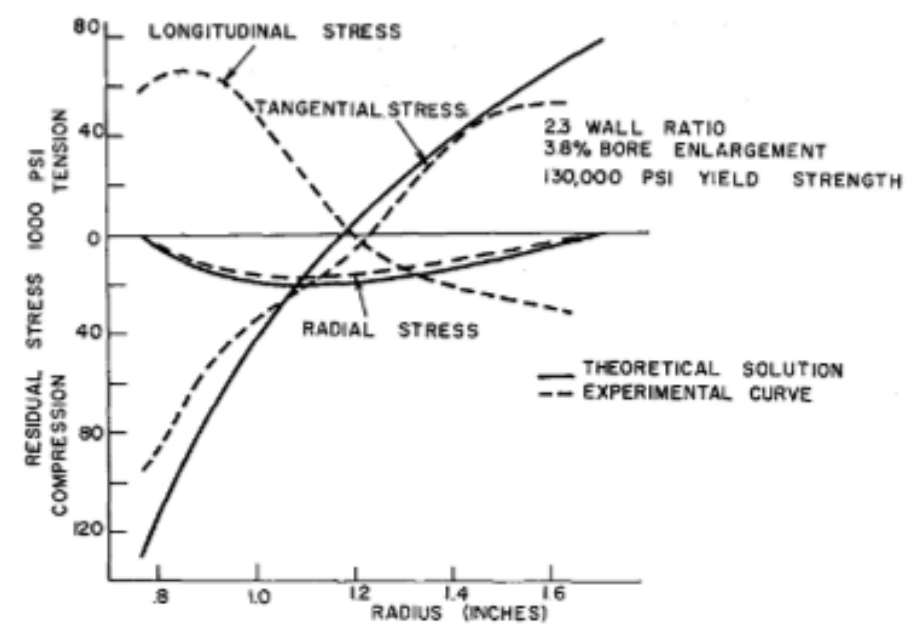

Figura 2.15. Tensiones residuales en las probetas de empuje mecánico. Davidson et al. [3].

Un año más tarde, en 1963, Davidson et al. [66] ampliaron su estudio anterior [3] determinando la distribución de tensiones residuales como una función de la sobredeformación (nivel de autozunchado) y el ratio diametral y como afectaba a las características de replastificación de cilindros autozunchados mecánicamente. Las fuerzas cortantes del mandrino producían al pasar tensiones longitudinales que debían tenerse en cuenta y que aumentaban con la sobredeformación, reduciendo como consecuencia las tensiones tangenciales. Cuanto mayor era el grado de plastificación en el autozunchado mecánico, mayores eran las tensiones longitudinales y por tanto inferiores eran las tensiones 
tangenciales, lo que hacía que no coincidiesen con las tensiones teóricas según fórmulas (las utilizadas para el autozunchado hidráulico). Realizaron ensayos de replastificación hidráulica en cilindros autozunchados para parametrizar la reducción de tensiones tangenciales con la sobredeformación. También compararon la sobredeformación óptima mínima con aquella para cilindros autozunchados hidráulicamente concluyendo que, para cilindros autozunchados mecánicamente, la presión de replastificación alcanzaba un máximo y después decrecía suavemente al aumentar el grado de plastificación durante el proceso. Este máximo ocurría a grados de plastificación menores que aquellos obtenidos en el autozunchado hidráulico. Dado los efectos negativos de las tensiones longitudinales (que eran positivas) producidas durante el swaging, era necesario estudiar formas de reducir la fuerza cortante durante el proceso mediante la geometría del mandrino y la utilización de mejores lubricantes.

Posteriormente, en 1967, Adachi y Baratta [67], realizaron una evaluación comparativa entre los procesos de autozunchado mecánico y autozunchado hidráulico. Realizaron comparaciones experimentales de vida obteniendo una mejora de 1,54 veces en el mecánico respecto al hidráulico para ratios (Diámetro exterior/Diámetro interior) de 2 con relativamente baja dispersión y una mejora no significativa en cilindros más gruesos con ratios de 3 , teniendo en este caso más dispersión.

Ya en 1969, Davidson y Kendall [68], realizaron un estudio muy completo recogiendo toda la teoría existente hasta la fecha en relación con el diseño de cilindros bajo muy alta presión. Recogieron los fundamentos de la teoría de cilindros de pared gruesa incluyendo la teoría elástica y elastoplástica, cilindros multicapa y autozunchados, incluyendo dentro de estos los autozunchados mecánicamente. También consideraron los factores a tener en cuenta para la selección adecuada de materiales para la fabricación de vasijas. En relación con el autozunchado mecánico recogieron los estudios realizados por ellos anteriormente dando una ecuación para la interferencia requerida entre el mandrino y el cilindro así como el diámetro final tras el autozunchado considerando las ecuaciones de Lamé. Seguían considerando el material elástico perfectamente plástico y considerando un cilindro de longitud infinita. Aunque remarcaron que no se había realizado una investigación en profundidad para los lubricantes, indicaron que los mejores resultados se habían obtenido con capas metálicas electrodepositadas como el plomo. 


\subsubsection{Década de los 70}

Durante los años 70 se realizaron algunos estudios de la geometría del mandrino. En los primeros años de la década, O'Hara [69] realizó un primer estudio de las tensiones elásticas en mandrinos cortos cilíndricos estudiando también la interacción en la intercara entre el empujador y el mandrino.

Ya en 1974, Goodheim y O’Hara [70] continuaron el estudio de la geometría de los mandrinos y ya utilizaron simulación por elementos finitos mediante el programa NASTRAN para hacer un análisis más preciso. Analizaron 12 diseños diferentes y comprobaron como las diferentes geometrías afectaban a la distribución tensional. Hasta entonces el diseño de los mandrinos era complicado ya que el análisis de cilindros cortos era difícil, era casi imposible obtener resultados experimentales precisos en los mandrinos y el material sinterizado de carburo de tungsteno, que se utilizaba para los mandrinos, era poco fiable. También mostraron que una simple bola de acero podía ser un mandrino fiable y barato.

\subsubsection{Década de los 80}

En 1982, Clark [71] realizó un informe para el Departamento de Defensa Australiano en el que describió las predicciones de distribución de tensiones residuales y de expansión para cañones forjados de gran calibre (en este caso $76 \mathrm{~mm}$ ) y evaluó dichas predicciones mediante comparación con las tensiones residuales obtenidas experimentalmente mediante la técnica de difracción de rayos X. Para ello consideró un material elástico, perfectamente plástico con un ratio $\sigma_{0.2} / \sigma_{\text {uts }}$ de 0,93 . Tambien consideró la condición de extremos abiertos (lo que implica tensión longitudinal cero) y como criterio de plastificación utilizó el criterio de Tresca con un límite elástico modificado. También tuvo en cuenta el efecto Bauschinger mediante la utilización de los datos reales obtenidos en una curva tensión (tracción-compresión) deformación en probetas sacadas del mismo material con los que se hicieron los ensayos. Los límites de medición permitieron deformaciones plásticas de $0,22 \%$ en tracción y $0,6 \%$ en compresión. Finalmente realizó la predicción de tensiones residuales tangenciales con y sin plastificación inversa (Figura 2.16) obteniendo muy buen resultado comparándolo con las tensiones residuales medidas mediante la técnica de Difracción de rayos X (Figura 2.17) excepto cuando la plastificación de todo el cilindro ocurría, en cuyo caso sucedía deformación no axisimétrica y las tensiones residuales variaban considerablemente alrededor de la pared. 


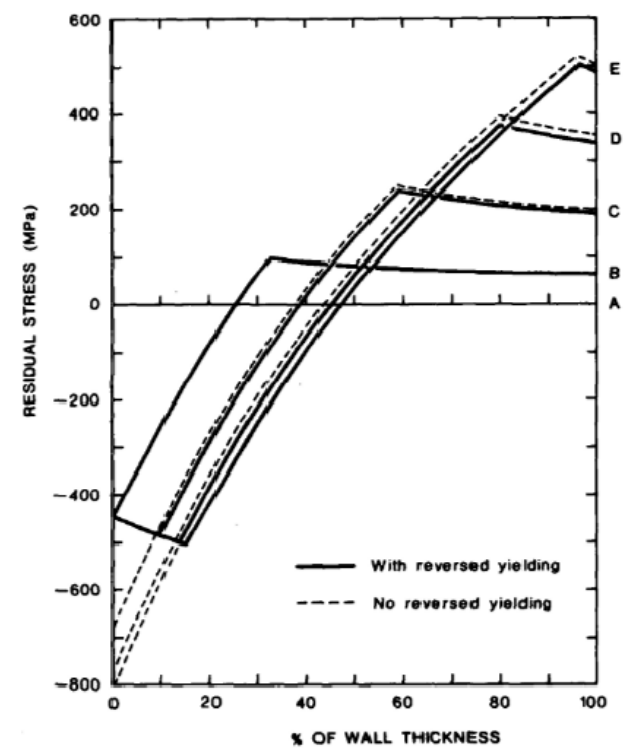

Figura 2.16. Tensiones residuales previstas [71].
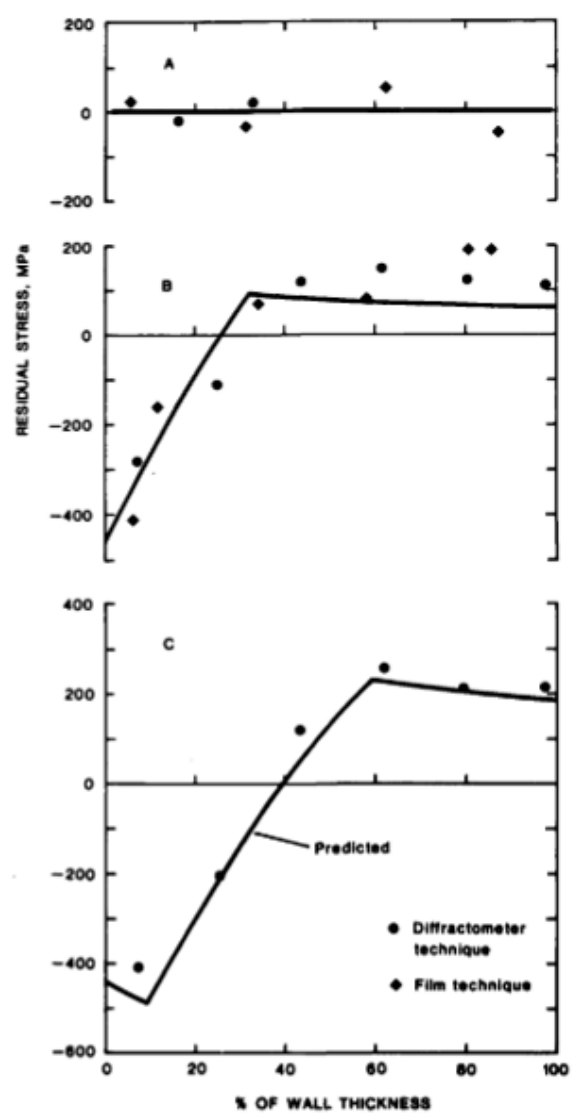

Figura 2.17. Tensiones residuales previstas vs medidas [71]. 
Como conclusiones más interesantes destacó que las tensiones residuales compresivas en la superficie interior eran independientes del nivel de autozunchado una vez que ocurría la plastificación inversa. Al final, el efecto del incrememento de interferencia durante el autozunchado mecánico lo que conseguía era aumentar la zona de material con la tensión de compresión máxima, además el incremento del nivel de autozunchado más allá que el requerido para extender la zona plastificada a aproximadamente la mitad del espesor de pared producía un beneficio muy bajo en relación con el nivel de tensiones residuales pero, sin embargo, aumentaba demasiado las tensiones de tracción en la superficie exterior pudiéndose producir el fallo del cilindro en el exterior.

Un año más tarde, en 1983, Till y Rammerstofer [72] presentaron un método para calcular la historia temporal de tensión y deformación así como el estado de tensiones residuales de un cilindro de pared gruesa autozunchado mecánicamente. Para ello realizaron un análisis no lineal por elementos finitos ya que la zona de contacto entre mandrino y cilindro no era conocida ya que cambiaba en situación y tamaño al avanzar el mandrino. El material fue considerado elastoplástico. Tras el autozunchado se simuló el mecanizado interior del cilindro. Con el objetivo de comparar realizaron también un modelo más simple de autozunchado hidráulico. Tal y como también concluyeron anteriormente otros investigadores [66], en el autozunchado mecánico se producían tensiones longitudinales que llevaban a regiones plásticas menores y tensiones residuales tangenciales de compresión también menores. Además el modelo simplicado de autozunchado hidráulico, debido a las tensiones longitudinales y su influencia en las tangenciales del autozunchado mecánico sólo daba estimaciones vastas para este segundo proceso.

Ya en 1988, Chen [73] propuso una solución analítica cerrada basada en suposiciones simplificadas como material elastoplástico y el criterio de plastificación de Tresca.

\subsubsection{Década de los 90}

En los primeros años de la década de los 90, O’Hara [74] realizó un análisis del proceso de autozunchado mecánico para el ejercito de Estados Unidos mediante elementos finitos en una pequeña sección de un cañon de calibre $105 \mathrm{~mm}$. Para realizar dicho estudio utilizó el software de elementos finitos ABAQUS. El modelo que desarrolló consistió en un cilindro de calibre $105 \mathrm{~mm}$ con una longitud 4 veces el diámetro y en un material con un límite elástico de 1195 
MPa el cual endurecía por deformación hasta 1332 MPa a una deformación plástica de 0,0368. El coeficiente de fricción $\mu$ considerado entre el mandrino y el cilindro fue de $0,015 \mathrm{y}$ entre el empujador y el mandrino fue de 0,05 y tuvo en cuenta los resultados obtenidos previamente en relación con la interacción del empujador y el mandrino en estudios anteriores [69], [70]. El mandrino considerado estaba realizado en carburo de tungsteno con un ángulo de entrada de $1,5^{\circ}$, un ángulo de salida de $3^{\circ}$ y una zona recta entre medias interfiriendo un $2,5 \%$ con el cilindro. Se compararon los resultados dados por la solución teórica convencional para una deformación del $83 \%$, en el que las tensiones longitudinales son nulas (tensión plana) con lo obtenido mediante la simulación FEM donde se podía ver un rápido aumento de las tensiones delante del mandrino y el desarrollo de tensiones residuales por detrás de la superficie de contacto. Se podían ver diferencias entre ambas soluciones pues el método convencional no tenía en cuenta las tensiones longitudinales (Figura 2.18). La diferencia más llamativa entre la solución FEM y la convencional era, según el autor, la gran presión de intercara en la pequeña zona de contacto cuyo efecto ya fue predicho por él mismo en un trabajo anterior [69]. Las tensiones obtenidas no fueron comparadas experimentalmente.
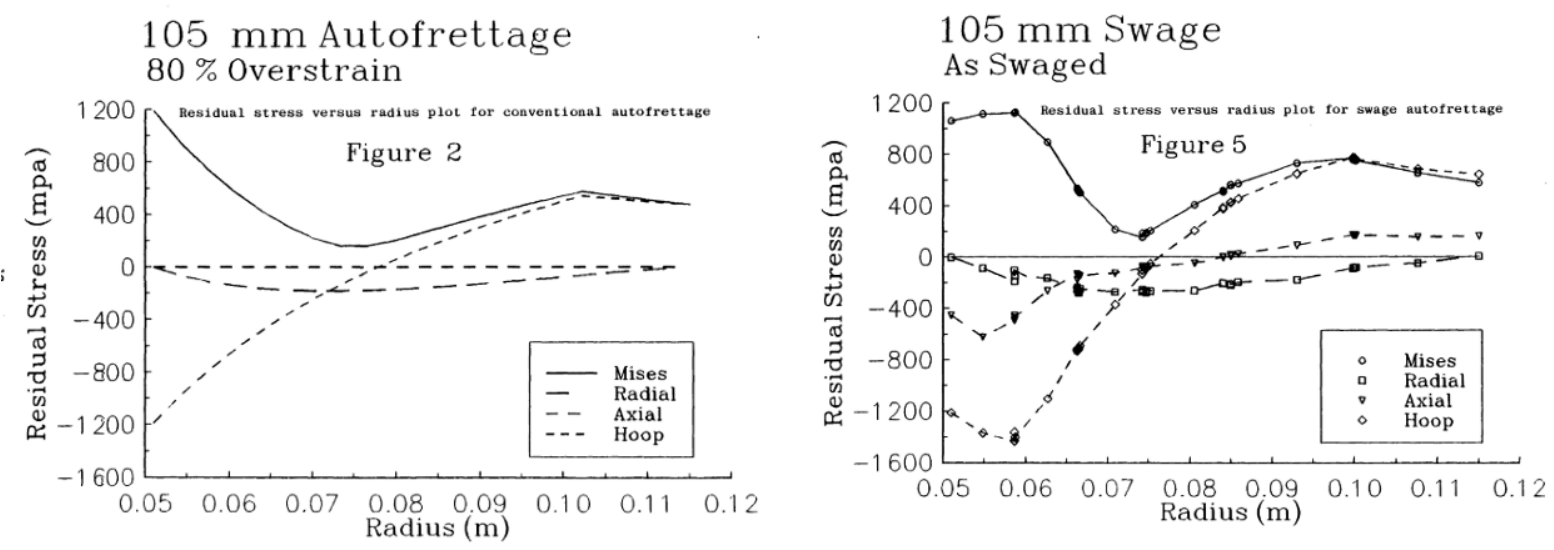

Figura 2.18. Tensiones residuales previstas modelo teórico y simulación [74].

Ese mismo año, Lee et al. [75] realizaron un informe, en el que también participaba O'Hara, para el ejército de Estados Unidos en el que realizaron investigaciones teóricas y experimentales de las tensiones residuales generadas en un autozunchado mecánico en un cilindro asimétrico con pequeñas variaciones de espesor de pared. Para comprobar la precisión del método de cálculo utilizaron en los experimentos realizados medición mediante 
Difracción por Rayos X. El modelo FEM realizado para calcular las tensiones residuales se basaba en el anteriormente desarrollado [74] y los resultados obtenidos coincidían en general con los resultados experimentales excepto cerca del diámetro interior. Para obtener una precisión mayor realizaron un método alternativo FEM que mostró tensiones tangenciales compresivas reducidas cerca del diámetro interior, similares a las obtenidas asumiendo el efecto Bauschinger.

Un año más tarde, en 1993 Lee [76] amplió su estudio y ya consideró el efecto Bauschinger, el factor Bauschinger considerado como el límite elástico en compresión entre el límite elástico en tracción. El material utilizado para este estudio fue el A723, acero ampliamente utilizado en los cañones y determinó que el factor Bauschinger era de 0,5 para este material.

\subsubsection{Años 2000}

En 2003, Malik et al. [77] realizaron una revisión del proceso de autozunchado mecánico centrándose en la predicción del campo tensional y un campo de temperatura equivalente para simular un autozunchado parcial, el efecto de las propiedades de material en el campo tensional, la triaxialidad de tensiones en la región crítica de fallo, el efecto Bauschinger y su influencia en la vida a fatiga así como los métodos para la medición de tensiones residuales. También analizaron el efecto del mecanizado interior o exterior en el cilindro tras el autozunchado.

Ese mismo año, Iremonger et al. [78] realizaron un análisis numérico del autozunchado mecánico. También utilizaron dicho análisis para investigar el efecto de la geometría del mandrino en la fuerza axial requerida para desplazarlo así como la deformación y tensiones en el cilindro. A la vez, investigaron un proceso de autozunchado mecánico en 2 pasadas, la primera con menos interferencia para reducir las tensiones de empuje y la segunda con la misma interferencia que la que se utilizaría si se hiciera en una sóla pasada.

El procedimiento numérico lo realizaron utilizando PR2D, el cual es un código en dos dimensiones, Lagrangiano, basado en diferencias finitas y explícito. El cilindro considerado tenía un diámetro de entrada de $111 \mathrm{~mm}$ el cual se reducía rápidamente a 107,95mm. En cuanto al mandrino considerado el ángulo frontal era de $3^{\circ}$, una zona recta de $9,9 \mathrm{~mm}$ y con un diámetro de $110,82 \mathrm{~mm}$ y un ángulo de salida de $1,5^{\circ}$. Para los materiales considerados tanto 
el cilindro como el mandrino se eligieron de acero de alta resistencia con un comportamiento elástico, perfectamente plástico en tracción y posterior compresión basada en el criterio de plastificación de Von Mises, considerando sólo el efecto básico del límite elástico a través del BEF. Para evitar dificultades numéricas el mandrino fue modelizado como un material elastoplástico con un limite elástico tres veces superior al del cilindro. En cuanto a la influencia de la geometría del mandrino en la fuerza axial requerida concluyeron que el incremento del ángulo frontal aumentaba la fuerza, el incremento del ángulo de salida la reducía, ya que se reducía más rápidamente el área de contacto entre el cilindro y el mandrino y el incremento de la longitud de la zona recta aumentaba muy poco la fuerza, es decir, tenía poca influencia. Cada uno de estos parámetros los estudiaron por separado y su conclusión principal fue que la modificación del ángulo de salida era la que más influía en la fuerza axial de empuje. En cuanto al análisis del autozunchado mecánico en dos pasadas, con el objetivo de poder reducir la fuerza necesaria para realizar el autozunchado mecánico, pues se realizaría un primer autozunchado con un mandrino de menor diámetro para posteriormente utilizar el que se utilizaría si se hiciera en una sóla pasada concluyeron que un autozunchado mecánico en dos pasadas podía reducir la fuerza de empuje hasta en un $22 \%$ comparado con el realizado en una sóla pasada. El incremento en el diámetro interior era similar en los dos casos y las tensiones residuales generadas eran muy similares mientras que mayores deformaciones plásticas existían cerca del diámetro interior en el caso de dos pasadas.

En agosto de 2003, Parker et al. [79] publicaron un trabajo en el que compararon el autozunchado hidráulico y mecánico y las implicaciones del efecto Bauschinger. El objetivo del trabajo era presentar un procedimiento para modificar los resultados de los trabajos que se habían realizado hasta entonces considerando un material elástico, perfectamente plástico, como el trabajo realizado por O’Hara [74]. Para ello realizaron tres modelos, la solución para el autozunchado mecánico sin efecto Bauschinger utilizando ABAQUS siguiendo esencialmente el procedimiento de O'Hara citado anteriormente, un modelo analítico simple de un cilindro autozunchado hidráulicamente con efecto Bauschinger y el modelo numérico incorporando el efecto Bauschinger. Los resultados mostraban una reducción importante de las tensiones tangenciales de compresión cuando se tenía en cuenta el efecto Baushinger y que las tensiones obtenidas con el autozunchado mecánico eran mejores que las obtenidas con el hidráulico para el mismo porcentaje de deformación (Figura 2.19). 


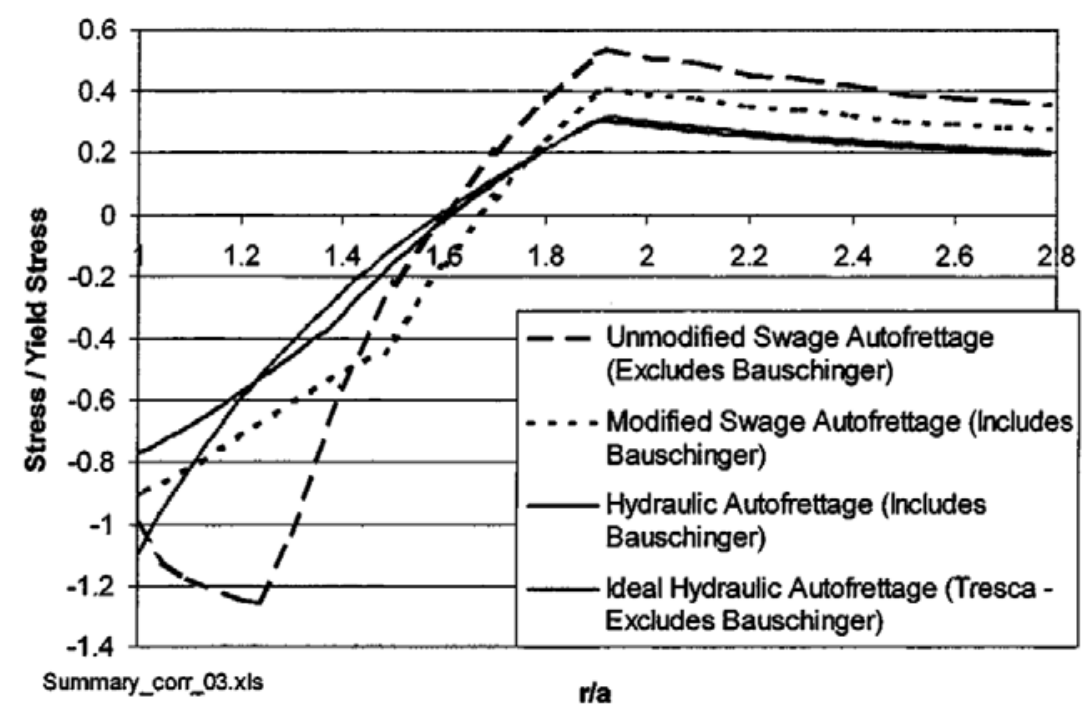

Figura 2.19. Tensiones residuales en el cilindro autozunchado [79].

También realizaron el cálculo a fatiga determinando que esta era significativamente superior en el caso del autozunchado mecánico con respecto al hidráulico. Para finalizar concluyeron que la presión para replastificar tanto un cilindro autozunchado mecánicamente como el autozunchado hidráulicamente era la misma en ambos casos, sin embargo el nivel de presión para producir deformación permanente en un cilindro autozunchado mecánicamente era inferior.

Al mismo tiempo Parker y Kendall [49] realizaron un estudio muy interesante sobre las tensiones residuales introducidas y la vida obtenida al combinar dos técnicas de introducción de tensiones residuales en cilindros de pared gruesa, zunchado térmico y autozunchado hidráulico, en este caso realizando el autozunchado tras el zunchado térmico. Este era el primer intento serio de combinar dos tecnologías que se habían utilizado por separado pero que podían ser complementarias aunque previamente ya se había estudiado, teniendo en cuenta el efecto Bauschinger, la incorporación del zunchado térmico tras el autozunchado. Concluyeron que la realización del autozunchado tras un zunchado térmico era beneficiosa en la reducción de aproximadamente un $50 \%$ de la deformación plástica cerca del diámetro interior comparada con un cilindro monobloque autozunchado reduciendo de esta forma el impacto del efecto Bauschinger y como consecuencia inmediata la reducción de las tensiones tangenciales compresivas cerca del diámetro interior (Figura 2.20). Esto finalmente se traducía en una mejora de la vida a fatiga de hasta un $41 \%$. 

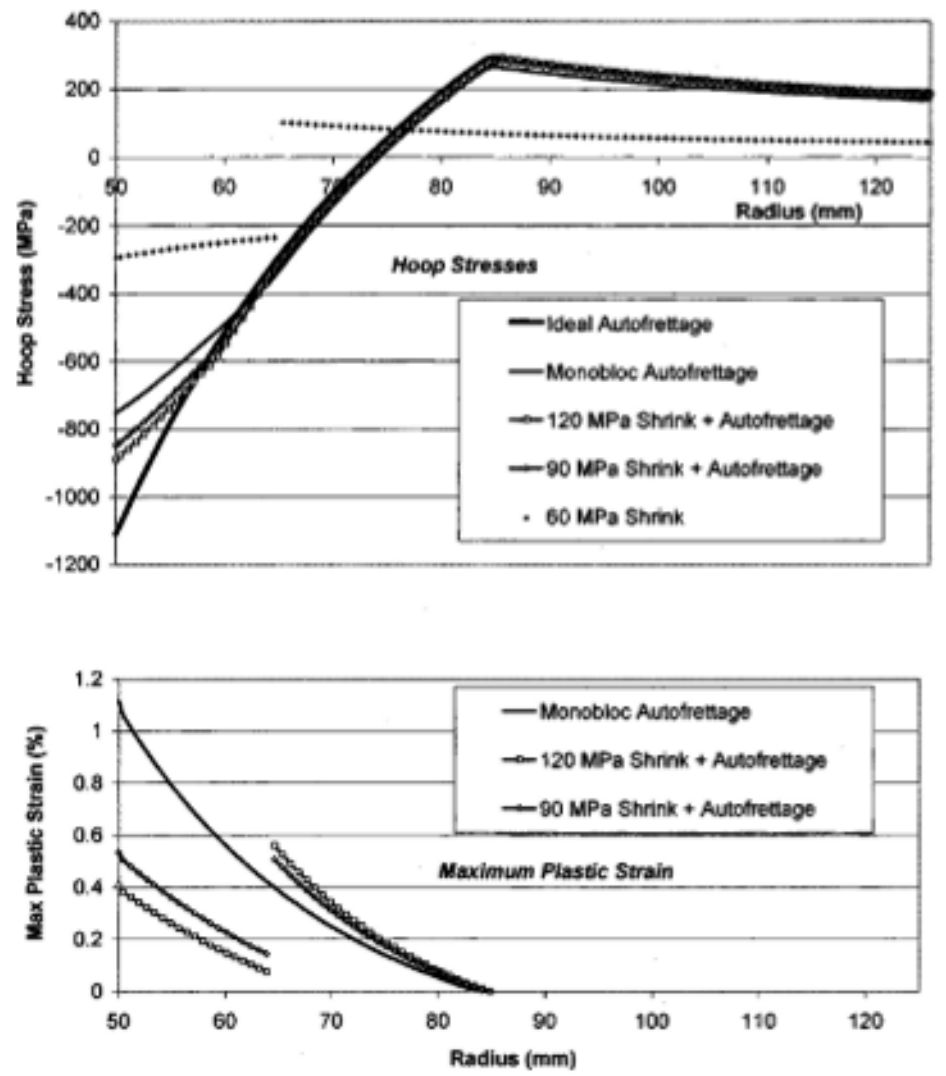

Figura 2.20. Tensiones tangenciales residuales (arriba) y deformación plástica máxima (abajo) [49].

También en 2003, Perry et al. [80] desarrollaron un nuevo método para la determinación de las tensiones residuales en un cilindro de pared gruesa. Las metodologías utilizadas hasta entonces estaban basadas en, como forma más simple, la consideración del criterio de plastificación de Tresca y la consideración del material elástico, perfectamente plástico sin efecto Bauschinger. Posteriormente se comenzó a utilizar el criterio de plastificación de Tresca o de Von Mises junto con un parámetro para considerar el efecto Bauschinger. Los presentes autores asumieron el criterio de plastificación de Von Mises, endurecimiento por deformación isótropa en conjunción con la teoría de Prandtl-Reuss, descarga de presión teniendo en cuenta el efecto Bauschinger y condiciones de tensión plana. También consideraron que las tensiones longitudinales en el autozunchado mecánico debidas a las fuerzas de fricción con el mandrino no afectaban a los resultados del cálculo en dos dimensiones de un autozunchado hidráulico. Para la medición de tensiones residuales 
utilizaron el método Sachs obteniendo buena correlación de lo calculado con los resultados experimentales.

En esta década los estudios del autozunchado mecánico se incrementaron exponencialmente, las herramienta de simulación por elementos finitos mejoraron sustancialmente y fueron más asequibles por lo que se iniciaron muchas investigaciones en este campo. Las ventajas del autozunchado mecánico eran cada vez más evidentes desde el punto de vista ciéntifico además de desde el punto de vista experimental, como ya se había comprobado años antes. Fruto del interés por esta tecnología incluso se solicitó alguna patente como la de Hermanson et al. [81] en 2004 en la que patentaron una metodología para la fabricación de un cañon monobloque calculando un perfil óptimo de tensiones residuales para posteriormente realizar un autozunchado mecánico mediante la introducción de mandrinos personalizados teniendo en cuenta la distribución térmica en el cañón debido a la cadencia de fuego.

A mediados de la década, ya en 2005, Malik et al. [82] desarrollaron un modelo FEM para el análisis del autozunchado mecánico. El modelo incluía el efecto Bauschinger y realizaron estudios paramétricos para optimizar el proceso.

Ya en 2006, Jahed et al. [50] continuaron el trabajo iniciado por Parker et al. [79] considerando vasijas multicapas, es decir, con más de dos capas. En su estudio combinaron zunchado térmico y autozunchado y determinaron con una secuencia de pasos apropiada los valores óptimos de espesor de cada capa, presiones de zunchado y porcentajes de autozunchado para obtener la máxima vida a fatiga en una vasija de tres capas. A la hora de obtener las tensiones residuales tuvieron en cuenta un modelo de material basado en el comportamiento real del material, obtenido mediante ensayos. De esta forma tenían en cuenta el comportamiento no lineal del material desde el inicio de la descarga, el cambio del módulo elástico en la descarga y la presencia del efecto de endurecimiento después de la plastificación inversa. Todos esos efectos no eran tenidos en cuenta con los modelos de material ideales. En este caso siguieron estudiando varias configuraciones en las que alternaban las técnicas de introducción de tensiones residuales. En el Caso 1 realizaban autozunchado en cada capa separadamente y luego zunchaban térmicamente, en el Caso 2 zunchaban térmicamente las dos primeras capas, seguidas de un autozunchado y posteriormente zunchaban la tercera capa tras autozuncharla y en el Caso 3 zunchaban todas las capas y posteriormente realizaban el autozunchado de todo el conjunto. La observación más importante que hicieron fue que, en el 
diseño óptimo para cada caso, la vida a fatiga de las tres capas era la misma por lo que las tres capas alcanzaban el final de sus vidas de forma conjunta, no dejando exceso de vida desperdiciado en ninguna de ellas. Tambien vieron que el primer caso era el que tenía una vida a fatiga superior aunque económicamente no era la solución más óptima.

Ese mismo año, Bihamta et al. [83] desarrollaron un estudio numérico bastante completo del autozunchado mecánico de cilindros de pared gruesa. Para ello realizaron tres modelos: un modelo axisimético, un modelo simétrico tridimensional y un último modelo completamente tridimensional teniendo en cuenta una ranura helicoidal en el mandrino y el giro del mismo durante el proceso de autozunchado. Para realizar la simulación utilizaron ABAQUS y realizaron ensayos para obtener las propiedades mecánicas reales del material así como los coeficientes de rozamiento de diferentes lubricantes. Posteriormente validaron el modelo axisimétrico mediante comparación con resultados experimentales en cilindros de 7,85mm de diámetro interior y $25 \mathrm{~mm}$ de diámetro exterior en los que midieron la carga axial para diferentes ángulos de entrada del mandrino y la variación dimensional del diámetro exterior así como la recuperación elástica. En cuanto a los modelos tridimensionales midieron la fuerza axial para empujar el mandrino para un ángulo de entrada de $5^{\circ}$ a lo largo del tubo y lo compararon con lo obtenido en el modelo FEM. Fueron varios los parámetros que analizaron para el estudio del autozunchado mecánico una vez validados los modelos entre los que estaban las tensiones residuales, el efecto del ángulo de entrada del mandrino en la fuerza axial de empuje, el efecto del espesor del cilindro en la carga axial de empuje, el efecto de la longitud de la zona calibrada recta del mandrino en la carga axial de empuje y en el diámetro final del cilindro así como el efecto del coeficiente de fricción $\mu$ en la carga axial. Como conclusiones más interesantes advirtieron que un lubricante basado en una capa de fosfato, lubricante RATAK y un lubricante jabonoso daba el mejor resultado en cuanto a mínimo coeficiente de rozamiento. También observaron que las tensiones longitudinales eran de tracción en la superficie interior y de compresión en la externa. En cuanto a la forma del mandrino, cuanto mayor era el ángulo de entrada la carga axial de empuje aumentaba, como ya habían concluido Iremonger et al. [78] y generaban menores tensiones radiales lo que podía aumentar la vida del mandrino. En cuanto a la longitud calibrada del mandrino, cuanto más larga era, aumentaba la carga axial de empuje hasta una determinada longitud en la que se estabilizaba (Figura 2.21). 


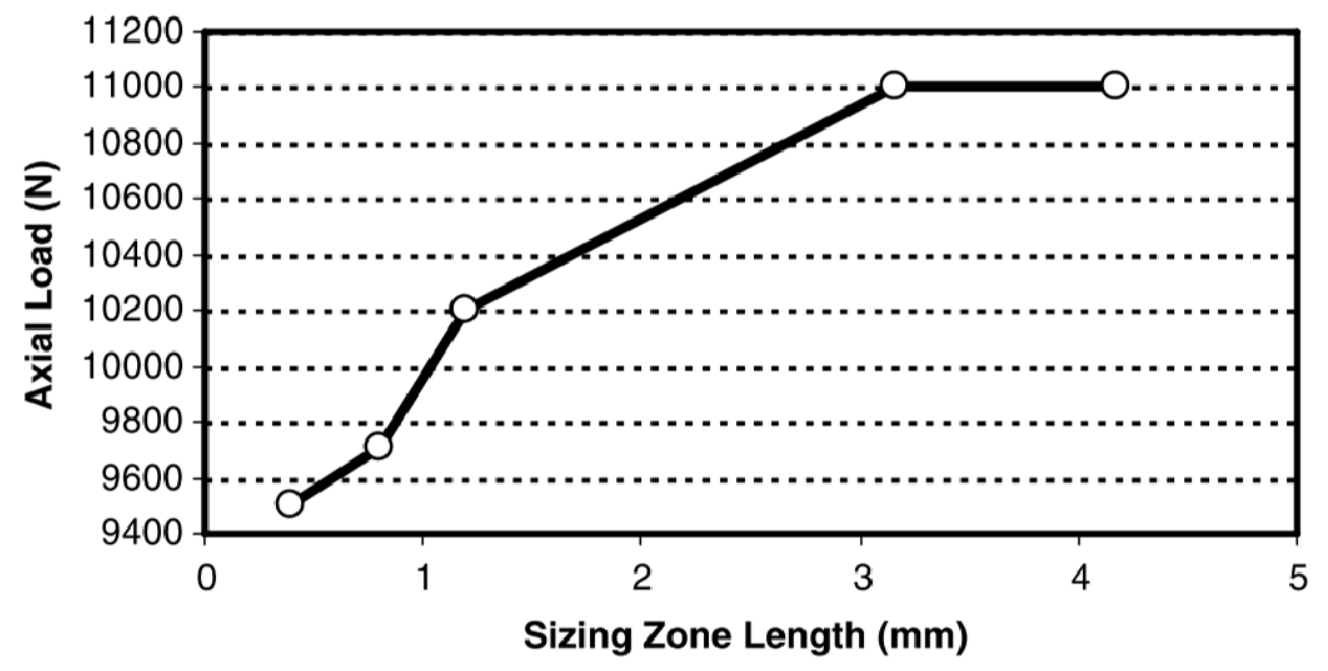

Figura 2.21. Efecto de la longitud calibrada recta del mandrino en la carga axial [83].

Un resultado muy interesante fue que incrementar el espesor del cilindro aumentaba la carga axial de empuje requerida hasta un cierto nivel más allá del cual si se incrementaba el espesor no aumentaba la carga (Figura 2.22). También a más espesor se obtenía más recuperación elástica en la superficie interior. Además la carga axial se reducía cuando el mandrino tenía ranuras longitudinales o helicoidales.

Para resumir, concluyeron que la geometría de la oliva y el lubricante tenían el efecto mayor en la carga axial de empuje.

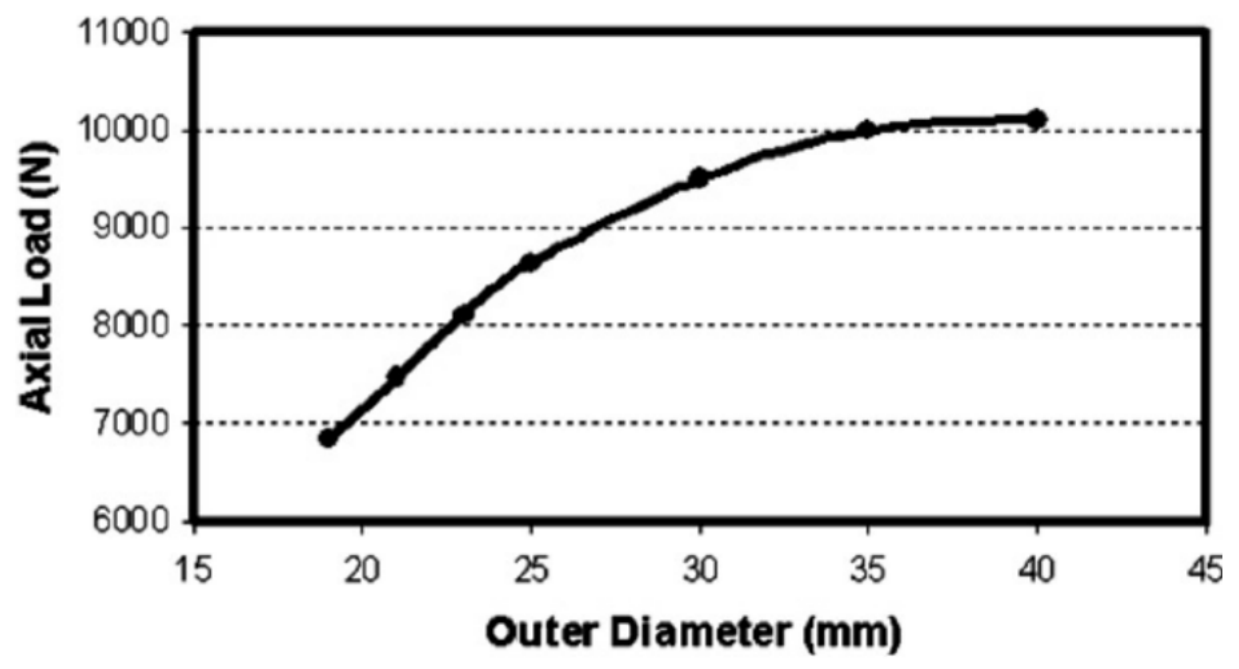

Figura 2.22. Carga axial vs. Diámetro exterior [83]. 
Tambien en 2006, Malik et al. [84] realizaron un estudio en el que realizaban autozunchado mecánico para cilindros de gran calibre $(125 \mathrm{~mm})$ que normalmente por su dimensión se autozunchaban hidráulicamente. Para realizarlo consideraron un autozunchado mecánico en 2 etapas hasta conseguir el diámetro final requerido $(118 \mathrm{~mm}$ en la primera etapa y $125 \mathrm{~mm}$ tras el mecánicado en la segunda etapa). Desarrollaron un modelo FEM para el análisis de dicha solución y realizaron 5 probetas experimentales. Como conclusión más importante destacaron que los resultados para el autozunchado mecánico en dos etapas daban los mismos resultados que los obtenidos por la técnica simple, tal y como también concluyeron Iremonger et al. [78].

Ya en 2008, Gibson [85] publicó su tesis doctoral basada en la determinación de la distribución de tensiones residuales en cilindros de pared gruesa autozunchados. Dentro de su tesis dedicó buena parte al estudio del autozunchado mecánico para lo que desarrolló un modelo FEM partiendo de modelos más simples en el que conseguía el comportamiento no lineal a través de la manipulación directa de los estados tensionales y de deformación plástica del modelo FEM. Para validar el modelo lo comparó con el modelo desarrollado por O’Hara [74] considerando el mandrino que O'Hara tuvo en cuenta (Figura 2.23) y una vez demostrada su validez, le sirvió de base para investigar en profundidad el efecto de la geometría de los mandrinos y los parámetros de contacto, como el rozamiento, en la generación de tensiones residuales.

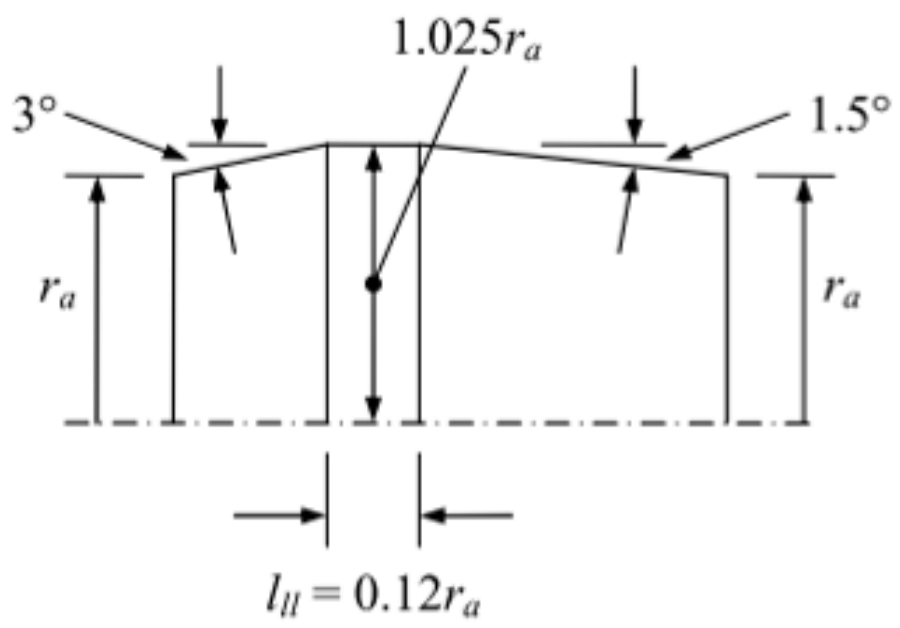

Figura 2.23. Dimensiones del mandrino empleado por Gibson [85]. 
En primer lugar realizó el análisis de la influencia de la longitud de los tubos en las tensiones generadas en la mitad de la longitud para que estas fueran representativas del proceso, viendo que con una longitud de 15 veces $r_{a}$, siendo $r_{a}$ el radio delantero del mandrino (Figura 2.23), los resultados eran representativos de las propiedades de mitad de longitud.

En cuanto a la influencia de la longitud calibrada del mandrino realizó el estudio de varias longitudes, referenciadas respecto a la unidad considerada como 0,12ra (Figura 2.23). Las conclusiones fueron que la presión de contacto aumentaba al aumentar la longitud, las tensiones tangenciales residuales cerca del diámetro interior indicaban mayores tensiones de cortadura para valores más cortos de la longitud y las tensiones longitudinales eran más negativas cerca del diámetro interior para valores más cortos de la longitud.

En cuanto a la influencia del coeficiente de rozamiento, observó que la profundidad de la plastificación aumentaba ligeramente cuando el coeficiente de fricción $\mu$ aumentaba. Las tensiones radiales y longitudinales apenas variaban con el coeficiente de rozamiento, más en particular, la presión de contacto (tensión radial en $r_{a}$ ) permanecía relativamente estable con la variación del coeficiente de rozamiento y las tensiones longitudinales eran menos negativas cuando el coeficiente de fricción $\mu$ aumentaba. La mayor influencia se producía en la componente de cortadura pero también destacó que cuando las tensiones longitudinales aumentaban, también lo hacían las tensiones tangenciales para unas tensiones radiales estables, por lo que unas tensiones longitudinales más negativas mejoran el nivel de tensiones tangenciales de compresión.

En cuanto a la influencia de los ángulos de entrada y salida, la presión de contacto aumentaba cuando los ángulos aumentaban. Además las tensiones tangenciales eran más negativas cuando los ángulos aumentaban. Resumiendo, los ángulos tenían una gran influencia en las tensiones desarrolladas, destacando que el ángulo trasero influía más directamente en las tensiones residuales desarrolladas ya que colabora directamente en la generación de tensiones longitudinales de compresión cerca del diámetro interior.

También en 2008 Perry et al. [86] desarrollaron un modelo numérico 3D para evaluar las tensiones residuales debido a un autozunchado mecánico. 
Ese mismo año Parker et al. [87] patentaron un método de fabricación de cilindros de pared gruesa que incluía un primer paso de realización de un autozunchado mecánico, un segundo paso de aplicación de calor y un tercer paso de realización de un autozunchado hidráulico, pudiéndose repetir el segundo y tercer paso todas las veces necesarias. Finalmente se realizaría una aplicación de calor. El objetivo de este proceso era aumentar las tensiones residuales introducidas mediante la reducción del impacto del efecto Bauschinger.

En 2009 Malik et al. [88] completaron el trabajo empezado en 2006 realizando un estudio comparativo paramétrico de un autozunchado mecánico en una y dos etapas utilizando técnicas numéricas y analíticas y comparando los resultados con aquellos obtenidos mediante simulación FEM. Para ello realizaron autozunchado mecánico en cinco tubos metálicos.

Ya al final de la década, con la patente ya solicitada, Parker et al. [89] publicaron en 2010 el artículo que justificaba la patente presentada previamente en 2008. El procedimiento producía mejoras significativas en la presión de replastificación inicial y en la máxima presión, también se producía un incremento en la vida a fatiga de los componentes.

\subsubsection{Ultima década}

Recién iniciada la década, Chang et al. [90] analizaron la relación entre el radio de interferencia del mandrino y el cilindro con el radio plástico para calcular el grado de autozunchado. En el proceso de carga, la tensión radial en la sección cilíndrica del mandrino y en el cilindro es la misma. Utilizando esta condición de contorno realizaron un análisis elástico para el mandrino y plástico para el cilindro de pared gruesa obteniendo unas fórmulas para calcular el radio plástico. Conociendo la interferencia, el radio plástico podía ser calculado directamente y por lo tanto la interferencia podía ser estimada utilizando dicho radio plástico. Para verificar los resultados utilizaron diez probetas con diferentes interferencias.

Ese mismo año, los mismos autores [91] ampliaron el estudio para derivar una nueva fórmula para calcular el radio plástico y realizaron varias simulaciones con diferentes coeficientes de fricción viendo que $\mu$ no tenía influencia en la tensión residual y el radio plástico, lo cual no coincidía del todo con lo estudiado por Gibson [85], que determinó una ligera influencia. 
Ya en 2012, Chang et al. [92] volvieron a ampliar el estudio calculando también las tensiones y deformaciones del cilindro de pared gruesa y el mandrino durante la carga.

También en 2012, Perl et al. [93] aplicaron el modelo numérico 3D que habían desarrollado en 2008 [86] y que permitía una simulación realista tanto del autozunchado hidráulico como del mecánico. Lo aplicaron a dos cañones típicos autozunchados mecánicamente de $120 \mathrm{~mm}$ de calibre y posteriormente compararon los resultados con datos obtenidos en tests de fuego. Vieron que la nueva simulación reproducía excelentemente el incremento permanente medido de diámetro y la presión máxima segura del cañon. Posteriormente uno de los cañones lo compararon con uno similar pero autozunchado hidráulicamente. Concluyeron que la presión máxima segura y la presión de explosión del cañon autozunchado mecánicamente era significativamente superior que en el autozunchado hidráulicamente y que las deformaciones plásticas del primero eran inferiores que las del segundo.

Alinezhad et al. [94], también en 2012, realizaron un estudio del efecto de la geometría del mandrino en el proceso de autozunchado mecánico. Para ello realizaron una simulación del proceso utilizando ABAQUS y para validarlo realizaron varios experimentos. En cuanto a la simulación, el mandrino fue considerado como una pieza rígida discreta y el cilindro considerado fue uno monobloque, con diámeto interior $7,86 \mathrm{~mm}$, diámetro exterior $25 \mathrm{~mm}$, de material CK45 con propiedades elastoplásticas obtenidas de un ensayo de tracción por lo que no fue considerado el efecto Bauschinger. Como resultados obtuvieron que, para la geometría de mandrino que consideraron (ángulo de entrada, zona recta calibradas pero sin ángulo de salida), las tensiones longitudinales eran positivas, el nivel de tensión radial en el diámetro interior y exterior era muy bajo y para obtener los mejores resultados, la zona recta calibrada del mandrino debía ser lo más corta posible ya que las tensiones tangenciales residuales eran más compresivas (Figura 2.24). 


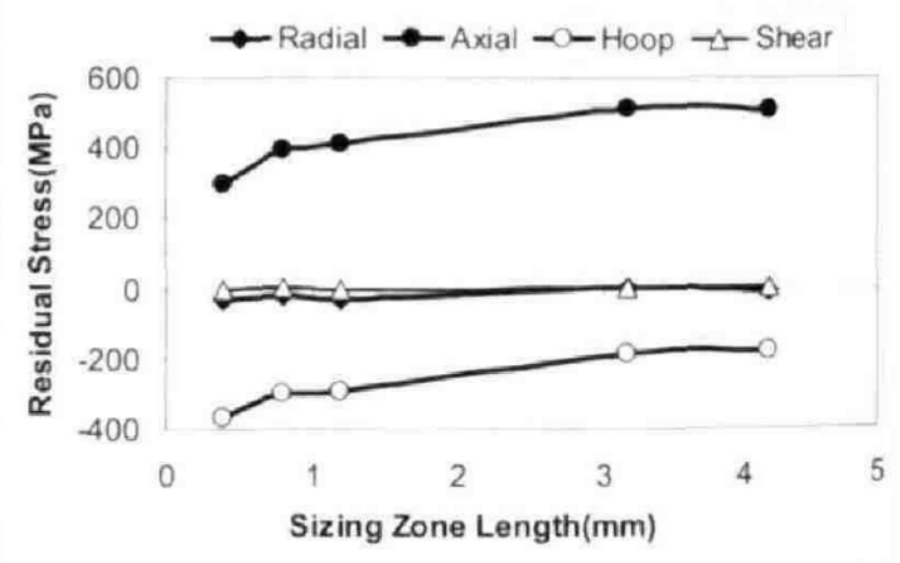

Figura 2.24. Efecto de la longitud de la zona recta calibrada en la distribución tensional en el diámetro interior [94].

Ese mismo año, Gibson et al. [95] utilizaron el modelo FEA de autozunchado mecánico que Gibson creó en 2008 [85] para analizar diferentes parámetros que influían en la fuerza de empuje del mandrino. Para validar la precisión de la fuerza de empuje calculado mediante FEM compararon los resultados con aquellos obtenidos en 2003 por Iremonger et al. [78] mediante otra simulación y que fueron validados empíricamente, es decir, utilizaron los mismos datos de partida (geometría, condiciones de contorno, modelo de material...) para reproducir el trabajo realizado en 2003 validando de esa forma el modelo FEM desarrollado. El modelo de mandrino considerado consistía en un ángulo de entrada, una zona calibrada y un ángulo de salida (Figura 2.25).

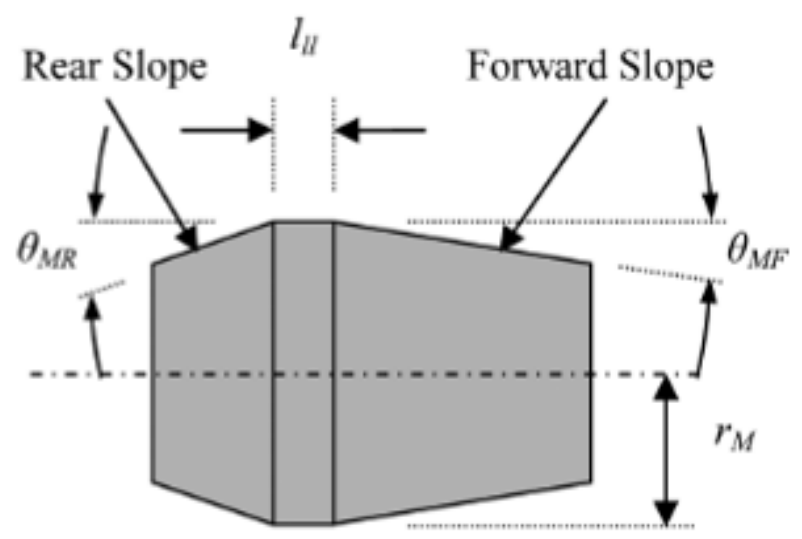

Figura 2.25. Esquema del mandrino empleado por Gibson [95]. 
El mandrino original tenía un ángulo de entrada de $3^{\circ}$, uno de salida de $1,5^{\circ}$ y realizaron una variación geométrica incrementando el ángulo de entrada a $6^{\circ}$, el de salida a $4,5^{\circ}$ y la zona calibrada reduciéndola a $6,6 \mathrm{~mm}$. Se comprobó que únicamente el ángulo de entrada tenía una gran influencia en la fuerza de empuje incrementándose esta cuanto mayor era el ángulo (Figura 2.26).

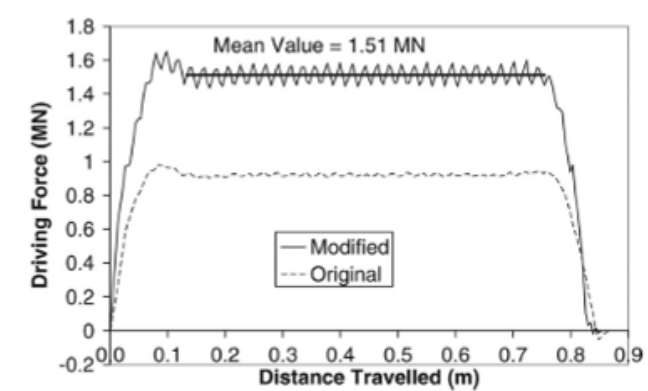

a)

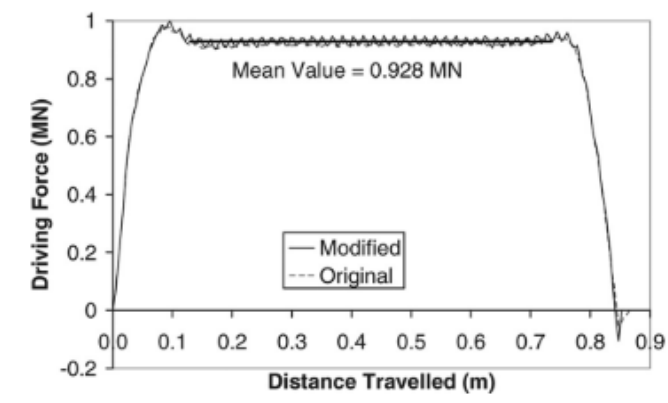

b)

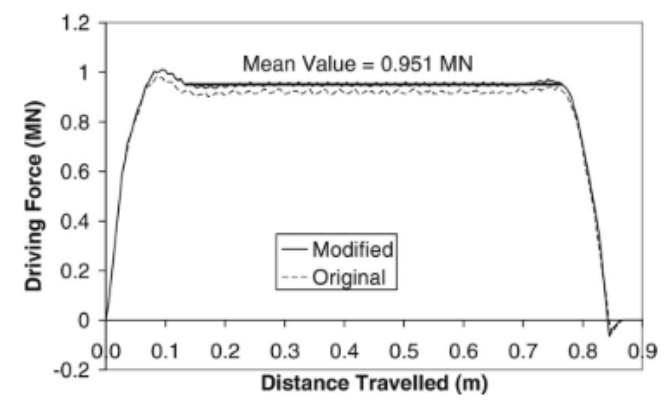

c)

Figura 2.26. Fuerza de empuje respecto a a) ángulo de entrada, b) ángulo de salida y c) longitud calibrada [95].

En cuanto al coeficiente de rozamiento $\mu$, se observó que el incremento de fuerza de empuje era proporcional con el coeficiente de rozamiento $\mu$.

Finalmente realizaron un análisis de autozunchado mecánico en dos etapas para escalar el primer mandrino de tal forma que la fuerza de empuje requerida para ambas pasadas fuera inferior que la obtenida para una pasada, optimizando así el proceso de fabricación.

En 2013, Bhatnagar [47] trabajó en el modelizado, validación y diseño de un cilindro zunchado térmicamente y autozunchado tal y como también hicieron anteriormente Parker et al. [79] o Jahed et al. [50] en este caso consideraba el autozunchado previo al zunchado térmico y utilizaba para el modelizado el modelo de Huang [96]. Las conclusiones obtenidas fueron que la combinación de ambas técnicas reducía costes de autozunchado debido a que la presión requerida era inferior. Además, las pérdidas de tensiones residuales causadas por la 
plastificación inversa debido a la combinación del efecto Bauschinger y un mayor ratio diametral eran inferiores.

Ese mismo año, Sedigui y Jabbari [19] realizaron una investigación muy interesante de las tensiones residuales introducidas en cilindros de pared gruesa mediante la combinación de autozunchado y bobinado. Es este caso era autozunchado hidráulico pero también podía haber sido mecánico por lo que los resultados eran muy interesantes. Las conclusiones más destacadas fueron que el bobinado hacía que el campo de tensiones residuales introducidas fuera mejor en más espesor de la vasija, es decir, las tensiones de compresión se aumentaban y las de tracción se disminuían por lo que se aumentaba la capacidad de contención de presión, mejoraba la vida a fatiga y reducía la iniciación de grietas. Además, el nivel de tensión tangencial de compresión no estaba limitado como en los cilindros únicamente autozunchados.

Por las mismas fechas, Chang et al. [97] [98] publicaron dos artículos en los que ampliaron sus estudios anteriores para diferentes modelos de material. También en 2013, Chang et al. [99] continuaron analizando el efecto del coeficiente de rozamiento $\mu$ en las tensiones residuales viendo que para coeficientes de rozamiento en el rango de 0-0,1 no tenía prácticamente influencia en las tensiones residuales y en el radio plástico. Un año más tarde, Chang et al. [100] volvieron a ampliar el estudio considerando un material con endurecimiento cinemático.

En 2014, Hu y Penumarthy [101] realizaron un modelo axisimétrico FEM considerando un material elasto-plástico con endurecimiento por deformación no lineal y endurecimiento cinémático (efecto Bauschinger) (Figura 2.27). Evaluaron la influencia del efecto Baushinger y la fricción en la distribución tensional y de deformación. También determinaron la interferencia óptima del mandrino con el cilindro bajo la presión máxima de trabajo. 


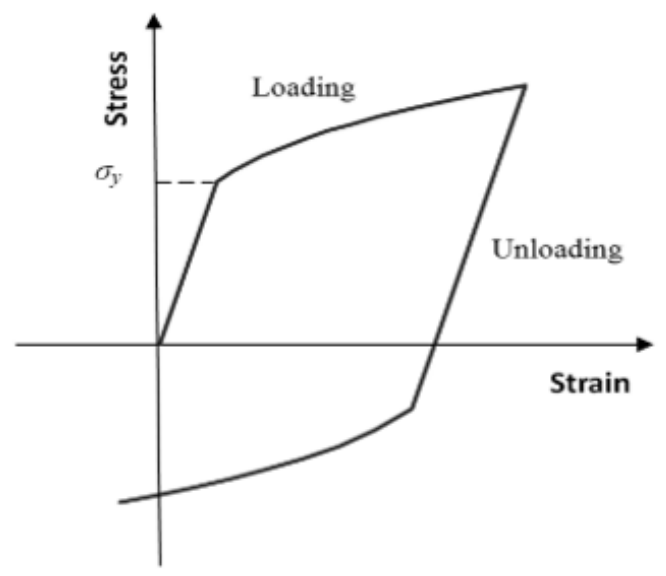

Figura 2.27. Modelo de material del cilindro empleado por Hu y Penumarthy [101].

Para el mandrino consideraron carburo de tungsteno con un módulo de elasticidad de 500GPa y un coeficiente de Poisson $v$ de 0,24 . Las conclusiones más destacables fueron que era importante, como es lógico, considerar el efecto Bauschinger en el modelo numérico pues afectaba bastante a la distribución de tensiones residuales, a mayor porcentaje de autozunchado, mayor era la deformación plástica inducida y mayor el efecto Bauschinger. En cuanto a la fricción, tenía poca influencia para las tensiones excepto para las tensiones longitudinales en el diámetro interior como ya determinó Gibson [85] en 2008 aunque con una influencia muy baja (Figura 2.28), sin embargo aumentaba dramáticamente la fuerza de empuje. Para el cilindro que estudiaron obtuvieron que la condición óptima era para una interferencia radial del 0,62\% y la correspondiente reducción de la tensión de Von Mises era sobre un $18 \%$.

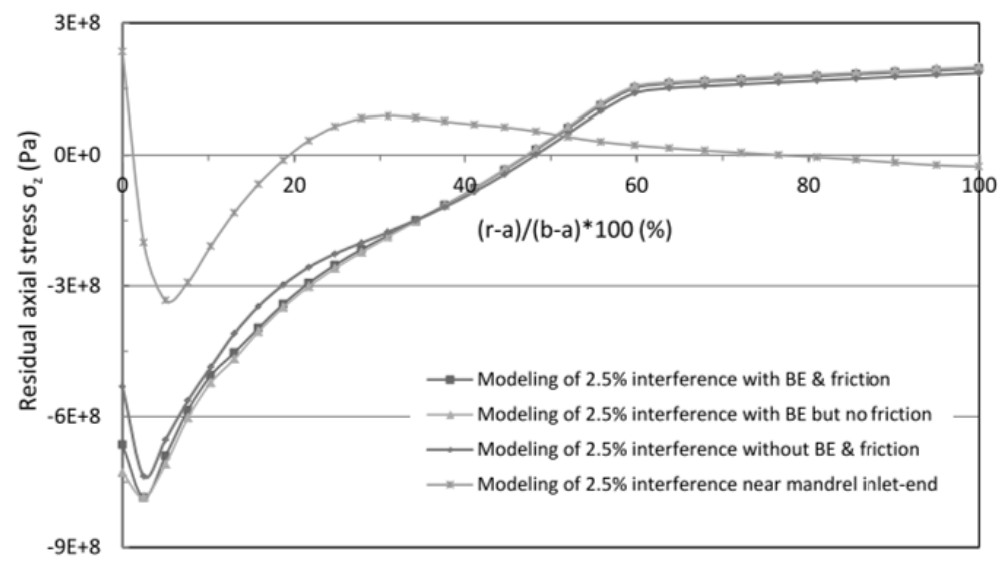

Figura 2.28. Tensiones residuales longitudinales [101]. 
Ese mismo año, Gibson et al. [102] ampliaron el estudio de 2012 [95] centrándose en las tensiones residuales generadas y la influencia de varias propiedades como los ángulos y la longitud de la sección calibrada del mandrino y el coeficiente de rozamiento en las mismas. Utilizaron las mismas condiciones de partida que O’Hara [74] en cuanto a geometría del mandrino, coeficiente de rozamiento, modelo de material, condiciones de contorno del modelo FEM... para poder comparar con sus resultados y así validar el modelo. Posteriormente modificaron las propiedades del mandrino para estudiar su sensibilidad en las tensiones residuales. Como resultado, destacar que la longitud de la sección calibrada tenía un impacto significativo en las tensiones longitudinales y en los perfiles de deformación plástica. En cuanto a los ángulos también tenían una gran influencia en las tensiones desarrollada, el ángulo frontal tenía la mayor influencia ya que su pendiente más baja deformaba una mayor longitud de tubo pero el ángulo trasero influenciaba más directamente las tensiones residuales debido a la creación de tensiones longitudinales de compresión cerca del diámetro interior. Resumiendo, la tensión axial jugaba un papel crucial en la determinacion de las tensiones residuales tangenciales y en la plastificación inversa. En cuanto al coeficiente de rozamiento $\mu$ la mayor influencia se producía en la componente de cortadura, la profundidad de autozunchado sólo se incrementaba ligeramente con el coeficiente de rozamiento $\mu$, las tensiones longitudinales y radiales variaban ligeramente con la fricción volviéndose las tensiones longitudinales más menos negativas debido al aumento de la carga axial resultante del aumento del coeficiente de fricción $\mu$, es decir, llegó a las mismas conclusiones que en su trabajo de 2008 [85].

Ya en el año 2015, Chang et al. [103] realizaron un análisis elasto-plástico de la descarga de un cilindro de pared gruesa tras un autozunchado mecánico para derivar las tensiones residuales teniendo en cuenta el efecto Bauschinger y el efecto de endurecimiento en la descarga. Derivaron la solución elasto-plástica y la elástica. Combinado con la solución elasto-plástica del modelo de material elasto-plástico ideal derivaron las fórmulas del radio de plastificación inversa, tensiones residuales y desplazamiento radial residual.

Ese mismo año, Dewangan y Panigrahi [104] desarrollaron un modelo FEM para el análisis de las tensiones residuales de un cilindro de pared gruesa sometido a un autozunchado mecánico. Para el análisis consideraron un modelo de material bilineal con endurecimiento cinemático. El programa utilizado fue ANSYS y el modelo realizado fue axisimétrico. En esta 
simulación analizaron las tensiones residuales a mitad de longitud cuando el mandrino iniciaba el flujo de material, cuando el mandrino estaba en interferencia completa con el cilindro y cuando el mandrino dejaba el cilindro con el objetivo de entender la causa de la formación de tensiones.

En el año 2016, Perl y Saley [105] [106] realizaron un estudio dividido en dos partes en el que analizaron el impacto del autozunchado mecánico e hidráulico en la resistencia a fractura y la vida a fatiga de un cañón internamente agrietado. En la primera parte analizaron el efecto del autozunchado y en la segunda el efecto combinado de la presión y el autozunchado. Evaluaron el Factor de Intensidad de Tensiones $K_{I}$ (FIT) tridimensional en Modo I a lo largo del frente de grieta. Para ello realizaron un análisis 3D utilizando un método FEM empleando elementos singulares a lo largo del frente de grieta y calcularon el campo de tensiones residuales para los dos tipos de autozunchado incorporando el efecto Bauschinger. Por temas comparativos también aplicaron el campo de tensiones residuales calculado por Hill [107]. Los tres campos de tensiones residuales fueron simulados en el modelo FEM utilizando campos de temperatura equivalentes. Se analizaron varias profundidades de grieta, varias relaciones de forma elíptica de las grietas y cinco niveles diferentes de autozunchado hidráulico, mecánico y de Hill. Se pudo observar que el efecto del autozunchado mecánico era bastante superior al hidráulico con una relación entre los FIT en Modo I de un 32\% a favor del mecánico. En cuanto al autozunchado de Hill, sobreestimaba el campo de tensiones residuales y no era un modelo realista pues no tenía en cuenta el efecto Bauschinger. Un incremento del nivel de autozunchado de un $70 \%$ a un $100 \%$ sólo obtenía un beneficio residual incrementado el FIT un 9\% en el mecánico y un 15\% en el hidráulico.

Posteriormente, en la segunda parte del estudio tuvieron en cuenta el efecto combinado de la presión y el autozunchado y comprobaron que en el cilindro estudiado, la vida a fatiga del cilindro con autozunchado mecánico era un $75 \%$ superior a la obtenida en el cilindro con autozunchado hidráulico.

Ya en 2017 Güngör [108] realizó una aproximación para la optimización del espesor de pared en un cilindro de pared gruesa teniendo en cuenta las tensiones residuales después del proceso de autozunchado, la eliminación de material en el diámetro interior y exterior así como la presión de servicio variable en todo el cilindro generada en el disparo del cañon. 
En el año 2018 Sedigui et al. [22] continuaron su estudio de 2013 [19] en un cilindro autozunchado y bobinado posteriormente analizando la influencia de la presión de autozunchado, espesor del cilindro, número de capas de bobinado, tensión de bobinado y presión de trabajo. Para el material considerado se aplicaron el comportamiento real en carga, descarga y recarga. Las conclusiones fueron que se podía obtener una vasija con vida infinita mediante la combinación de las dos técnicas, algo que no se podía obtener sólo con el autozunchado. Incrementando la tensión de bobinado se necesitaba menos presión de autozunchado. El aumento de espesor del cilindro aumentaba la presión de autozunchado óptima para tener vida infinita. También era muy importante el grado óptimo de autozunchado pues si no, los efectos beneficiosos del bobinado se reducían drásticamente. Este estudio lo realizaron para un autozunchado hidráulico pero sus conclusiones también sirven para un autozunchado mecánico.

Ese mismo año Jin y Yuan [109] realizaron el análisis y diseño de un mandrino con un agujero interior. Como indicaron, el carburo de tungsteno es el material recomendado para la fabricación de mandrinos pues tiene un módulo de elasticidad elevado, lo que hace que no sufra elevadas deformaciones bajo tensión y también tiene buena resistencia al desgaste. La fabricación de piezas de carburo de tungsteno de gran volumen es complicado y se produce un fenómeno de elevado carbón en el centro y bajo contenido en carbón en la superficie. Debido a lo anterior, para mandrinos de gran calibre (en este caso $152 \mathrm{~mm}$ ), propusieron un mandrino combinado con dos partes, un cilindro interior de acero rápido y zunchado térmicamente a este un anillo de carburo de tungsteno, siendo este la parte que interaciona con el cilindro de pared gruesa durante el proceso de autozunchado. Geométricamente el mandrino tendría un ángulo frontal, una zona cilíndrica calibrada y un ángulo trasero (Figura 2.29).

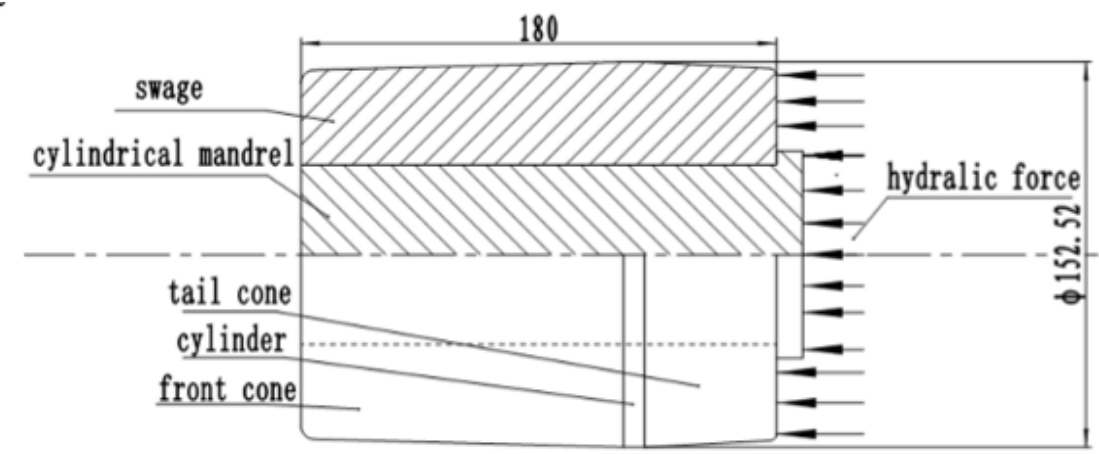

Figura 2.29. Estructura del mandrino combinado diseñado por Jin y Yuan [109]. 
Realizaron la simulación FEM (modelo axisimétrico) mediante ABAQUS del mandrino combinado con diferentes interferencias entre las dos partes y analizaron las tensiones y desplazamientos comparando los desplazamientos con aquellos de mandrinos monobloque de carburo de tungsteno y de acero rápido bajo las condiciones de trabajo. Observaron que la máxima tensión de Von Mises cambiaba según la interferencia entre las dos partes. La tensión máxima en la parte de acero rápido aumentaba con la interferencia y la tensión máxima en la parte de carburo de tungsteno (TCS) disminuía hasta una interferencia de $0,06 \mathrm{~mm}$ en la que aumentaba de nuevo (Figura 2.30).

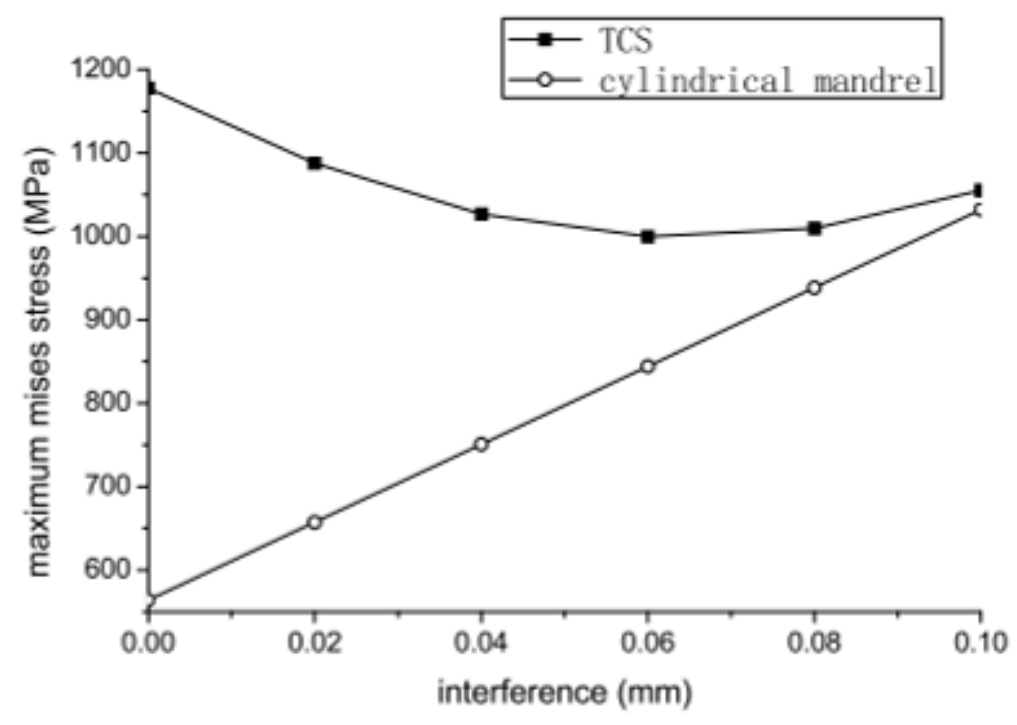

Figura 2.30. Tensión Máxima de Von Mises en las partes del mandrino vs Interferencia [109].

En cuanto a los desplazamientos del mandrino, el combinado tenía desplazamientos similares a aquel realizado sólo en carburo de tungsteno pero muy inferiores al realizado sólo en acero rápido, además el valor era independiente de la interferencia entre las dos partes en el mandrino combinado (Figura 2.31). 


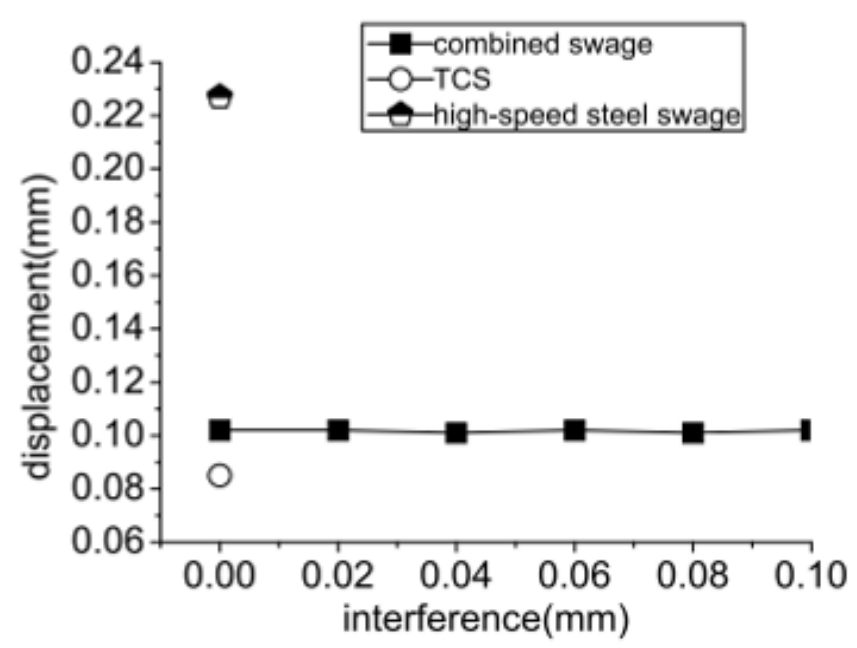

Figura 2.31. Desplazamientos de los mandrinos bajo iguales condiciones de trabajo [109].

El mandrino combinado era una buena solución para el autozunchado mecánico de vasijas de gran calibre pues reducía la dificultad de fabricación del carburo de tungsteno y no tenía efecto en el cilindro de pared gruesa.

También en 2018, Zhong [110] realizó un estudio muy completo de un proceso de autozunchado mecánico en dos pasadas mediante simulación FEM. Para ello consideró un cañon de $105 \mathrm{~mm}$ de calibre en un material elásto-plástico con endurecimiento no lineal con efecto Bauschinger (Figura 2.32).

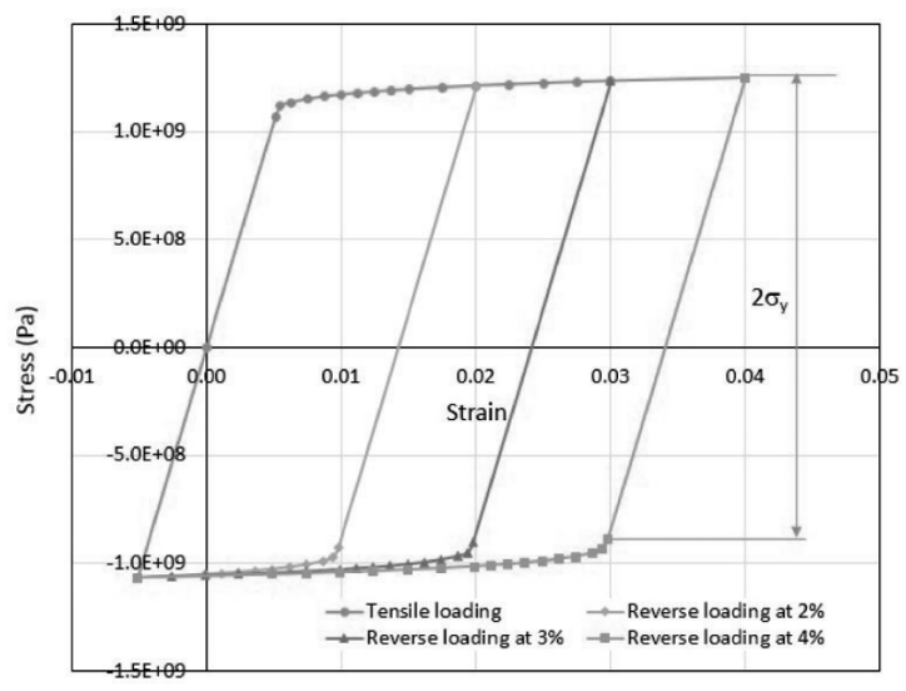

Figura 2.32. Modelo de material empleado por Zhong [110]. 
Analizó las fuerzas axiales de empuje del mandrino para varias interferencias, las tensiones residuales inducidas y propuso la interferencia radial óptima. Además comparó los resultados con aquellos obtenidos en un autozunchado mecánico en una sola pasada. Para la validación de los resultados utilizó mediciones con difracción de neutrones. Las conclusiones más interesantes fueron que la fuerza de empuje era reducida en un $30-35 \%$ al realizar el proceso en dos pasadas comparada con el proceso en una pasada (Figura 2.33).
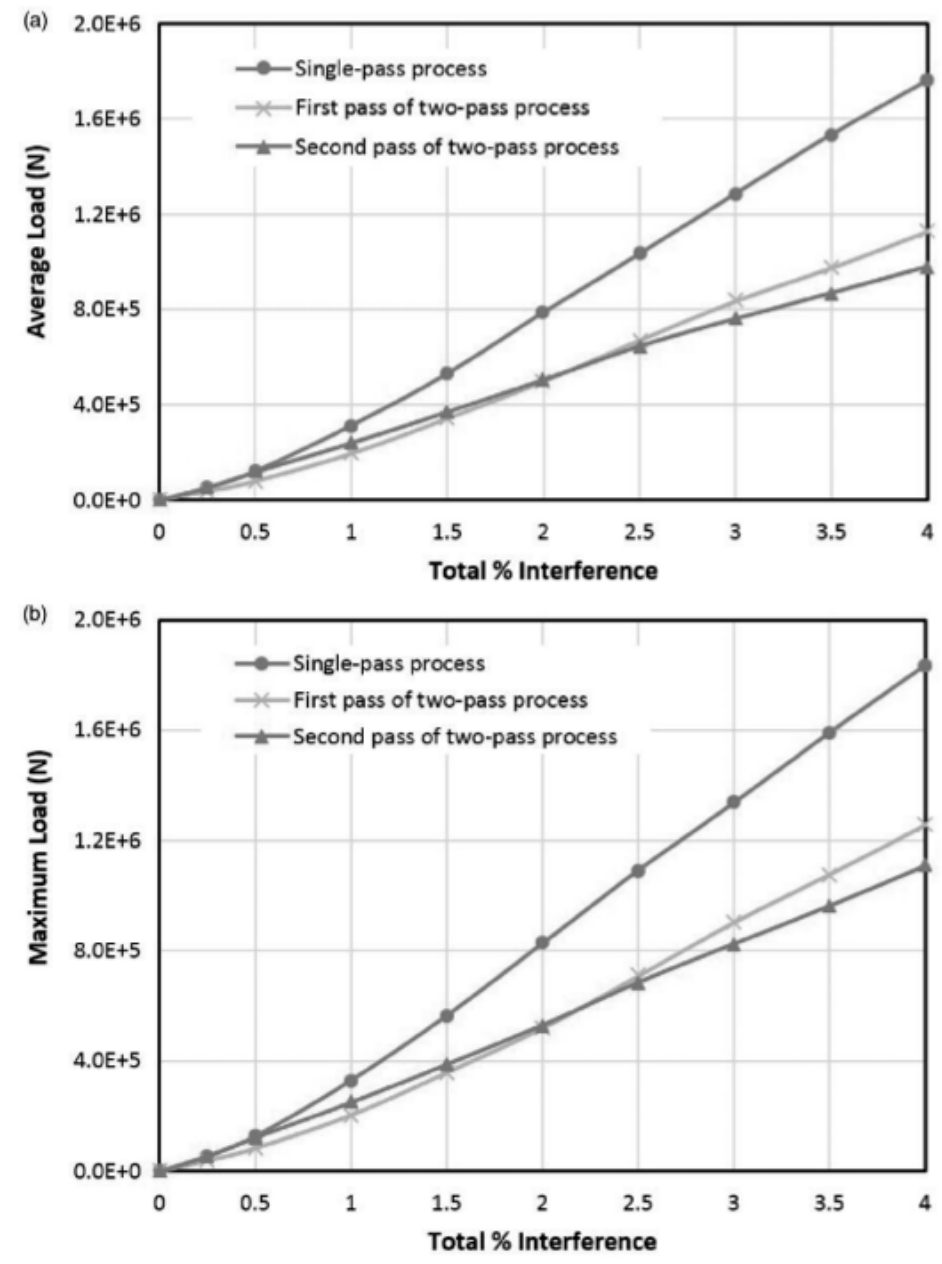

Figura 2.33. Carga axial vs. Interferencia radial (a) carga media (b) carga máxima [110].

En cuanto a las tensiones generadas eran muy similares en el caso de dos pasadas y de una pasada, únicamente la tensión tangencial residual de compresión cerca del diámetro interior era ligeramente mayor (más negativa) en el caso de dos pasadas respecto al de una. Otra conclusión interesante era que el incremento de la presión capaz de resistir el cilindro era incrementado un $31 \%$ tras la realización del autozunchado mecánico. 


\subsection{TÉCNICAS DE MEDICIÓN DE TENSIONES RESIDUALES}

El presente apartado se centra en la descripción de los métodos más utilizados para la medición de las tensiones residuales en cilindros. No se hace una descripción de todos los métodos sino de aquellos más utilizados en los cilindros de pared gruesa. Se realizará una breve descripción de cada una de ellos incluso haciendo referencia a los trabajos en los que han sido utilizados para la medición de tensiones en cilindros tras un proceso de introducción de tensiones residuales describiendo con mayor detalle la técnica del Hole drilling por haber sido la utilizada en el desarrollo de la presente Tesis y cuya metodología es explicada en profundidad en el Capítulo 4. Todas las técnicas tienen sus ventajas e inconvenientes [111] siendo la resolución y la profundidad alcanzable dos de los parámetros importantes (Figura 2.34)

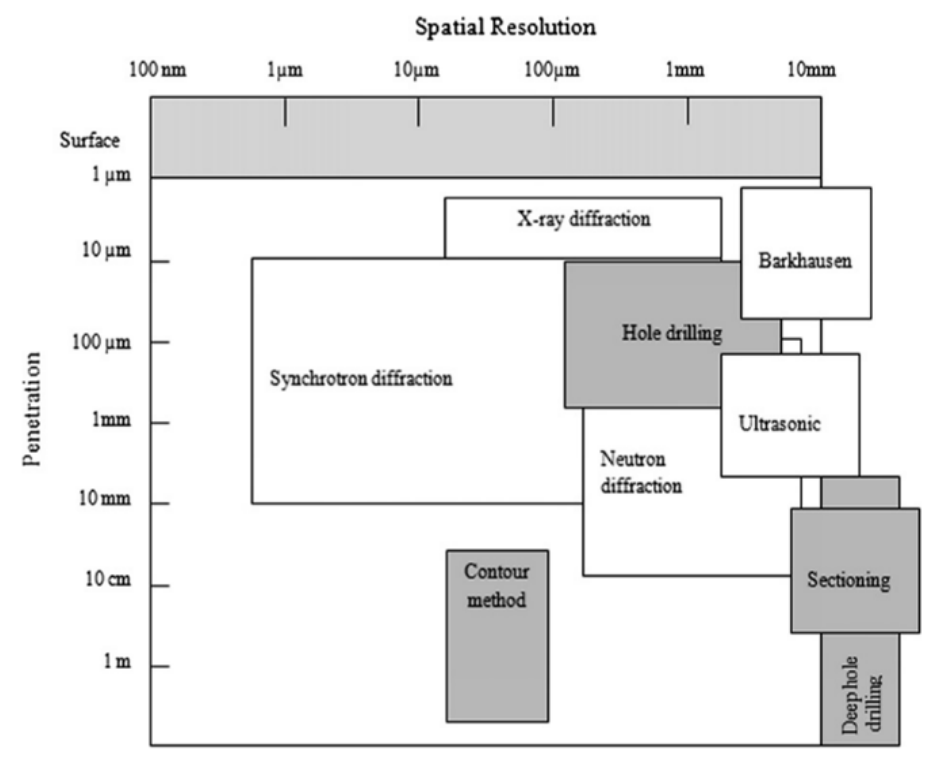

Figura 2.34. Penetración y resolución de varias técnicas. Los métodos destructivos y semidestructivos en gris [111].

De forma general, las técnicas de medición de tensiones residuales se pueden dividir en:

- Métodos destructivos: Método Sachs, Split-ring y el Método Compliance.

- Métodos semidestructivos: Método de Hole drilling.

- Métodos no destructivos: Difracción de Rayos X y Difracción de neutrones. 


\subsubsection{Método Sachs}

El método Sachs es un método destructivo de medición de tensiones residuales que consiste en la eliminación en capas de la superficie interna del cilindro autozunchado a través de una operación de mecanizado que causa fluctuaciones en la deformación de la superficie, que se miden mediante galgas extensiométricas adheridas a la superficie exterior. Las tensiones correspondientes a esas deformaciones son calculadas a partir de las ecuaciones básicas de elasticidad. El cálculo está basado en la suposición de que el proceso de descarga es completamente elástico. Este método fue descrito por Sachs en 1927 [112] y fue una de las primeras técnicas utilizadas para la medición de tensiones residuales en cilindros de pared gruesa, Davidson et el. [3], [66] ya lo utilizaron en los primeros estudios realizados del autozunchado mecánico.

Parker [113] afirmó ya en 2004 que esta aproximación no era válida debido al efecto Bauschinger. Desarrolló un modelo numérico simulando el Método Sachs y demostró que la omisión del efecto Bauschinger conducía a la sobreestimación del método Sachs de las tensiones radiales residuales en un $24 \%$ y las tangenciales residuales en un $43 \%$. Por lo tanto no era un método recomendable como fiable o conservador.

En cuanto a las ventajas principales del método cabe destacar que es simple y preciso. En cuanto a las desventajas destaca que es un método destructivo y que lleva bastante tiempo su aplicación, pues necesita la eliminación de grandes cantidades de material. Además, la operación de eliminación de material induce tensiones residuales adicionales en la muestra.

\subsubsection{Método "Compliance"}

El método "Compliance" es un método simple para la medición de tensiones residuales. Fue sugerido por Cheng y Finnie [114] en 1983. Aplicaron esta técnica para medir las tensiones residuales inducidas en un cilindro autozunchado hidráulicamente. En esta técnica se realiza un corte en ranura en la superficie exterior de un anillo delgado de muestra del cilindro. Este corte se extiende incrementalmente midiendo al mismo tiempo el cambio en deformación debido a la relajación de las tensiones residuales mediante galgas extensiométricas colocadas en la superficie exterior de la muestra. Para la medición de tensiones residuales tangenciales en un anillo de muestra se realiza un corte axial y de la misma forma se realiza un corte 
circunferencial para la medición de tensiones residuales longitudinales (Figura 2.35). El método "Compliance" tiene la ventaja de que es simple y preciso pero sus desventajas principales son que es destructivo y es necesario mucho tiempo para realizarlo.

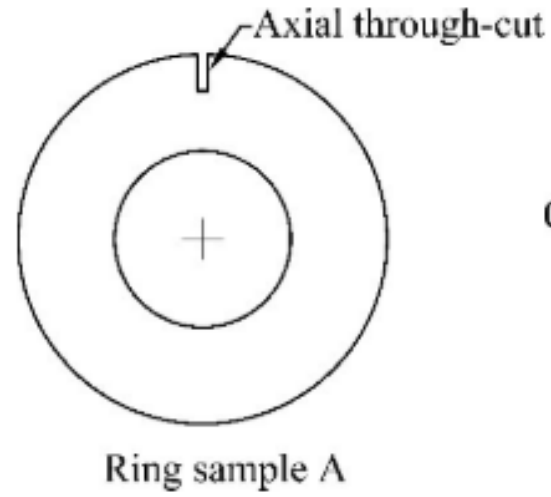

(a)

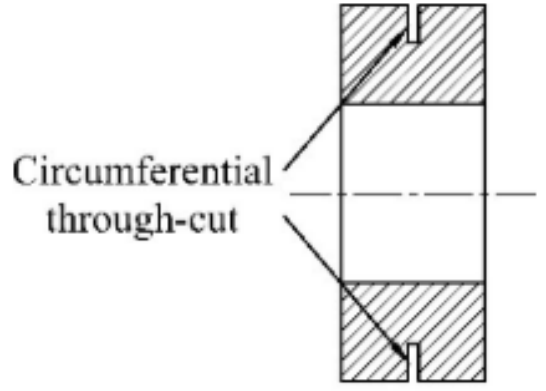

Ring sample B

(b)

Figura 2.35. Esquema del método Compliance con (a) corte axial para medir tensiones residuales tangenciales y (b) corte circunferencial para medir tensiones residuales longitudinales [39].

\subsubsection{Método Split-ring}

Es el método más simple para la identificación de la presencia de tensiones tangenciales residuales consistente en la medición del ángulo de apertura debido a un corte longitudinal realizado en un anillo de muestra del cilindro autozunchado (Figura 2.36). Este método fue utilizado por primera vez por Parker et al. [115].

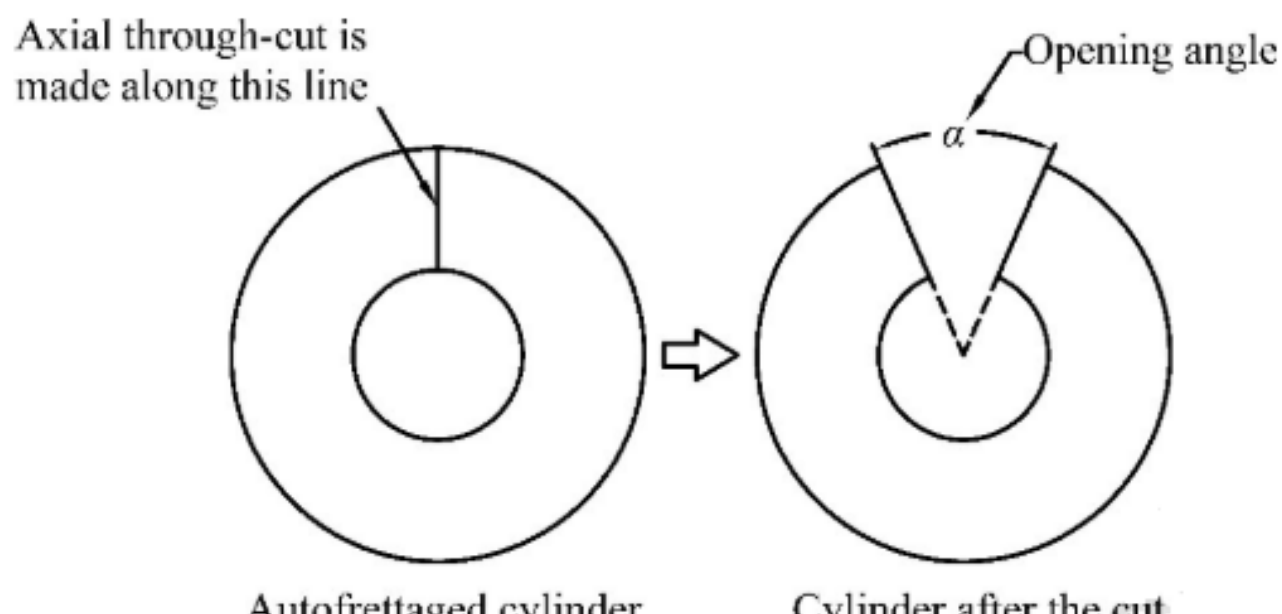

Figura 2.36. Esquema del método Split-ring [39]. 
Las principales ventajas de este método es que es simple y rápido pero como desventajas más importantes cabe señalar que es un método destructivo e incapaz de proporcionar una distribución detallada de las tensiones residuales.

\subsubsection{Hole drilling}

El método del "Hole drilling" es una técnica de medición de tensiones residuales semidestructivo que tiene varias variantes. Por ejemplo, en la técnica del "Deep hole drilling", la probeta es taladrada a través del espesor de pared y un núcleo conteniendo este agujero se extrae por medio de una operación de trepanación. La trepanación podría llevarse a cabo por medio de electroerosión. Esto causa la ampliación del agujero inicialmente taladrado debido a la relajación de tensiones cuya variación se mide con una sonda y la distribución de tensiones residuales se obtiene mediante una calibración adecuada (Figura 2.37). En otra variante como el "Incremental hole drilling", más común que la anterior por lo que se suele denominar simplemente "Hole drilling", únicamente se taladra un agujero pero no se extrae un núcleo aunque las deformaciones que se producen por la relajacion tensional al taladrar, también se miden mediante galgas. Resumiendo, el método del "Hole drilling" consta de tres fases: operación de taladrado, registro de las deformaciones descargadas y por último, el cálculo tensional. Para la medición de las deformaciones se utilizan rosetas extensiométricas.

Esta técnica ha sido utilizada para la medición de tensiones residuales en cilindros autozunchados de pared gruesa por autores como Jahed et al. [116]. Es importante señalar que un núcleo con diámetro más pequeño, resulta en valores experimentales más precisos. La norma para esta técnica, ASTM E837 -13 a [117] está basada en el Método Integral, aproximación matemática basada en el principio de superposición, y facilita la obtención de las matrices de coeficientes requeridas para resolver el problema inverso y calcular las tensiones residuales a profundidades hasta $1 \mathrm{~mm}$. 


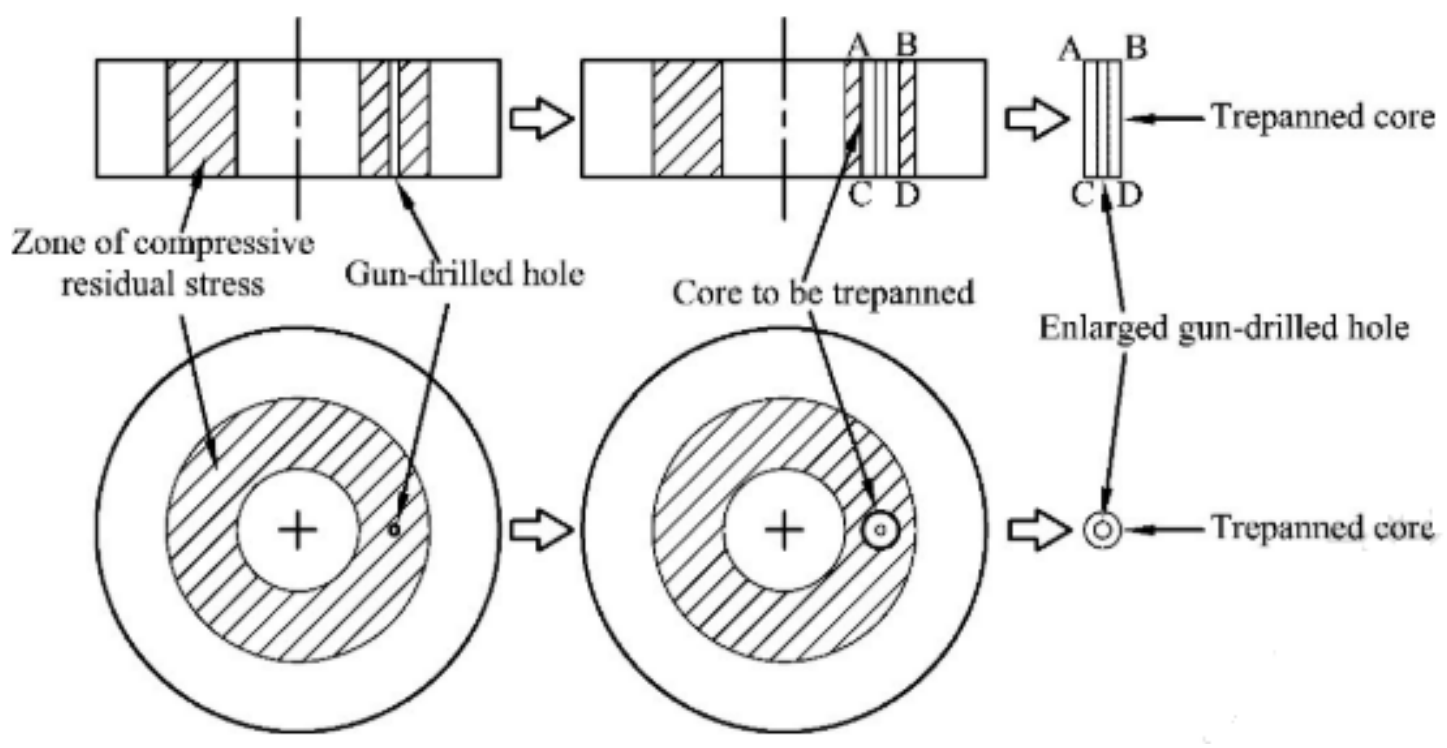

Figura 2.37. Esquema del método Deep Hole drilling [39].

En 2018, Alegre et al. [118] realizaron un análisis muy preciso de la influencia del espesor y el radio de agujero en el coeficiente de calibración del método del "Hole drilling" para la determinación de tensiones residuales no uniformes.

Como ventaja principal destacar que es un método simple y preciso, pero también su aplicación lleva bastante tiempo. En el Capítulo 4 se explicará en detalle la metodología pues es el método utilizado en esta Tesis para la medición de tensiones.

\subsubsection{Difracción de rayos $X$}

El método de difracción de rayos $\mathrm{X}$ es una técnica no destructiva para la medición de tensiones residuales en la superficie de materiales. Se basa en el hecho de que en el metal, cuando está bajo tensión, aplicada o residual, las deformaciones elásticas resultantes causan cambios en los espaciamientos de los planos atómicos de la estructura cristalina metálica. La difracción de rayos $\mathrm{X}$ puede medir directamente estos espaciamientos interatómicos pudiendo obtener de ello la tensión total en el metal. Esta técnica es adecuada solamente para la medición superficial de tensiones pues los rayos $\mathrm{X}$ interactúan con los electrones y son absorbidos por el material tras penetrar unas micras.

Esta técnica de medición ha sido utilizada para la medicion de tensiones residuales en cilindros de pared gruesa por varios autores como por ejemplo Lee et al. [75] en 1992. La 
ventaja principal de este método es que es no destructivo y preciso pero su principal desventaja es que sólo es un método útil para las mediciones de tensiones residuales en superficie, dado la poca penetrabilidad de los rayos $\mathrm{X}$.

\subsubsection{Difracción de neutrones}

El método de difracción de neutrones es muy similar al de difracción de rayos $\mathrm{X}$ ya que se basa en las deformaciones elásticas dentro de un material policristalino que causan cambios en el espaciado de los planos de la estructura cristalina desde su condición sin tensión. Esta técnica se ha generalizado en las últimas dos décadas. El poder de penetración de los neutrones es superior a la de los rayos $\mathrm{X}$, pues tienen menos carga y no interactúan con ninguna partícula.

Este método ha sido utilizado por varios autores como Underwood et al. [119] y Zhong [110] para la medición de tensiones residuales en cilindros de pared gruesa.

Las principales ventajas de este método es que es no destructivo, preciso y además tiene una capacidad de penetración superior a la técnica de difracción de rayos X, pudiendo llegar hasta los $25 \mathrm{~mm}$ en el acero. Las desventajas más reseñables son que es un método caro y que necesita de muchas medidas de seguridad.

\subsection{CONSIDERACIONES FINALES}

Como se ha podido comprobar en este capítulo, a lo largo de la historia han sido muchas las técnicas desarrolladas para la introducción de tensiones residuales en cilindros de pared gruesa para el aumento de su vida a fatiga y de su rendimiento. Han sido numerosos los autores que han investigado en dichas tecnologías y dentro de esas, no muchos en la tecnología del autozunchado mecánico. Las investigaciones han versado principalmente en la definición de los modelos para su simulación, el estudio de la geometría del mandrino y su influencia en los parámetros del proceso, el comportamiento del material del mandrino, la influencia del coeficiente de fricción $\mu$ entre el mandrino y el cilindro y la influencia del número de pasadas de mandrino. De entre todos los trabajos llevados a cabo, uno de los más relevantes para el desarrollo de esta Tesis, es el realizado por Gibson [85] debido a su profundo alcance en el análisis de sensibilidad realizado del proceso de autozunchado mecánico. 
que ninguno de los autores, durante este tiempo se han planteado en sus investigaciones la forma de poder realizar autozunchado mecánico en cilindros de muy gran calibre (diámetros interiores mayores de $300 \mathrm{~mm}$ ) en los cuales las fuerzas de empuje pueden ser muy elevadas y los mandrinos muy complicados de fabricar, habiéndose estudiado, pero para calibres de $152 \mathrm{~mm}$, la posibilidad de un mandrino combinado [109] para resolver los problemas de fabricación del mismo y estudiado la reducción de fuerza únicamente mediante el proceso de autozunchado mecánico en dos pasadas
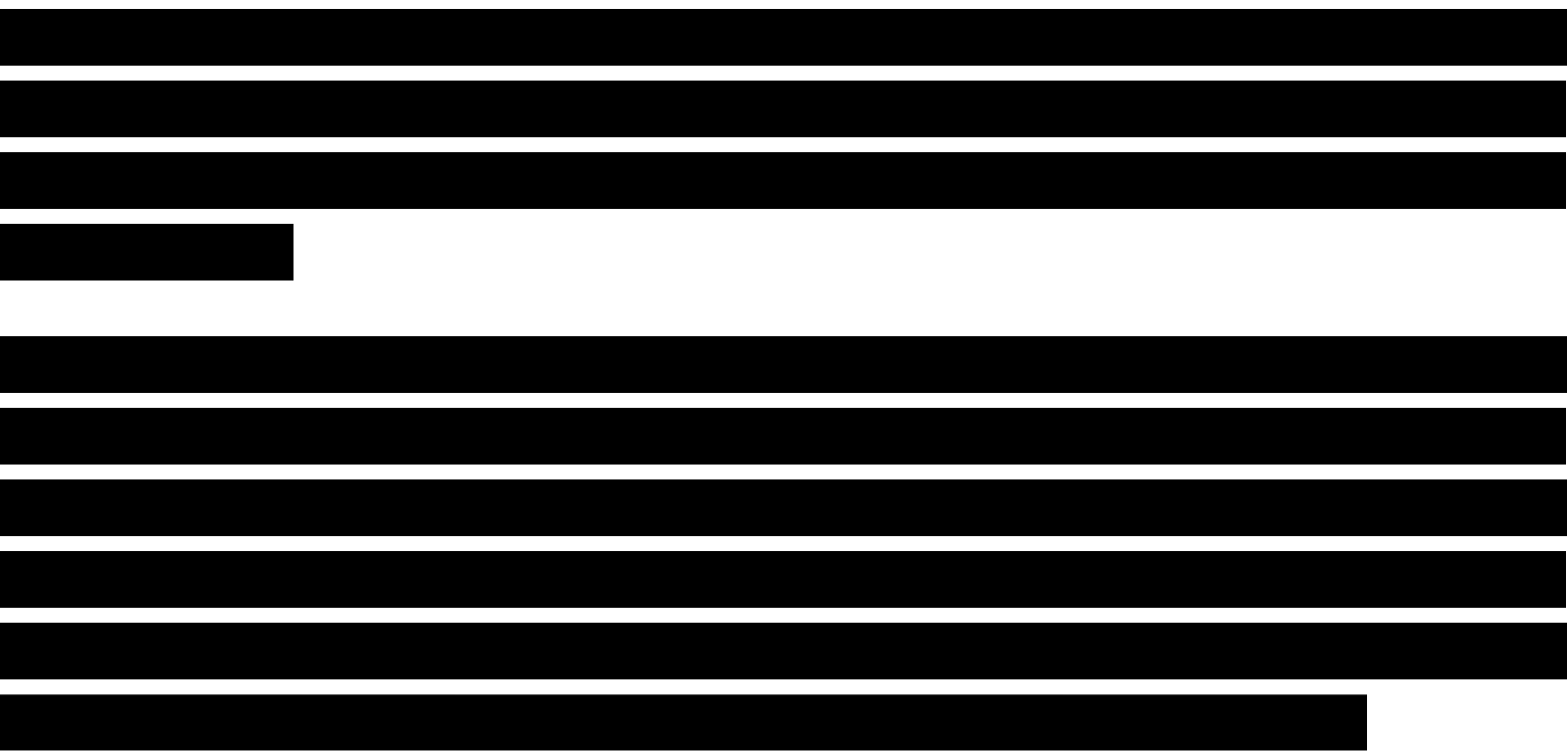

En cuanto a las tecnologías de medición de tensiones residuales recogidas en el apartado 2.4, las cuales son capaces de medir el efecto de las tecnologías de introducción de tensiones residuales, cabe destacar que es uno de los pilares de la presente Tesis pues permite validar el modelo desarrollado. En este capítulo se han descrito cada una de las técnicas y se han marcado las ventajas e inconvenientes de cada una de ellas. En concreto, el método seleccionado es esta Tesis ha sido el Hole drilling. 

Capítulo cifrado en virtud del Convenio de colaboración entre la Universidad de Burgos y la empresa "Hiperbaric, S.A." para la realización de tesis doctorales en el marco de doctorados industriales. Para su consulta se deberá solicitar permiso a Hiperbaric, S.A.

\author{
CAPÍTULO 3
}

\title{
CARACTERIZACIÓN DEL MATERIAL
}

\subsection{INTRODUCCIÓN}

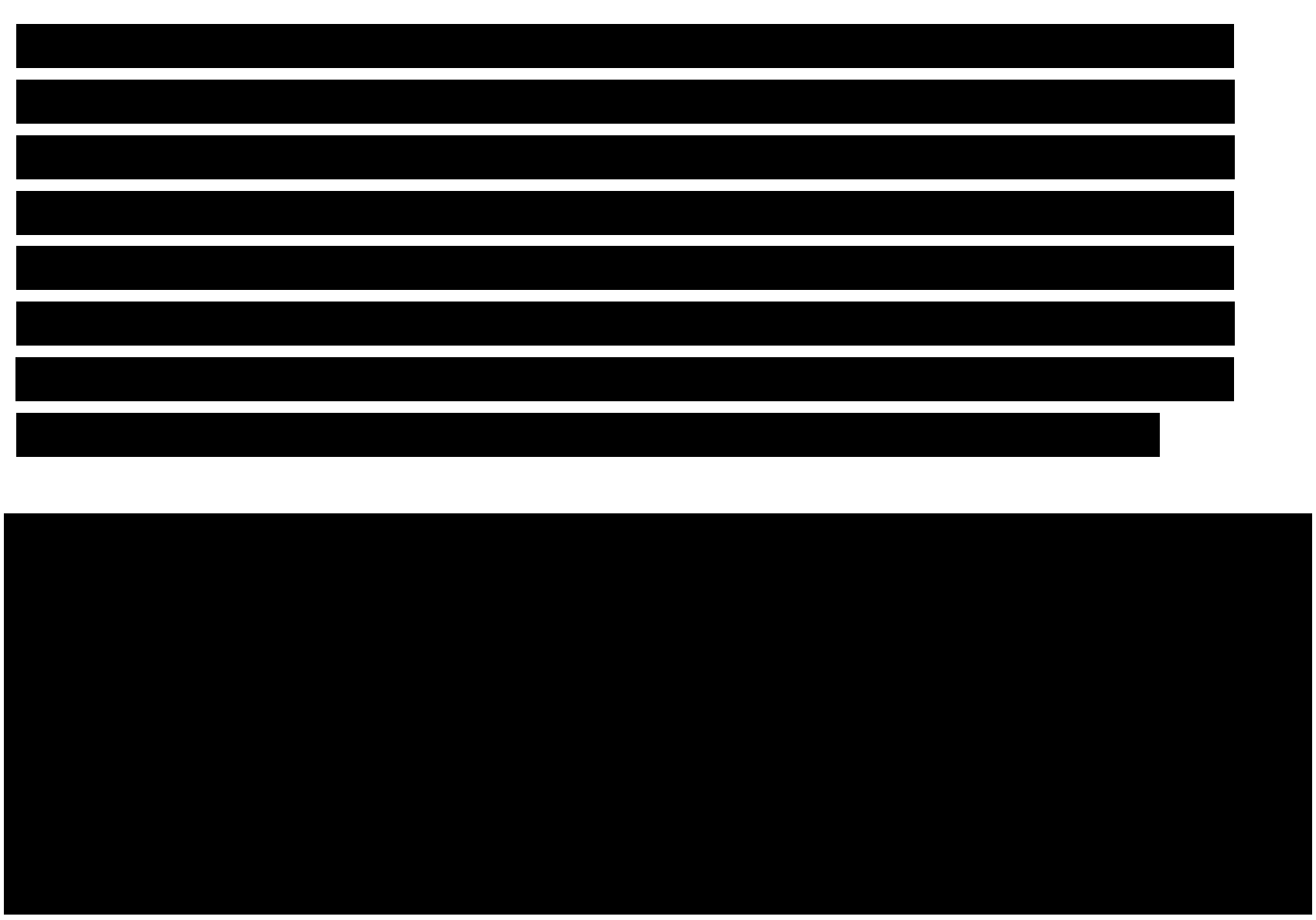



Capítulo cifrado en virtud del Convenio de colaboración entre la Universidad de Burgos y la empresa "Hiperbaric, S.A." para la realización de tesis doctorales en el marco de doctorados industriales. Para su consulta se deberá solicitar permiso a Hiperbaric, S.A.

\author{
CAPÍTULO 4
}

METODOLOGÍA

\title{
4.1. INTRODUCCIÓN
}

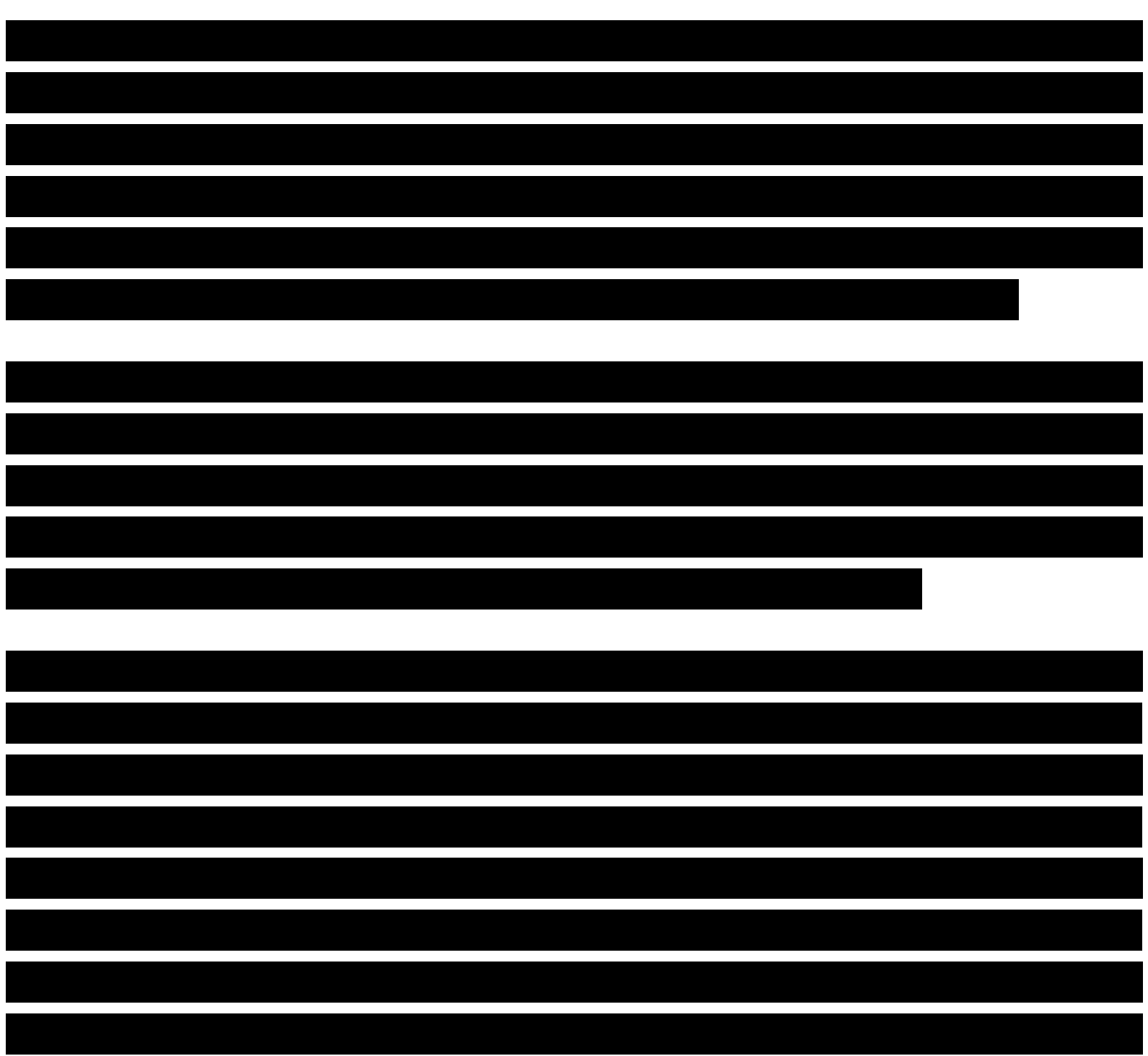



Capítulo cifrado en virtud del Convenio de colaboración entre la Universidad de Burgos y la empresa "Hiperbaric, S.A." para la realización de tesis doctorales en el marco de doctorados industriales. Para su consulta se deberá solicitar permiso a Hiperbaric, S.A.

\section{CAPÍTULO 5}

\section{APLICACIÓN DE LA METODOLOGÍA Y ANÁLISIS DE RESULTADOS}

\subsection{INTRODUCCIÓN}

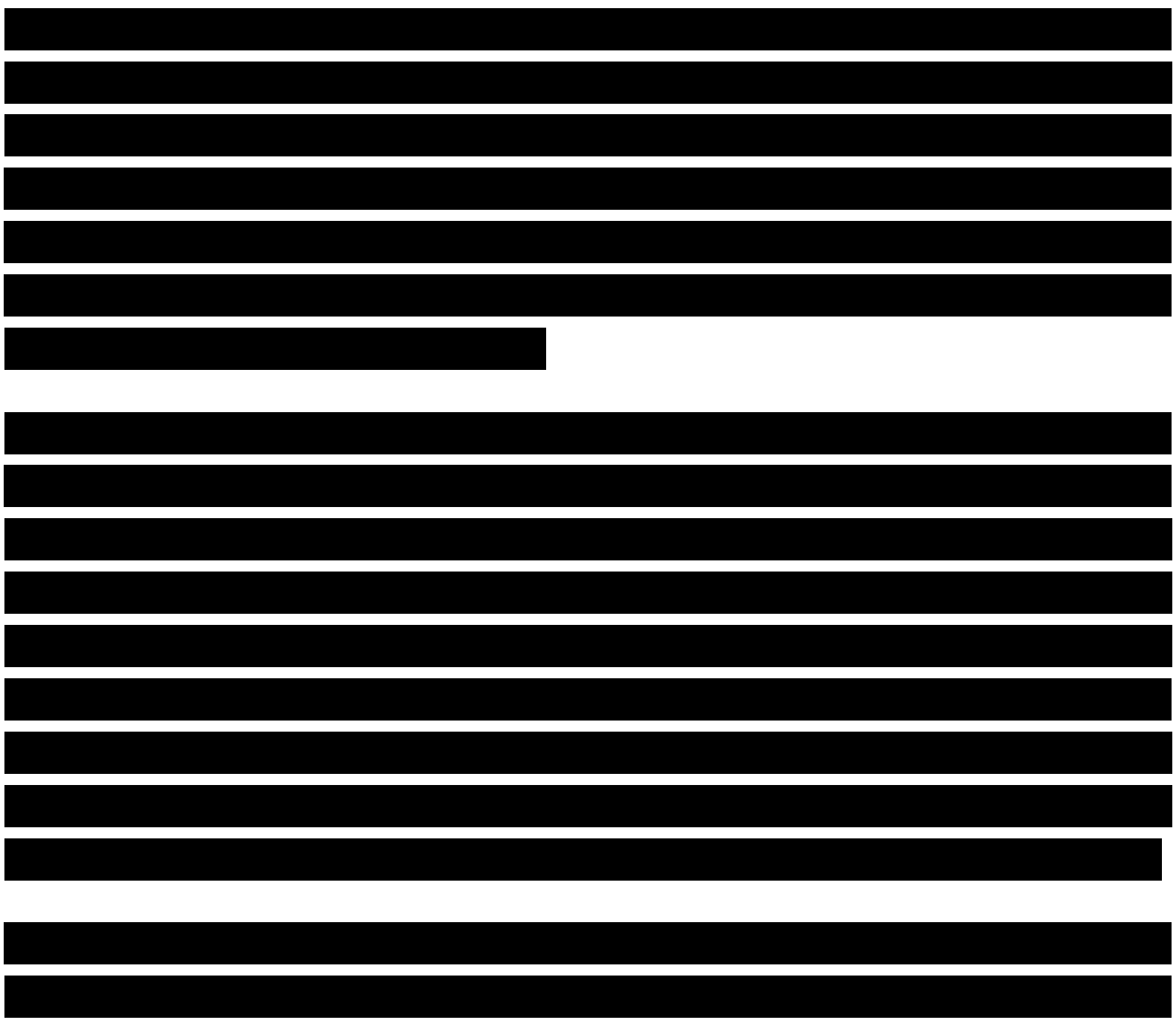



Capítulo cifrado en virtud del Convenio de colaboración entre la Universidad de Burgos y la empresa "Hiperbaric, S.A." para la realización de tesis doctorales en el marco de doctorados industriales. Para su consulta se deberá solicitar permiso a Hiperbaric, S.A.

\author{
CAPÍTULO 6
}

\title{
CONCLUSIONES Y TRABAJO FUTURO
}

\subsection{CONCLUSIONES}

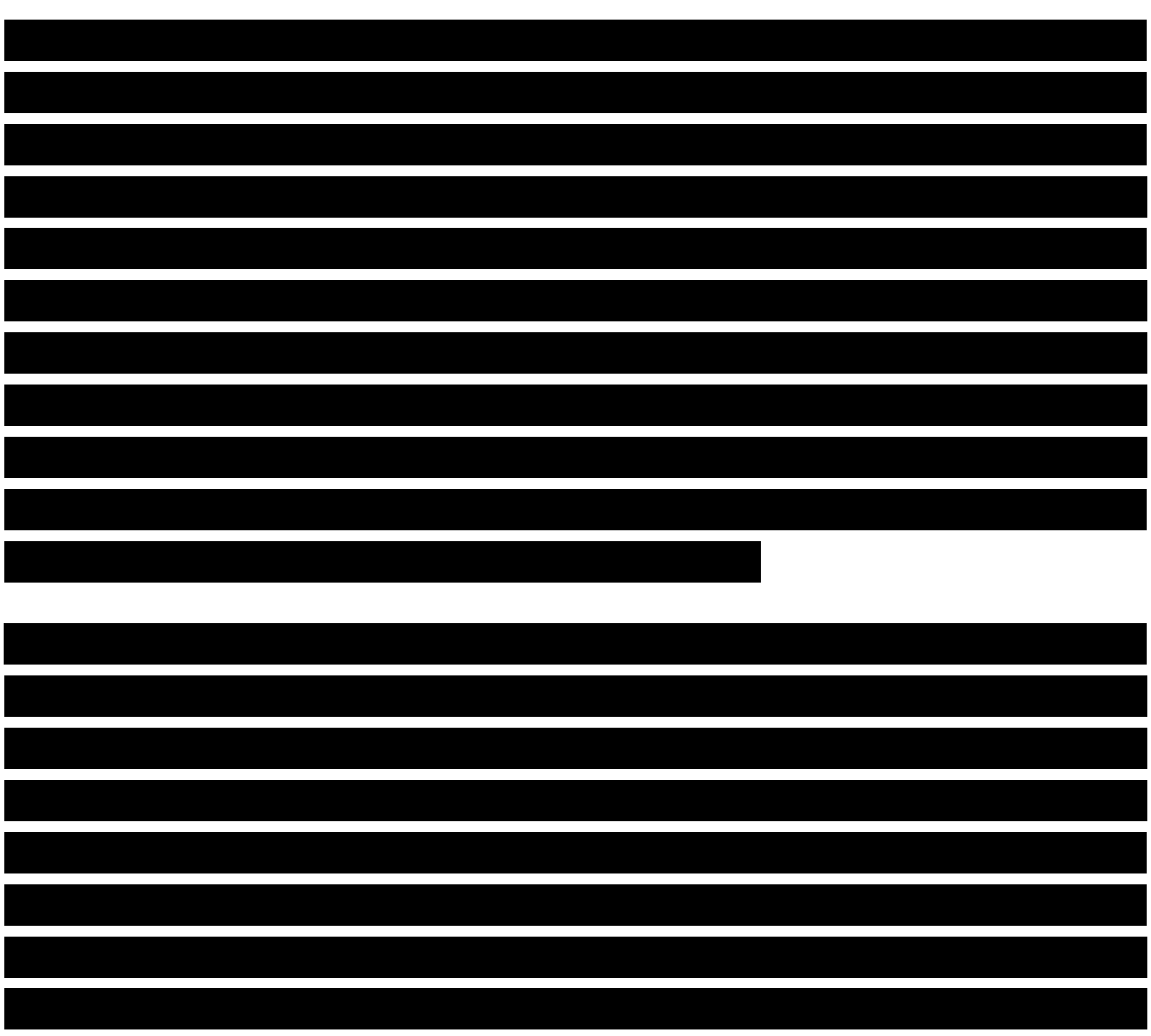




\section{CAPÍTULO 7}

\section{BIBLIOGRAFÍA}

[1] "Procesado por Altas Presiones (HPP)," 2018. [Online]. Available: https://www.hiperbaric.com/es. [Accessed: 10-Oct-2018].

[2] L. Jacob, “La Résistance et L'équilibre Élastique Des Tubes Frettés,” in Memorial de L'artillerie Navale, 1, 1907, pp. 43-155.

[3] T. E. Davidson, C. S. Barton, A. N. Reiner, and D. P. Kendall, "New approach to the autofrettage of high-strength cylinders," Exp. Mech., vol. 2, no. 2, pp. 33-40, 1962.

[4] G. Lamé and Clapeyron, Mém. prés. par viv. Savants, 2nd ser. 4, 463, 1833.

[5] S. Timoshenko, Strength of Materials, Part II. D.Van Nostrand Co., Princeton, N.J., 1930.

[6] W. R. D. Manning, "The Design of Compound Cylinders for High Pressure Service," Engineering, vol. 163, p. 349, 1947.

[7] H. L. D. Pugh, "Recent Developments in Cold Forming," Bullied Meml. Lect., vol. III, Unive, 1965.

[8] B. Crossland and D. J. Burns, "Behaviour of Compound Steel Cylinders Subjected to internal Pressure," Proc. Instn. Mech. Eng., vol. 175, No.27, 1961.

[9] S. J. Becker and L. Mollick, Theory of Ideal Design of a Compound Vessel. ASME, J. of Engin for Industry, 1960. 
[10] S. J. Becker, Analysis of a Yielded Compound Cylinder. ASME, J. of Engin for Industry, 1961.

[11] S. J. Becker, Yielded Compound Cylinder in Generalized Plane Strain. ASME, J. of Engin for Industry, 1961.

[12] J. M. Alegre, P. Bravo, M. Preciado, and M. Solaguren-Beascoa, "Simulation procedure of high pressure vessels using the wire winding technique," Eng. Fail. Anal., vol. 17, no. 1, pp. 61-69, Jan. 2010.

[13] E. H. Young and L. E. Brownell, Process equipment and design. New York: John Wiley and Sons, 1959.

[14] L. Maksimov, "Design of cylinder to withstand high internal pressure. Russ Eng $\mathrm{J} ; 44: 5-6, " 1964$.

[15] G. Harkegard, "A procedure for the analysis of wire-wound structure and its application to the optimum design of vessel for high pressure.," 4th int conf Press Vessel technol 1980 [Sweden. London], 1980.

[16] J. Talako, "Structure and analysis of wound pressure vessel. New York: Chapman \& Hal," 1998.

[17] D. M. Fryer and J. F. Havery, High pressure vessels. New York: Chapman \& Hal, 1998.

[18] ASME Boiler and Pressure Vessel Code, Section VIII, Division 3: Alternative Rules for Construction of High Pressure Vessels. American Society of Mechanical Engineers, 2017.

[19] M. Sedighi and A. H. Jabbari, "Investigation of residual stresses in thick-walled vessels with combination of autofrettage and wire-winding," Int. J. Press. Vessel. Pip., vol. 111-112, pp. 295-301, Nov. 2013.

[20] J. M. Alegre, P. M. Bravo, and I. I. Cuesta, "Fatigue design of wire-wound pressure vessels using ASME-API 579 procedure,” Eng. Fail. Anal., vol. 17, no. 4, pp. 748-759, 
Jun. 2010.

[21] API 579-1/ASME FFS-1, fitness-for-service. American Society of Mechanical Engineers, 2007.

[22] M. Sedighi, A. H. Jabbari, and A. M. Razeghi, "Effective parameters on fatigue life of wire-wound autofrettaged pressure vessels," Int. J. Press. Vessel. Pip., vol. 149, pp. 66-74, 2017.

[23] C. C. Wong, A. Hartawan, and W. K. Teo, "Deep Cold Rolling of Features on AeroEngine Components," Procedia CIRP, vol. 13, pp. 350-354, 2014.

[24] O. Föppl and A. Thum, "Steigerung der Dauerhaltbarkeit durch Oberflächendrücken (Zuschriftenwechsel)," VDI Zeitschrift 77 No50, pp. 1335-1337, 1933.

[25] O. J. Horger, "Effect of surface rolling on the fatigue strength of steel," J Appl Mech 57,pp. 128-136, 1935.

[26] K. H. Kloos, B. Fuchsbauer, and J. Adelmann, "Fatigue properties of specimens similar to components deep rolled under optimized conditions," Int. J. Fatigue, vol. 9, no. 1, pp. $35-42,1987$.

[27] P. Delgado, I. I. Cuesta, J. M. Alegre, and A. Díaz, "State of the art of Deep Rolling," Precis. Eng., vol. 46, pp. 1-10, 2016.

[28] E. Maleki, O. Unal, and A. Amanov, "Novel experimental methods for the determination of the boundaries between conventional, severe and over shot peening processes," Surfaces and Interfaces, vol. 13, pp. 233-254, 2018.

[29] R. Purohit, C. S. Verma, R. S. Rana, R. K. Dwivedi, R. Dwivedi, and D. Banoriya, "Optimization of Process Parameters of Shot Peening Using ABQUS," Mater. Today Proc., vol. 4, no. 2, Part A, pp. 2119-2128, 2017.

[30] R. Purohit, C. S. Verma, R. S. Rana, R. Dwivedi, and S. Dwivedi, "Simulation of shot peening process," Mater. Today Proc., vol. 4, no. 2, Part A, pp. 1244-1251, 2017.

[31] E. Maleki, O. Unal, and K. Reza Kashyzadeh, "Fatigue behavior prediction and 
analysis of shot peened mild carbon steels," Int. J. Fatigue, vol. 116, pp. 48-67, 2018.

[32] C. S. Montross, T. Wei, L. Ye, G. Clark, and Y.-W. Mai, "Laser shock processing and its effects on microstructure and properties of metal alloys: a review," Int. J. Fatigue, vol. 24, no. 10, pp. 1021-1036, 2002.

[33] C. A. A. Yan and E. M. Moroz, "Pressure on evaporation of matter in a radiation beam," J. Exp. Theor. Phys. Lett., vol. 16, pp. 1638-44, 1963.

[34] R. M. White, "Elastic wave generation by electron bombardment or electromagnetic wave absorption," J. Appl. Phys., vol. 34, pp. 2123-4, 1963.

[35] E. D. Jones, "Ultrafast laser-induced stress waves in solids," Appl. Phys. Lett., vol. 18, pp. 33-5, 1971.

[36] J. Zhao, Y. Dong, and C. Ye, "Laser shock peening induced residual stresses and the effect on crack propagation behavior,” Int. J. Fatigue, vol. 100, pp. 407-417, 2017.

[37] M. Kattoura, S. R. Mannava, D. Qian, and V. K. Vasudevan, "Effect of laser shock peening on residual stress, microstructure and fatigue behavior of ATI 718Plus alloy," Int. J. Fatigue, vol. 102, pp. 121-134, 2017.

[38] A. Salimianrizi, E. Foroozmehr, M. Badrossamay, and H. Farrokhpour, "Effect of Laser Shock Peening on surface properties and residual stress of Al6061-T6," Opt. Lasers Eng., vol. 77, pp. 112-117, 2016.

[39] R. Shufen and U. S. Dixit, "A Review of Theoretical and Experimental Research on Various Autofrettage Processes," J. Press. Vessel Technol. Trans. ASME, vol. 140, no. 5, p. 050802, 2018.

[40] R. Hill, E. H. Lee, and S. J. Tupper, "The Theory of Combined Plastic and Elastic Deformation With Particular Reference to a Thick Tube Under Internal Pressure," Proc. R. Soc. London, Ser.A, vol. 191, no. 1026, pp. 278-303, 1947.

[41] D. G. B. Thomas, "The autofrettage of thick tubes with free ends," J. Mech. Phys. Solids, vol. 1, no. 2, pp. 124-133, 1953. 
[42] D. P. Kendall, "INFLUENCE OF THE BAUSCHINGER EFFECT ON REYIELDING OF AUTOFRETTAGED THICK-WALLED CYLINDERS.,” in American Society of Mechanical Engineers, Pressure Vessels and Piping Division (Publication) PVP, 1987, vol. 125, pp. 17-21.

[43] A. P. Parker, J. H. Underwood, and D. P. Kendall, "Bauschinger effect design procedures for autofrettaged tubes including material removal and sachs' method," $J$. Press. Vessel Technol. Trans. ASME, vol. 121, no. 4, pp. 430-437, 1999.

[44] B. Avitzur, "Autofrettage - Stress distribution under load and retained stresses after depressurization,” Int. J. Press. Vessel. Pip., vol. 57, no. 3, pp. 271-287, 1994.

[45] A. P. Parker, "Autofrettage of open-end tubes-pressures, stresses, strains, and code comparisons," J. Press. Vessel Technol. Trans. ASME, vol. 123, no. 3, pp. 271-281, 2001 .

[46] D. Bähre and H. Brünnet, "Simulation of removing autofrettage-induced residual stress loaded layers by finite element analysis," Procedia Eng., vol. 19, pp. 9-15, 2011.

[47] R. M. Bhatnagar, "Modelling, validation and design of autofrettage and compound cylinder," Eur. J. Mech. A/Solids, vol. 39, no. May 2013, pp. 17-25, 2013.

[48] H. Jahed and G. Ghanbari, "Actual Unloading Behavior and Its Significance on Residual Stress in Machined Autofrettaged Tubes," J. Press. Vessel Technol., vol. 125, no. 3, pp. 321-325, 2003.

[49] A. P. Parker and D. P. Kendall, "Residual stresses and lifetimes of tubes subjected to shrink fit prior to autofrettage," J. Press. Vessel Technol. Trans. ASME, vol. 125, no. 3, pp. 282-286, 2003.

[50] H. Jahed, B. Farshi, and M. Karimi, "Optimum Autofrettage and Shrink-Fit Combination in Multi-Layer Cylinders," J. Press. Vessel Technol., vol. 128, no. 2, pp. 196-200, 2006.

[51] J. M. Alegre, P. Bravo, and M. Preciado, "Design of an autofrettaged high-pressure vessel, considering the Bauschinger effect," Proc. Inst. Mech. Eng. Part E J. Process 
Mech. Eng., vol. 220, no. 1, pp. 7-16, 2006.

[52] M. H. Hojjati and A. Hassani, "Theoretical and finite-element modeling of autofrettage process in strain-hardening thick-walled cylinders," Int. J. Press. Vessel. Pip., vol. 84, no. 5, pp. 310-319, May 2007.

[53] L. . b Ning, L. . Yourong, and Z. . Sizhu, "Implicit algorithm of hybrid hardening elastic-plastic constitutive relation and its application in autofrettage residual stress analysis," J. Softw. Eng., vol. 9, no. 1, pp. 144-156, 2015.

[54] P. Chen and G. P. O'Hara, "Finite Element Results of Pressurized Thick Tubes Based on Two Elastic-Plastic Material Models," ARLCB-TR-83047, Army Armament Res. Dev. Eng. Center, Benet Weapons Lab, NY, 1983.

[55] M. C. Gibson, A. P. Parker, A. Hameed, and J. G. Hetherington, "Implementing realistic, nonlinear, material stress-strain behavior in ANSYS for the autofrettage of thick-walled cylinders," J. Press. Vessel Technol. Trans. ASME, vol. 134, no. 5, 2012.

[56] J. D. Mote, L. K. W. Ching, R. E. Knight, R. J. Fay, M. A. Kaplan, and S. Marietta, "Explosive Autofrettage of Cannon Barrels," AMMRC CR 70-25, Army Mater. Res. Center, Watertown, Massachusetts, 1971.

[57] R. Zhan, C. Tao, and G. Zhao, "Elasto-Plastical Dynamic Analysis of Explosive Autofrettage," Journal-Southwest Pet. Inst., vol. 21, no. 4, pp. 82-85, 1999.

[58] R.-R. Zhan, C.-D. Tao, L. Han, Y.-M. Huang, and D.-X. Han, "Residual stress and its influence on the fatigue strength induced by explosive autofrettage," Baozha Yu Chongji/Explosion Shock Waves, vol. 25, no. 3, pp. 239-243, 2005.

[59] S. M. Kamal and U. S. Dixit, "Feasibility study of thermal autofrettage of thick-walled cylinders," J. Press. Vessel Technol. Trans. ASME, vol. 137, no. 6, 2015.

[60] G. P. O'Hara and E. Troiano, “Comparison of autofrettage calculation methods," Am. Soc. Mech. Eng. Press. Vessel. Pip. Div. PVP, vol. 406, pp. 105-110, 2001.

[61] E. Wen, E. Barbero, and P. Tygielski, "Autofrettage to offset CTE mismatch in metal- 
lined composite cryogenic feed lines," in Collection of Technical Papers AIAA/ASME/ASCE/AHS/ASC Structures, Structural Dynamics and Materials Conference, 2002, vol. 4, pp. 2555-2563.

[62] S. M. Kamal and U. S. Dixit, "A comparative study of thermal and hydraulic autofrettage,” J. Mech. Sci. Technol., vol. 30, no. 6, pp. 2483-2496, 2016.

[63] S. M. . Kamal, A. C. . Borsaikia, and U. S. . Dixit, "Experimental assessment of residual stresses induced by the thermal autofrettage of thick-walled cylinders," $J$. Strain Anal. Eng. Des., vol. 51, no. 2, pp. 144-160, 2016.

[64] H. R. Zare and H. Darijani, "A novel autofrettage method for strengthening and design of thick-walled cylinders," Mater. Des., vol. 105, pp. 366-374, 2016.

[65] H. R. Zare and H. Darijani, "Strengthening and design of the linear hardening thickwalled cylinders using the new method of rotational autofrettage," Int. J. Mech. Sci., vol. 124-125, no. December 2016, pp. 1-8, 2017.

[66] T. E. Davidson, D. P. Kendall, and A. N. Reiner, "Residual Stresses in Thick-walled Cylinders Resulting from Mechanically Induced Overstrain,” Exp. Mech., vol. 3, no. 11, pp. 253-262, Nov. 1963.

[67] J. Adachi and F. Baratta, "Comparative Evaluation of Swage-Autofrettage and Hydraulic-Autofrettage Processes," Army Materials and Mechanics Research Center, Watertown, MA, Letter Report dated 26 September 1967, 1967.

[68] B. E. Thomas Davidson and Ý.-A. David P-kendall, "The Design of Pressure Vessels for' Very High Pressure Operation Benet R\&E Laboratories," 1969.

[69] G. P. O’Hara, "Elastic Stress of Short Cylindrical Swage Mandrels.” Proceedings of the Third Navy-NASTRAN Colloquium, 1972.

[70] H. Goodheim and G. P. P. O'Hara, "Finite Element Analysis of Several Swage Mandrel Designs," WVT-TR-74011, Benet Weapons Laboratory, Watervliet, NY, 1974. 
[71] G. Clark and S. F. E. A. Lia, "RESIDUAL STRESSES IN SWAGEAUTOFRETTAGED THICK-WALLED CYLINDERS.," Rep. - Mater. Res. Lab., 1982.

[72] E. Till and F. Rammerstofer, "Nonlinear finite element analysis of an autofrettage process," Comput. Struct., no. 54, pp. 857-864, 1983.

[73] P. C. T. Chen, "A simple analysis of the Swage Autofrettage Process," ARCCB-TR88037, Army Armament Res. Dev. Eng. Center, Benet Weapons Lab, NY, 1988.

[74] G. P. O'Hara and C. C. A. Center, "Analysis of the Swage Autofrettage Process.," Press. Vessel. components, 1991 Incl. bolted joints, valves, high Press. Present. 1991 Press. Vessel. Pip. Conf. San Diego, California, June 23-27, 1991, vol. 217, p. 193, 1992.

[75] S. L. Lee, G. P. O'hara, V. Olmstead, and G. Capsimalis, "Characterization of Residual Stresses in an eccentric swage autofrettaged Thick-Walled Steel Cylinder," 1992.

[76] S. L. Lee, "Residual stress analysis in swage autofrettaged thick-walled cylinders by position sensitive x-ray diffraction techniques," in Proceedings of the 1993 Pressure Vessels and Piping Conference, 1993, vol. 263, pp. 165-169.

[77] M. A. Malik and S. Khushnood, "a Review of Swage - Autofrettage Process," Conf. Nucl. Eng., pp. 1-12, 2003.

[78] M. J. Iremonger and G. S. Kalsi, “A numerical study of swage autofrettage,” J. Press. Vessel Technol. Trans. ASME, vol. 125, no. 3, pp. 347-351, 2003.

[79] A. P. Parker, G. P. O'Hara, and J. H. Underwood, "Hydraulic versus swage autofrettage and implications of the Bauschinger effect," J. Press. Vessel Technol. Trans. ASME, vol. 125, no. 3, pp. 309-314, 2003.

[80] J. Perry and J. Aboudi, "Elasto-Plastic Stresses in Thick Walled Cylinders," J. Press. Vessel Technol., vol. 125, no. 3, p. 248, 2003.

[81] Hermanson M. J, Bauman B., and Nalley Donald A, "METHOD FOR GUN BARREL 


\section{MANUFACTURE USING TAILORED AUTOFRETTAGE MANDRELS,” 2004.}

[82] M. A. Malik, B. Rashid, M. Khan, and S. Khushnood, "Modeling and simulation of residual stresses in mechanical autofrettage," in American Society of Mechanical Engineers, Manufacturing Engineering Division, MED, 2005, vol. 16-2, pp. 905-913.

[83] R. Bihamta, M. R. Movahhedy, and A. R. Mashreghi, "A numerical study of swage autofrettage of thick-walled tubes," Mater. Des., vol. 28, no. 3, pp. 804-815, 2006.

[84] M. A. Malik, M. Khan, B. Rashid, and S. Khushnood, "Analysis of swage autofrettage in metal tube," in International Conference on Nuclear Engineering, Proceedings, ICONE, 2006, vol. 2006.

[85] M. C. Gibson, "Determination of residual stress distributions in autofrettaged thickwalled cylinders," Determ. Residual Stress Distrib. Autofrettaged Thick. Cylind., no. April, 2008.

[86] J. Perry and M. Perl, "A 3-D model for evaluating the residual stress field due to swage autofrettage," J. Press. Vessel Technol. Trans. ASME, vol. 130, no. 4, pp. 412111412116, 2008.

[87] J. H. Park, Y. S. Lee, J. H. Kim, K. U. Cha, and S. K. Hong, "Machining effect of the autofrettaged compound cylinder under varying overstrain levels," J. Mater. Process. Technol., vol. 201, no. 1-3, pp. 491-496, 2008.

[88] A. M. Malik, S. Khushnood, M. Khan, G. Gilani, and M. Khan, "A comparative parametric study of single step and double step swage autofrettage in swaged metal tubes," in International Conference on Nuclear Engineering, Proceedings, ICONE, 2009, vol. 2, pp. 11-16.

[89] A. P. Parker, E. Troiano, and J. H. Underwood, "Hydraulic re-autofrettage of a swage autofrettaged tube," in American Society of Mechanical Engineers, Pressure Vessels and Piping Division (Publication) PVP, 2010, vol. 5, pp. 45-54.

[90] L.-Z. Chang, Y.-T. Pan, X.-M. Ma, and D.-Y. Pan, "Calculation of plastic radius for thick-walled cylinders of mechanical autofrettage," Zhongbei Daxue Xuebao (Ziran 
Kexue Ban)/Journal North Univ. China (Natural Sci. Ed., vol. 32, no. 3, pp. 265-270, 2011.

[91] L.-Z. Chang, Y.-T. Pan, and X.-M. Ma, "A new method for calculating plastic radius of swage autofrettage thick-walled cylinder," Binggong Xuebao/Acta Armamentarii, vol. 32, no. 11, pp. 1405-1410, 2011.

[92] L.-Z. Chang, Y.-T. Pan, and X.-M. Ma, "Research of loading solution for swage autofrettage," Zhongbei Daxue Xuebao (Ziran Kexue Ban)/Journal North Univ. China (Natural Sci. Ed., vol. 33, no. 4, pp. 392-396, 2012.

[93] M. Perl, J. Perry, T. Aharon, and O. Kolka, "Is there an ultimate autofrettage process," J. Press. Vessel Technol. Trans. ASME, vol. 134, no. 4, 2012.

[94] P. Alinezhad and R. Bihamta, "A study on the tool geometry effects in the swage autofrettage process," 2011 International Conference on Material Science and Information Technology, MSIT2011, vol. 433-440. Islamic Azad University, Saveh Branch, Saveh, Iran, pp. 2206-2211, 2012.

[95] M. C. Gibson, A. Hameed, and J. G. Hetherington, "Investigation of driving force variation during swage autofrettage, using finite element analysis," J. Press. Vessel Technol. Trans. ASME, vol. 134, no. 5, 2012.

[96] X. P. Huang, "A General Autofrettage Model of a Thick-Walled Cylinder Based on Tensile-Compressive Stress-Strain Curve of a Material," J. Strain Anal. Eng. Des., vol. 40, no. 6, pp. 599-607, 2005.

[97] L.-Z. Chang, Y.-T. Pan, X.-M. Ma, and Y.-J. Zhang, "Residual stress calculation of swage autofrettage," Zhongbei Daxue Xuebao (Ziran Kexue Ban)/Journal North Univ. China (Natural Sci. Ed., vol. 34, no. 6, pp. 616-622, 2013.

[98] L.-Z. Chang, Y.-T. Pan, K.-W. Li, and X.-M. Ma, "Residual stress analysis of gun barrel with bi-linear material model," Binggong Xuebao/Acta Armamentarii, vol. 34, no. 4, pp. 385-391, 2013.

[99] L. Chang, Y. Pan, and X. Ma, "Residual Stress Calculation of Swage Autofrettage Gun 
Barrel,”Int. J. Comput. Sci. Issues, vol. 10, no. 2, pp. 52-59, 2013.

[100] X.-M. Ma, L.-Z. Chang, and B. Yu, "Residual stress of swage autofrettage gun barrel with kinematic hardening material," Zhongbei Daxue Xuebao (Ziran Kexue Ban)/Journal North Univ. China (Natural Sci. Ed., vol. 35, no. 6, pp. 654-661, 2014.

[101] Z. Hu and C. Penumarthy, "Computer Modeling and Optimization of Swage Autofrettage Process of a Thick-Walled Cylinder Incorporating Bauschinger Effect," Am. Trans. Eng. Appl. Sci., vol. 3, no. 1, pp. 31-63, 2014.

[102] M. C. . C. Gibson, A. . Hameed, and J. G. . G. Hetherington, "Investigation of residual stress development during swage autofrettage, using finite element analysis," J. Press. Vessel Technol. Trans. ASME, vol. 136, no. 2, pp. 43-50, 2014.

[103] L.-Z. . Chang, Y.-T. . Pan, and X.-M. . Ma, "Residual stress analysis of mechanical autofrettage gun barrel," Zhongbei Daxue Xuebao (Ziran Kexue Ban)/Journal North Univ. China (Natural Sci. Ed., vol. 36, no. 3, pp. 304-310, 2015.

[104] M. K. Dewangan, S. K. Panigrahi, M. Science, and A. Technology, "Residual stress analysis of swage autofrettaged gun barrel via finite element method," J. Mech. Sci. Technol., vol. 29, no. 7, pp. 2933-2938, Jul. 2015.

[105] M. Perl and T. Saley, "Swage and hydraulic autofrettage impact on fracture endurance and fatigue life of an internally cracked smooth gun barrel Part I - The effect of overstraining," Eng. Fract. Mech., vol. 182, pp. 372-385, 2017.

[106] M. Perl and T. Saley, "Swage and hydraulic autofrettage impact on fracture endurance and fatigue life of an internally cracked smooth gun barrel Part II - The combined effect of pressure and overstraining," Eng. Fract. Mech., vol. 182, pp. 386-399, 2017.

[107] R. Hill, The mathematical theory of plasticity. New York: Oxford University Press, 1950.

[108] O. Güngör, "An approach for optimization of the wall thickness (weight) of a thickwalled cylinder under axially non-uniform internal service pressure distribution," Def. Technol., vol. 13, no. 2, pp. 150-157, 2017. 
[109] C. S. Jin and R. S. Yuan, "Design and analysis of the swage for swage autofrettage with a center hole," in IOP Conference Series: Materials Science and Engineering, 2018, vol. 392, no. 6, p. 062041.

[110] Z. Hu, "Design of two-pass swage autofrettage processes of thick-walled cylinders by computer modeling," Proc. Inst. Mech. Eng. Part C J. Mech. Eng. Sci., vol. 0, no. 0, p. $095440621877022,2018$.

[111] N. S. Rossini, M. Dassisti, K. Y. Benyounis, and A. G. Olabi, "Methods of measuring residual stresses in components," Mater. Des., vol. 35, pp. 572-588, 2012.

[112] Sachs G., "Der Nachsweiss immerer spannungen in stangen und roh ren," $Z$. Metallkunde, no. 19, pp. 352-357, 1927.

[113] A. P. Parker, "A critical examination of sachs' material-removal method for determination of residual stress," J. Press. Vessel Technol. Trans. ASME, vol. 126, no. 2, pp. 234-236, 2004.

[114] W. Cheng and I. Finnie, "Measurement of residual hoop stresses in cylinders using the compliance method," J. Eng. Mater. Technol. Trans. ASME, vol. 108, no. 2, pp. 87-92, 1986.

[115] A. P. Parker, J. H. Underwood, J. F. Throop, and C. P. Andrasic, "STRESS INTENSITY AND FATIGUE CRACK GROWTH IN A PRESSURIZED AUTOFRETTAGED THICK CYLINDER.," in ASTM Special Technical Publication, 1983, pp. 216-237.

[116] H. Jahed, M. R. Faritus, and Z. Jahed, "Residual stress measurements in an autofrettage tube using hole drilling method," J. Press. Vessel Technol. Trans. ASME, vol. 134, no. 5, 2012.

[117] “ASTM E837 - 13a (2013) Standard test method for determining residual stresses by the hole-drilling strain-gage method." ASTM International, West Conshohocken.

[118] J. M. Alegre, A. Díaz, I. I. Cuesta, and J. M. Manso, "Analysis of the Influence of the Thickness and the Hole Radius on the Calibration Coefficients in the Hole-Drilling 
Method for the Determination of Non-uniform Residual Stresses,” 2018.

[119] J. H. Underwood, R. R. DeSwardt, A. M. Venter, E. Troiano, E. J. Hyland, and A. P. Parker, "Hill stress calculations for autofrettaged tubes compared with neutron diffraction residual stresses and measured yield pressure and fatigue life," in American Society of Mechanical Engineers, Pressure Vessels and Piping Division (Publication) PVP, 2008, vol. 5, pp. 47-52.

[120] ASME Boiler and Pressure Vessel Code, Section II, Part A: Ferrous Material Specifications. American Society of Mechanical Engineers, 2017.

[121] ASME Boiler and Pressure Vessel Code, Section II, Part D: Properties (Customary). American Society of Mechanical Engineers, 2017.

[122] ASTM, "E 8M Standard Test Methods of Tension Testing of Metallic Materials [Metric]." Annual Book or ASTM Standards, American Society for Testing and Materials, Vol 3.01.

[123] “ASTM E647-00. Standard Test Method for Measurement of Fatigue Crack Growth Rates.” ASTM International, West Conshohocken.

[124] ASTM "E 399-12 (2012) Standard Test Method for Linear-Elastic Plane-Strain Fracture Toughness KIc of Metallic Materials.” Annual Book or ASTM Standards, American Society for Testing and Materials.

[125] ASTM "E 1820-13 Standard Test Method for Measurement of Fracture Toughness." Annual Book or ASTM Standards, American Society for Testing and Materials.

[126] G. S. Schajer, "Measurement of non-uniform residual stresses using the hole- drilling method. part i-stress calculation procedures," J. Eng. Mater. Technol. Trans. ASME, vol. 110 , no. 4 , pp. 338-343, 1988.

[127] G. S. Schajer and M. B. Prime, "Use of inverse solutions for residual stress measurements," J. Eng. Mater. Technol. Trans. ASME, vol. 128, no. 3, pp. 375-382, 2006. 
[128] G. S. Schajer, "Hole-drilling residual stress profiling with automated smoothing," $J$. Eng. Mater. Technol. Trans. ASME, vol. 129, no. 3, pp. 440-445, 2007. 